\title{
INTERLAMINAR TOUGHNESS OF FUSION BONDED THERMOPLASTIC COMPOSITES
}




\section{INTERLAMINAR TOUGHNESS OF FUSION BONDED THERMOPLASTIC COMPOSITES}

Francisco Sacchetti 
Promotie commissie:

Voorzitter en secretaris:

prof. dr. G.P.M.R. Dewulf

Universiteit Twente

Promotor:

prof. dr. ir. R. Akkerman

Universiteit Twente

Co-promotor:

dr. I. F. Villegas

Technische Universiteit Delft

Leden:

prof. dr. A. Blume

Universiteit Twente

prof. dr. R. Frassine

Politecnico di Milano

prof. dr. ir. T. Tinga

Universiteit Twente

prof. dr. W. van Paepegem

Universiteit Gent

This research project was financially supported by the ThermopPlastic composites Research Center (TPRC)

Interlaminar toughness of fusion bonded thermoplastic composites

Francisco Sacchetti

PhD thesis, University of Twente, Enschede, the Netherlands

September 2017

ISBN 978-90-365-4378-1

DOI 10.3990/1.9789036543781

(C)2017 by F. Sacchetti, Enschede, the Netherlands

Printed by Gildeprint, Enschede, the Netherlands

Cover: Scanning electron micrograph of the fracture surface of a press co-consolidated specimen (chapter four) 


\title{
INTERLAMINAR TOUGHNESS OF FUSION BONDED THERMOPLASTIC COMPOSITES
}

\author{
PROEFSCHRIFT
}

ter verkrijging van

de graad van doctor aan de Universiteit Twente, op gezag van de rector magnicus,

prof. dr. T.T.M. Palstra

volgens besluit van het College voor Promoties

in het openbaar te verdedigen

op donderdag 7 september 2017 om 14:45 uur

door

Francisco R. Sacchetti

geboren op 1 juni 1985

te Mar del Plata, Argentina 
Dit proefschrift is goedgekeurd door de promotor:

prof. dr. ir. R. Akkerman

en door de co-promotor:

dr. I. F. Villegas 


\section{Summary}

Thermoplastic composites are of increasing interest to the aerospace industry. Compared to metals, they provide a higher specific strength, specific stiffness, and an increased design freedom, as composite materials have the ability to tailor mechanical performance to a particular application. Moreover, the melt-processability of the thermoplastic matrix allows for fast manufacturing and assembling techniques, such as thermoforming and fusion bonding, which are also highly suitable for process automation. Fusion bonding involves heating of the interface between the parts to be bonded, application of pressure and finally cooling of the bonded parts. Even though successful commercial application of fusion bonding can already be found in the aerospace industry, a wider use requires additional developments in order to improve the predictability, reliability and robustness of fusion bonded joints. This first of all requires a better understanding of that what is perceived as 'the load bearing capacity', as measured by mechanical testing of fusion bonded joints.

Two mechanisms that are essential for the generation of the load bearing capacity of fusion bonded joints are (i) intimate contact development, followed by (ii) the interdiffusion of polymer chains across the interface. Although these two mechanisms are a prerequisite for the development of a bond, they are not the only mechanisms that determine the performance of a fusion bonded joint. The physical state of the bond line and the structural morphology of the interface also plays an important role. The objective of this work is to identify, to analyse and, if possible, to quantify the relation between the physical state and the structural morphology induced by the fusion bonding process, and the resulting mechanical performance of the joints. For this purpose, the most relevant variations in physical state and structural morphology, as induced by the fusion bonding process, were identified. These factors were then isolated experimentally, and their effects on the interlaminar fracture toughness of the joints were studied. Three aerospace grade materials were used in this study, namely, unidirectional (UD) Carbon fibre reinforced polyether-ether-ketone (Carbon/PEEK), a 5 harness satin (5HS) woven Carbon/PEEK, and a UD Carbon fibre reinforced polyphenylene-sulfide (Carbon/PPS).

Regarding the physical state of the bond line, two factors were identified to play a fundamental role in the interlaminar fracture toughness of the joint. The first comprises contamination of the substrates to be bonded from the release media used during the consolidation of the substrates. The presence of contaminants was found to block proper development of the toughness of the bond. The second factor that was found to play an important role is the degree of crystallinity obtained at the bond line as a function of the thermal history. For PPS, a semicrystalline polymer, a low degree of crystallinity at the bond line was found to produce bonds with higher interlaminar toughness, resulting from 
the greater plasticity of the polymer.

Concerning the structural morphology, two factors were investigated. Firstly, the effect of the thickness of the matrix-rich bond line on the toughness was studied. An additional polymer layer is sometimes added at the bond line to ensure good wetting of the two surfaces to be bonded. As a result, depending on the nature of the process and the process parameters, a matrix-rich bond line at the interface may be generated. Such a matrix-rich bond line was found to increase the interlaminar toughness of the bond, suggesting more plastic energy dissipation before fracture occurs. This can be due to a larger volume of matrix involved in the fracture process, possibly in combination with a higher strain to failure caused by a smaller constraining effect of the fibres. Depending on the processing time of the fusion bonding technique, migration of fibres towards the matrix-rich bond line may occur. This migration was found to have no significant effect on the interlaminar fracture toughness of the bond compared to the effect of the matrix-rich bond line itself. Secondly, the direction of crack propagation with respect to the fibre direction and weave architecture in woven fabric reinforced laminates were found to affect the interlaminar fracture toughness of the joint. The presence of fibres perpendicular to the direction of crack propagation was found to generate a more tortuous crack path, leading to a tougher interface.

In the last part of this work, the results are discussed in a broader perspective by looking at the mechanisms that govern the interlaminar fracture toughness of fusion bonded joints. The knowledge gained is translated into practical guidelines for industry to manufacture fusion bonded joints with a high interlaminar fracture. 


\section{Samenvatting}

$\mathrm{Er}$ is een groeiende interesse in de luchtvaartindustrie voor het gebruik van thermoplastisch composietmaterialen. Thermoplastische composieten leveren, in vergelijking met lichtgewicht metalen, een hogere specifieke sterkte en stijfheid, en een grotere ontwerpvrijheid dankzij de mogelijkheid om materiaaleigenschappen lokaal te variëren. Ten opzichte van thermoharders zijn thermoplastisch composieten bovendien aantrekkelijk vanwege de potentie om de productietijden en -kosten te verlagen door het gebruik van efficiënte fabricage- en lastechnologieën. Het lassen van thermoplastisch composieten is een aantrekkelijk alternatief voor conventionele verbindingstechnologieën zoals lijmen of klinken. Het omvat het lokaal opsmelten, samenbrengen en, onder druk, afkoelen van de te verbinden delen. Hoewel verschillende lastechnologieën al succesvol worden toegepast voor secundaire structurele onderdelen in vliegtuigen, is er verdere kennisontwikkeling nodig om de voorspelbaarheid, betrouwbaarheid en robuustheid van lasverbindingen te vergroten teneinde de toepassing voor primaire structurele onderdelen mogelijk te maken.

Op het grensvlak tussen de te verbinden delen spelen twee fenomenen een rol bij de ontwikkeling van de lasverbinding. Ten eerste dient er intiem contact tussen de twee oppervlakken gecreëerd te worden. Vervolgens, indien de temperatuur hoog genoeg is, zal er diffusie van polymeerketens optreden om de twee oppervlakken te versmelten. Hoewel deze twee mechanismen ten grondslag liggen aan het lasproces, zijn dit niet de enige factoren die het draagvermogen van de ontstane las bepalen. De fysische toestand van de te lassen oppervlakken en het grensvlak, alsmede de morfologie van het grensvlak spelen ook een belangrijke rol. De doelstelling van dit werk is het identificeren, analyseren en, waar mogelijk, kwantificeren van het effect van deze factoren op het draagvermogen van de lasverbinding. Hiertoe zijn eerst de meest relevante variaties in fysische staat en morfologie vastgesteld. Vervolgens zijn de effecten van deze variaties op de scheurtaaiheid van de lasverbinding afzonderlijk bestudeerd. Drie verschillende materiaalsystemen zijn onderzocht, allen relevant voor de luchtvaartindustrie, namelijk uni-directioneel (UD) koolstofversterkt PEEK, UD koolstofversterkt PPS en 5-kams satijn koolstofversterkt PPS.

Wat betreft de fysische staat van de te lassen oppervlakken en het grensvlak, zijn twee factoren onderzocht. Ten eerste is gekeken naar het effect van oplosmiddelen, welke gebruikt worden bij de verwerking van de te verbinden delen, op de taaiheid van de lasverbinding. Het blijkt dat verontreinigingen door het gebruik van sommige oplosmiddelen de ontwikkeling van een taaie lasverbinding verhinderen. Ten tweede is de invloed van de kristallisatiegraad van het polymeer op het grensvlak op de taaiheid van de lasverbinding onderzocht. Hieruit blijkt dat een verlaging van de kristallisatiegraad, ten gevolge van een verhoging van de afkoelsnelheid na het lassen, samengaat met een 
verhoging van de scheurtaaiheid, hetgeen een direct gevolg is van de vergrote plasticiteit van de polymere matrix.

Ook wat betreft de morfologie van het grensvlak zijn er twee factoren onderzocht. Ten eerste is gekeken naar de invloed van een matrixrijke zone op het grensvlak. Hieruit blijkt dat, voor het geteste materiaalsysteem en de gekozen diktevariatie, de scheurtaaiheid proportioneel is met dikte van de matrixrijke zone. Wederom is dit te relateren aan de toegenomen plastische energie-dissipatie in de matrix, waardoor meer energie benodigd is voor scheurvorming. Tevens is gebleken dat de taaiheid van de lasverbinding nauwelijks wordt beïnvloed door vezelmigratie vanuit de composiet delen naar het matrixrijke grensvlak. Ten tweede is de invloed van weefstructuur alsmede de scheurrichting ten opzichte van de dominante vezelrichting op de scheurtaaiheid onderzocht. Hieruit blijkt dat de scheurtaaiheid sterk toeneemt met de mate van kronkeling van het scheurpad en daarmee sterk afhankelijk is van de scheurrichting en weefselstructuur.

In het laatste gedeelte van dit proefschrift worden de resultaten beschouwd vanuit een breder perspectief door de te kijken naar de mechanismen die de taaiheid van de lasverbinding bepalen. De verkregen kennis is uiteindelijk vertaald naar richtlijnen voor de industrie die gebruikt kunnen worden om thermoplastische composiet lasverbindingen te vervaardigen met een hoge taaiheid. 


\section{Nomenclature}

The symbols used in this thesis are classified into a Roman, a Greek or a Geometric symbol group. Although some symbols can represent multiple quantities, its intended meaning follows from the textual context.

\section{Roman symbols}

$\begin{array}{llr}A & \text { Area } & {\left[\mathrm{m}^{2}\right]} \\ a, a_{\text {app }} & \text { Crack length and effective crack length } & {[\mathrm{m}]} \\ C & \text { Compliance } & {[\mathrm{m} / \mathrm{N}]} \\ C_{0} & \text { Initial compliance } & {[\mathrm{m} / \mathrm{N}]} \\ E, E_{1} & \text { Young's modulus and apparent bending modulus } & {[\mathrm{Pa}]} \\ F & \text { Large deformation correction factor } & {[-]} \\ F_{\mathrm{a},} F_{\mathrm{p}} & \text { Alignment force and peel force } & {[\mathrm{N}]} \\ G_{C}, & \text { Critical energy release rate } & {\left[\mathrm{J} / \mathrm{m}^{2}\right]} \\ G_{I C}, G_{I I C}, & \text { Mode I and Mode II critical energy release rate } & {\left[\mathrm{J} / \mathrm{m}^{2}\right]} \\ h & \text { Half of the specimen thickness } & {[\mathrm{m}]} \\ h & \text { Thickness of the peel arm } & {[\mathrm{m}]} \\ I & \text { Moment of inertia } & {\left[\mathrm{m}{ }^{4}\right]} \\ K_{I C} & \text { Critical stress intensity factor } & {\left[\mathrm{Pa} \cdot \mathrm{m}^{1 / 2}\right]} \\ M & \text { Applied moment } & {\left[\mathrm{N} \cdot \mathrm{m}^{2}\right]} \\ N & \text { Load block stiffening correction factor } & {[-]} \\ L & \text { Span length } & {[\mathrm{m}]} \\ P & \text { Applied force } & {[\mathrm{N}]} \\ \mathrm{R}_{\mathrm{q}} & \text { Root mean square roughness } & {[\mathrm{m}]} \\ r_{y} & \text { Plastic zone radius } & {[\mathrm{m}]} \\ \mathrm{T} & \text { Temperature } & {\left[{ }^{\circ} \mathrm{C}\right]} \\ \mathrm{T}_{\mathrm{g}}, \mathrm{T}_{\mathrm{m}} & \text { Glass transition and melting temperature } & {\left[{ }^{\circ} \mathrm{C}\right]} \\ U & \text { Elastic energy } & {[\mathrm{J}]} \\ W_{f} & \text { Weight fraction of reinforcing fibre in the composite } & {[-]} \\ W & \text { Specimen width } & {[\mathrm{m}]} \\ x & \text { Moment arm length } & {[\mathrm{m}]} \\ x, y & \text { In-plane co-ordinates } & {[\mathrm{m}]}\end{array}$

\section{Greek symbols}

$\begin{array}{llr}\Delta, \Delta_{\text {clamp }} & \text { Correction factor for the DCB and ELS test } & {[\mathrm{m}]} \\ \Delta H_{f} & \text { Melting enthalpy } & {[\mathrm{J} / \mathrm{g}]} \\ \Delta H_{c} & \text { Cold crystallization enthalpy } & {[\mathrm{J} / \mathrm{g}]} \\ \Delta H_{f}^{0} & \text { Reference melting enthalpy } & {[\mathrm{J} / \mathrm{g}]} \\ \delta & \text { Cross-head displacement } & {[\mathrm{m}]} \\ k & \text { Curvature } & {[1 / \mathrm{m}]} \\ \mu & \text { Peel setup friction coefficient } & {[-]} \\ \rho & \text { Radius of curvature } & {[\mathrm{m}]}\end{array}$


$\begin{array}{ll}v & \text { Poisson's ratio } \\ \sigma_{y} & \text { Yield stress } \\ X_{c} & \text { Degree of crystallinity }\end{array}$

\section{Geometric symbols}
//
Parallel
$\perp$
Perpendicular

\section{Abbreviations}

$\begin{array}{ll}\text { AFP } & \text { Automated fibre placement } \\ \text { C } & \text { Carbon } \\ \text { CBT } & \text { Corrected beam theory } \\ \text { DCB } & \text { Double cantilever beam } \\ \text { DOC } & \text { Degree of crystallinity } \\ \text { DSC } & \text { Differential scanning calorimetry } \\ \text { ELS } & \text { End loaded split } \\ \text { ENF } & \text { End notch flexure } \\ \text { HS } & \text { Harness satin } \\ \text { IFSS } & \text { Interfacial shear strength } \\ \text { LEFM } & \text { Linear elastic fracture mechanics } \\ \text { LVDT } & \text { Linear variable displacement transducer } \\ \text { MP } & \text { Mandrel peel } \\ \text { N } & \text { Nitrogen } \\ \text { O } & \text { Oxygen } \\ \text { PEEK } & \text { Polyether-ether-ketone } \\ \text { PI } & \text { Polyimide } \\ \text { PPS } & \text { Polyphenylene-sulfide } \\ \text { R-curve } & \text { Crack growth resistance curve } \\ \text { SBS } & \text { Short beam strength } \\ \text { SEM } & \text { Scanning electron microscope } \\ \text { Si } & \text { Silicon } \\ \text { S-LSS } & \text { Single lap shear strength } \\ \text { TPCs } & \text { Thermoplastic composites } \\ \text { UD } & \text { Unidirectional } \\ \text { XPS } & \text { X-ray photoelectron spectroscopy } \\ & \end{array}$




\section{Contents}

Summary

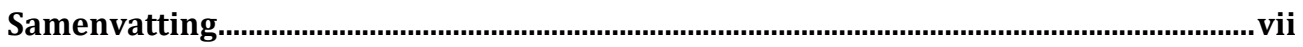

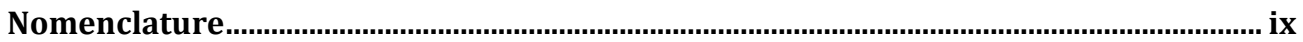

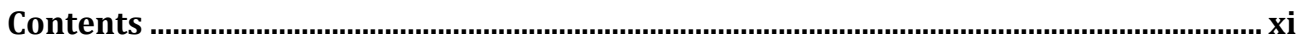

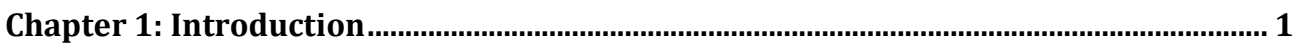

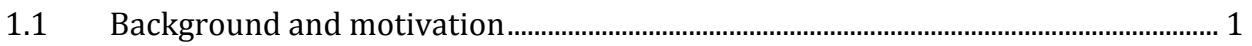

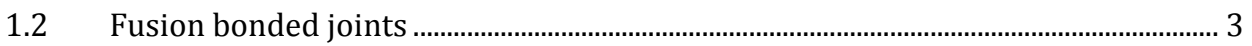

1.3 Relation Process - Structure - Performance ................................................................. 5

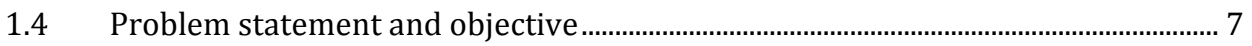

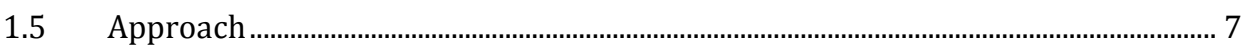

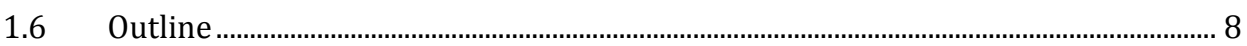

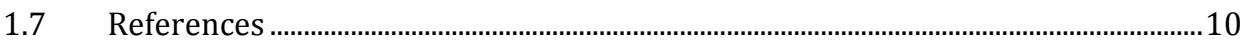

Chapter 2: Effects of release media on the fusion bonding of Carbon/PEEK laminates

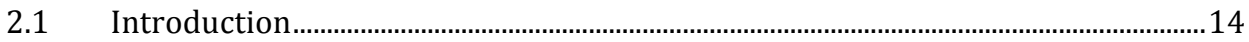

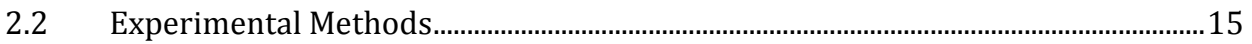

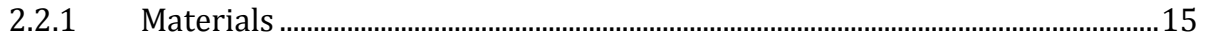

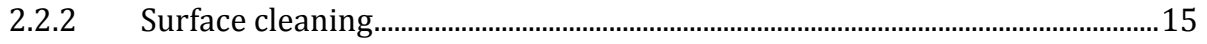

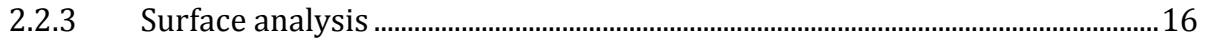

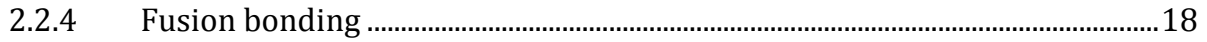

2.2.5 Mechanical testing...................................................................................................

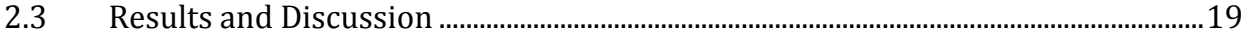

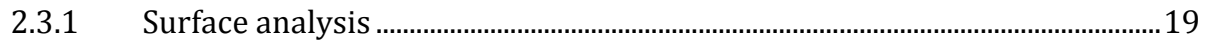

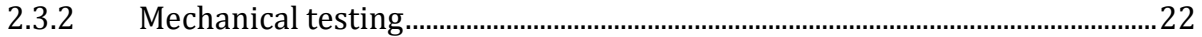

2.3.3 Cross-sectional micrographs and fractography....................................................24

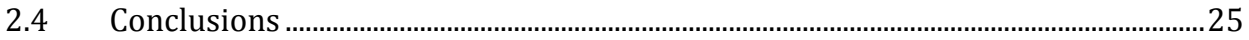

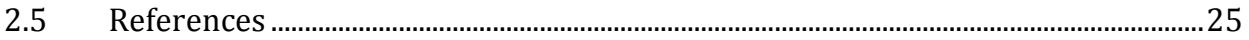

Chapter 3: Effect of cooling rate on the interlaminar fracture toughness of

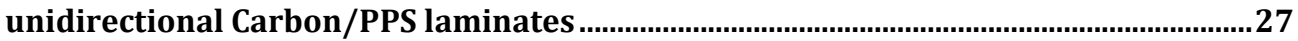

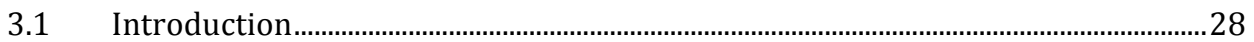

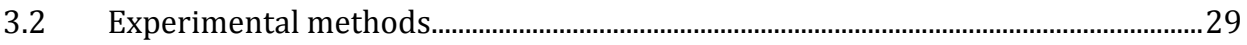


3.2.1 Materials \& laminate consolidation .................................................................. 29

3.2.2 Stamp forming process ..................................................................................... 30

3.2.3 Differential Scanning Calorimetry experiments.................................................. 32

3.2.4 Double cantilever beam experiments .................................................................... 33

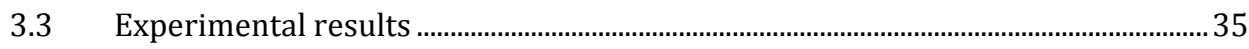

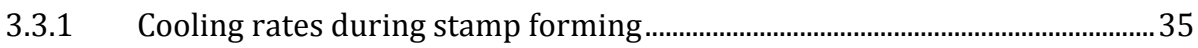

3.3.2 Differential scanning calorimetry measurements (DSC) .................................36

3.3.3 Interlaminar fracture toughness ......................................................................... 39

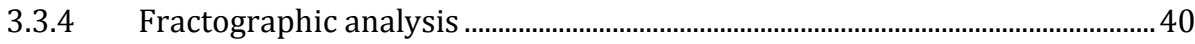

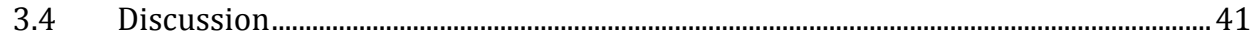

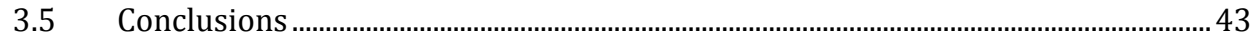

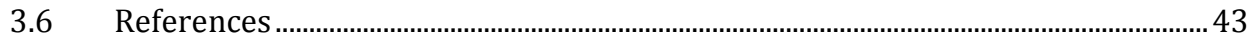

Chapter 4: Effect of resin-rich bond line thickness and fibre migration on the

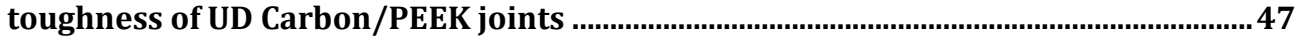

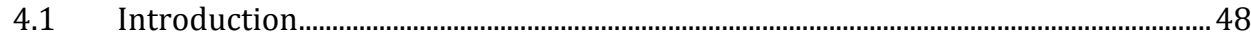

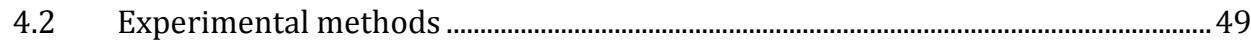

4.2.1 Materials and substrate manufacturing ............................................................ 49

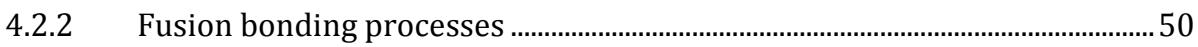

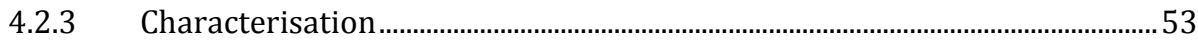

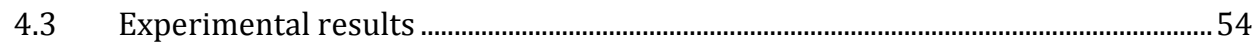

4.3.1 Physical state of the samples................................................................................ 55

4.3.2 Double cantilever beam experiments .................................................................... 56

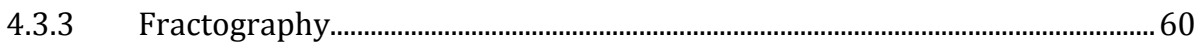

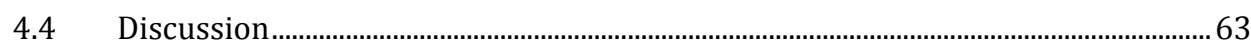

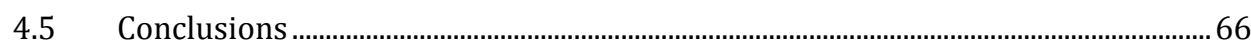

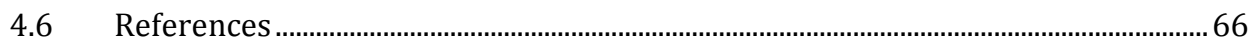

Chapter 5: Interlaminar fracture toughness of 5HS Carbon/PEEK laminates. A

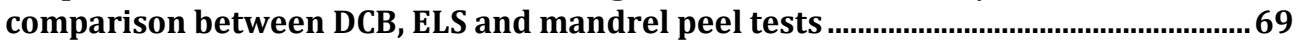

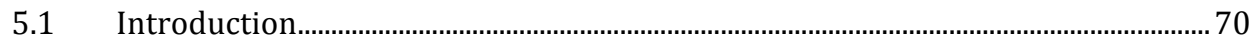

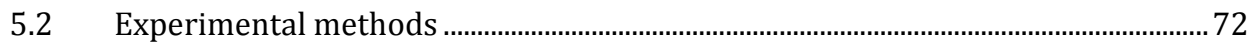

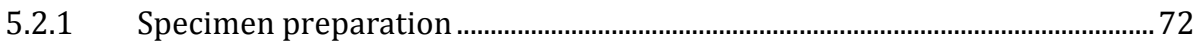

5.2.2 Double Cantilever Beam (DCB) test ...................................................................... 74

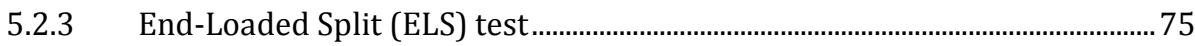

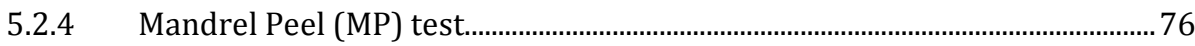

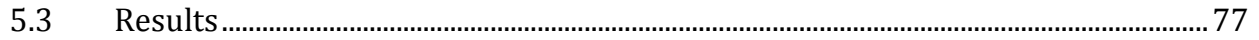


5.3.1 Double cantilever beam experiments................................................................. 78

5.3.2 End-loaded split experiments.......................................................................... 79

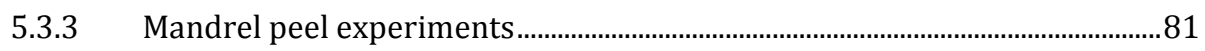

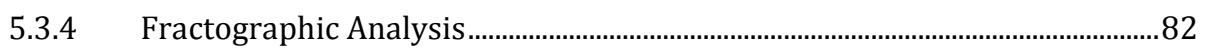

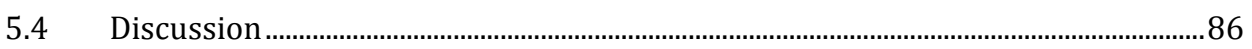

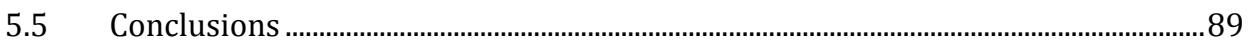

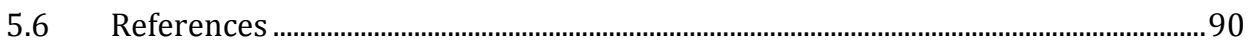

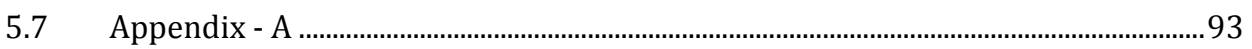

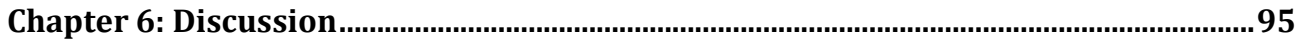

6.1 Structure - interlaminar fracture toughness relationship.........................................95

6.1.1 Bond line contamination .................................................................................... 96

6.1.2 Matrix degree of crystallinity ………................................................................. 96

6.1.3 Matrix-rich bond line thickness …….........................................................................

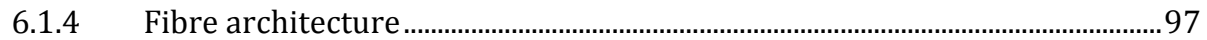

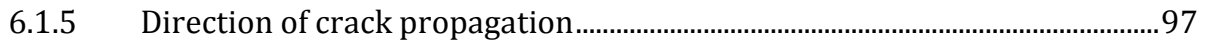

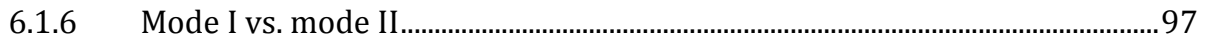

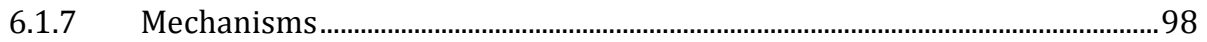

6.2 The global load bearing capability of fusion bonded joint .........................................99

6.2.1 Effect of surface contamination............................................................................

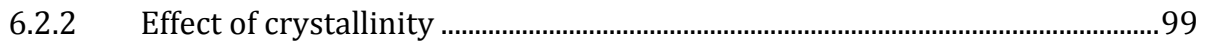

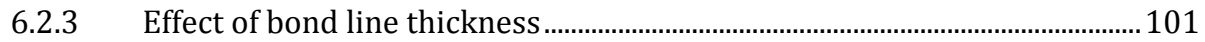

6.2.4 Interface architecture - Unidirectional vs. woven ............................................ 102

6.3 Towards an advanced fusion bonded joint .................................................................. 102

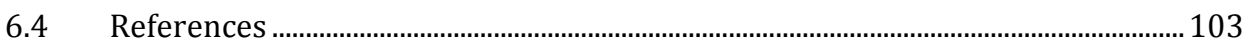

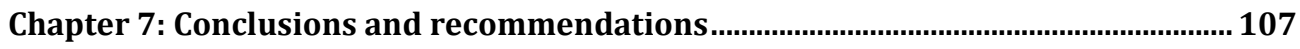

7.1 Conclusions ......................................................................................................................... 107

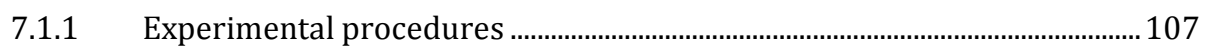

7.1.2 Structure-property relation in fusion bonded thermoplastic composites......

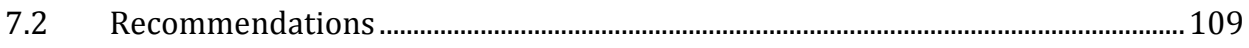

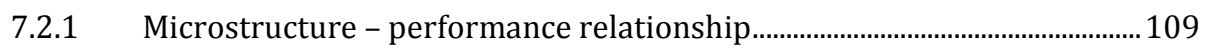

7.2.2 Towards predictable joint performance .......................................................... 109

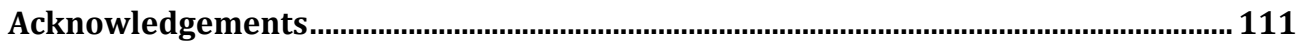

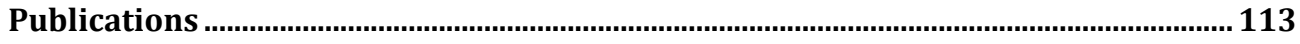





\section{Chapter 1: Introduction}

\subsection{Background and motivation}

Reduction of fuel consumption has been one of the main drivers for the development and incorporation of technology in the commercial aerospace industry. The new generation of aircraft, including the Boeing 787 Dreamliner, 737MAX, Airbus A350XWB, A320neo, Embraer E2 series and Bombardier CSeries, offer improvements in fuel consumption and greenhouse gas emissions. The reduction of fuel consumption is mainly driven by two factors, namely a new generation of engines and the extensive use of composite materials in the structures. The higher specific properties of composite materials help reduce the weight, increase payload capacity, increase operational range, and enhance the mechanical efficiency of the structures, making these aircraft economically more attractive than their metallic counterparts [1].

In the context of reducing aircraft manufacturing costs and weight, thermoplastic composites are particularly attractive. Firstly and more importantly, the processing of thermoplastic composites only involves softening of the matrix through heating followed by consolidation and cooling and does not involve any chemical reactions. This allows for fast manufacturing and assembling techniques, such as thermoforming and fusion bonding, which are also highly suitable for process automation [2-4]. Several business models have already shown the advantages of cost reduction through the use of thermoplastic composites by automation, shorter process cycles and higher production rates $[5,6]$. Moreover, the near-infinite shelf life and lenient requirements for storage, e.g. no need for refrigeration, provide additional cost benefits compared to thermoset composites [7]. Additionally, thermoplastic composites show an increased fracture toughness and damage tolerance compared to thermoset based composites. This potential allows the construction of lighter structures, which further improve fuel efficiency of aircraft.

Current aircraft design is based on the assembly of a number of separate structures, each of them made up of simple geometries. The design of large or complex structures would preferably avoid joints, as these are potential sources of weakness and additional weight. Nevertheless, the experience available in the composite industry showed that the most cost-effective and viable method to design such structures often involves manufacturing multiple parts and joining them together [8]. Figure 1.1 shows a simplified sketch of the assembly of a typical composite aerostructure (torsion box) using fasteners. 


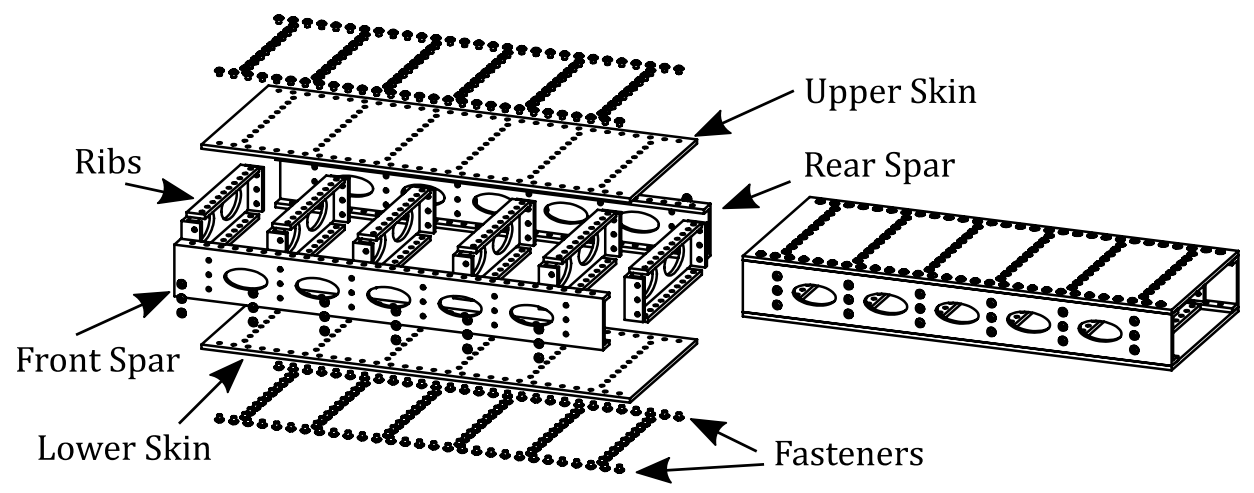

Figure 1.1: Sketch of the torsion box assembly using fasteners.

Many techniques are available to join thermoplastic composites parts which can be subdivided into three main groups, namely mechanical fastening, adhesive bonding and fusion bonding. The most traditional technique is mechanical fastening. Fasteners are the primary joining method used in the aerospace industry. According to the Boeing Company, the Boeing 787 includes over 2.4 million fasteners. Although mechanically fastened joints are reliable and have excellent load bearing capacity, they have also some disadvantages. Besides the labour intensiveness and high costs involved, non-uniform load distribution across the joint interface (transfer of the load at the point where the fasteners are located) [9], stress concentrations created by the holes, and the risk of delamination during drilling [10], are some of the difficulties related to mechanical fastening mentioned in the literature.

Adhesive bonding relies on an intermediate material (the adhesive layer) to create a connection between two substrates. The adhesives used are often designed for specific material systems and applications to ensure proper bond quality. Adhesive bonding techniques sometimes are described as a preferable technique over mechanical fastening in the open literature, as provides a continuous bond between two surfaces, resulting in a more uniform stress distribution across the interface avoiding the stress concentrations induced by mechanical fastening. Nevertheless, an extensive surface preparation treatment prior to adhesive bonding is always required to improve wetting of low energy surfaces and to increase the surface roughness. The surface preparation, generally difficult to control in an industrial environment [10], together with long curing times for the adhesive, and the absence of a non-destructive test methodology to evaluate the bond, make adhesive bonding labour intensive, costly and sometimes less reliable $[11,12]$. These problems slow down the certification process and the incorporation of adhesive bonding in the industry.

From a practical viewpoint, fusion bonding involves heating of the interface between the parts (substrates) to be bonded, followed by the application of pressure and cooling down. During this process the material (polymer) at the interface melts and fuses together 
forming a bond. After solidification the generated joint allows the transfer of forces among the substrates. The melting and fusing process can be subdivided in to intimate contact formation and healing which will be discussed in detail in the following section. The application of fusion bonding techniques can potentially overcome the problems of mechanical fastening and adhesive bonding when it comes to thermoplastic based composites [13]. Fusion bonding maintains the uniform stress distribution of adhesive bonding, while it is less sensitive to surface treatment and features short cycle times. Applications of fusion bonding technologies in thermoplastic composite aircraft structures can be found nowadays, demonstrating the great potential of this technology [3]. Examples of such applications are the main wing leading edges on the Airbus A340 and A380, which are assembled using a resistance welding technology by GKN Fokker Aerostructures, and the elevators and rudder in the Gulfstream G650 and Dassault Falcon 5X, which are induction welded by GKN Fokker Aerostructures using a method developed and provided by KVE Composites Group (The Hague, The Netherlands). Figure 1.2 illustrates both these applications. Even though successful commercial applications of fusion bonding can already be found, a wider use requires additional developments in order to improve predictability, reliability and robustness of the bonds.
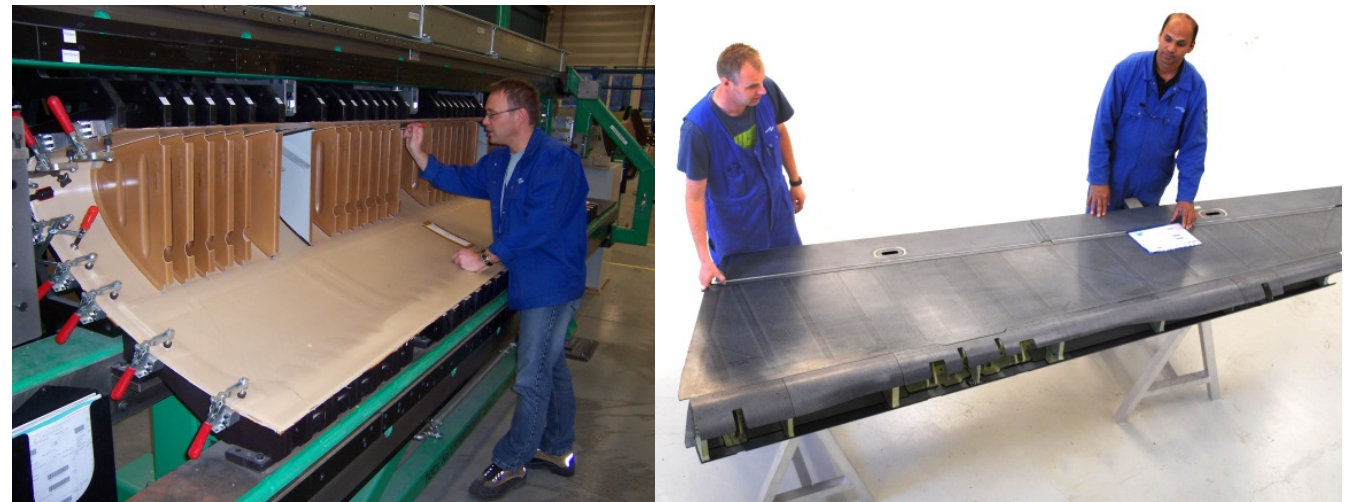

Figure 1.2: Left) Assembly of ribs before the resistance welding of the Airbus A380 leading edge. Right) Induction welded rudder of the Gulfstream G650. Pictures courtesy GKN Fokker Aerostructures.

\section{$1.2 \quad$ Fusion bonded joints}

Fusion bonding techniques are long-established technologies in the unreinforced thermoplastic industry, where the performance of the welded joint is reported to approach the bulk properties of the adherends [14]. Unfortunately, some issues appear when fusion bonding techniques are applied to continuous fibre reinforced thermoplastic composites. This is especially true in the case of high fibre volume fraction composites. Among the issues most mentioned in the literature are uneven heating, delamination, and distortion of the laminates [15], as well as a low amount of resin available to melt and reconsolidate into a fused bonded joint [16]. 
There are many fusion bonding techniques available for thermoplastic composites, all differing in the way heat is applied at the interface $[17,18]$. Two main groups of fusion bonding techniques can be distinguished by the location and zone to be heated, namely bulk heating and local heating (welding). The former group involves bringing the entire part to melt and using the tooling to maintain pressure on the entire part throughout the whole process. Consequently, as it involves bulk heating, this technique is characterised by long processing times (1-2 hours). The second group is characterised by local heating, and usually local pressure. As a consequence of this local heating, short processing times can be achieved (seconds to minutes). Among all the different welding techniques available, the most established for continuous fibre reinforced thermoplastic composites are resistance, induction and ultrasonic welding $[19,20]$.

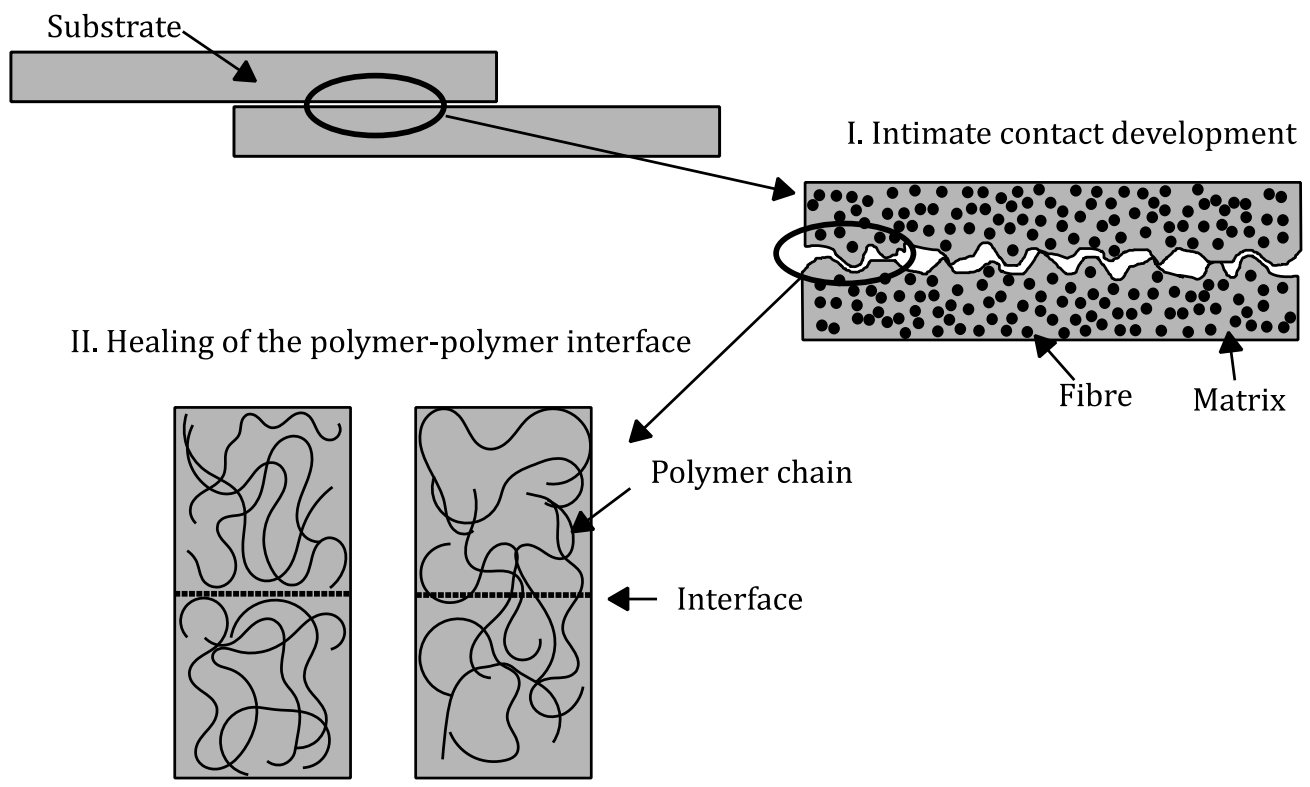

Figure 1.3: Fusion bonding process of thermoplastic composites. Two substrates are brought together under the application of pressure and heat. First intimate contact is developed.

Subsequently, in the areas where intimate contact is reached, healing of the polymer-polymer interface takes place. Figure adapted from [15] and [23].

The main physical mechanisms governing bond strength development are: I. Intimate contact between the two adherents (also known as wetting), and II. inter-molecular diffusion of the polymer chains across the interface [19] (also known as healing or autohesion) which takes place between the surfaces in intimate contact. Figure 1.3 illustrates these two mechanisms. Intimate contact involves the flattening of surface asperities under the application of heat and pressure. The time required to achieve full intimate contact depends on the viscosity of the polymer at the processing temperature, the initial surface roughness and the applied pressure [21, 22]. For the fusion bonding process, the roughness of the substrates is usually low as these were already consolidated 
prior to bonding [19]. Once intimate contact is achieved and the temperature is sufficiently high, the polymeric chains are free to move across the interface in order to entangle with the polymer chains on the opposite side. As the polymer chains cross the interface the strength of the bond is developed. Complete healing occurs when migration and entanglement of the polymer chains makes the bond line indistinguishable from the bulk [23]. The diffusion of molecules across the interface is a thermal random motion process, where the diffusion rate increases as the temperature increases. For amorphous polymers, the diffusion process can be described by the reptation theory of chains developed by De Gennes [24]. For semicrystalline polymers, the healing process appears to be more complicated. The crystalline regions hinder chain mobility, therefore melting and crystallisation kinetics interact with the interdiffusion process [25]. A common finding is that when the temperature of the mating surfaces of the substrates is above $T_{\mathrm{m}}$ a quick increase of the resulting bond strength is observed [26].

\subsection{Relation Process - Structure - Performance}

A thorough description of the relationship between the material, the process, the resulting structure at the fusion bonded interface, and the mechanical performance is required in order to improve the predictability, reliability and robustness of fusion bonded joints. A proper understanding of these relationships will allow the formulation of joint design and manufacturing guidelines, which will then again increase or broaden the domains of application for the fusion bonding technique in various industries.

The work on fusion bonding techniques, available in the open literature, is mostly focused on one single fusion bonding technique, such as induction, ultrasonic or resistance welding $[14,15,17,27,28]$. Besides, most commonly, those investigations aim at establishing relationships between process parameters and mechanical performance with the final aim of determining a processing window for a certain material system. In those scientific studies, process parameters are varied in an isolated manner, and the effect on the mechanical performance is evaluated. The dashed line in Figure 1.4 illustrates the followed approach. Although very insightful and absolutely required for technology development, translation of these results into other material systems or other welding technologies can be challenging.

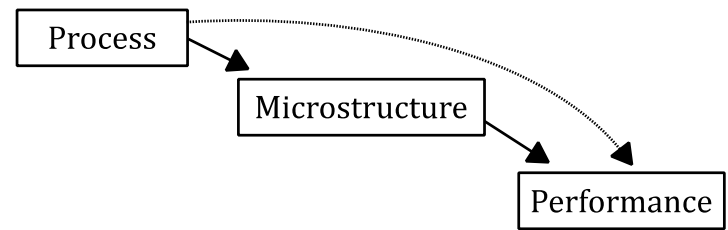

Figure 1.4: A schematic overview of the research approach

In order to develop a more generic understanding of the interrelation between materials, 
processing and performance, that holds for multiple materials and process, one needs to consider the microstructure of the fusion bonded interface. More specifically, a proper understanding of microstructure development during fusion bonding as well as the influence of the microstructure on joint performance is required as is illustrated by the continuous line in Figure 1.4. Microstructure in this context is defined rather broadly. It does not only involve the degree of bonding, comprising intimate contact and healing, but also other structural features such as fibre-matrix distribution, contamination of the bond line, degree of crystallinity of the matrix, residual stresses, void fraction and degree of polymer degradation $[15,19,27,28]$. A proper description of the relationships between such (micro)structural parameters and mechanical performance is required to predict the mechanical performance of fusion bonded joints, independently of the bonding technique used.

This thesis focuses on the interrelation between the microstructure in the bond line and the bond performance. The latter can be characterised in different ways. Generally, the mechanical performance of fusion bonded joints is evaluated by single lap shear strength (S-LSS) tests $[15,19,27]$. The specimen of a S-LSS test is manufactured by joining two substrates in an overlap configuration as shown in Figure 1.5. The test is easy to perform and consists of pulling apart the two substrates until failure. The result of the measurement is an apparent shear strength of the joint. The S-LSS is a popular test, as it is regarded as a simple to perform, and with a loading situation close to the real application. However, the result of the test is highly dependent on the specimen geometry, bond line thickness, bond line stiffness, adherend stiffness among other variables, which sometimes are difficult to control accurately. The geometry of the test specimen creates a complex stress distribution throughout the specimen, which is a combination of both peel, and shear stresses [29]. Consequently, the S-LSS result can only be considered as an apparent property rather than the desired material/structural property. As such the apparent shear strength provided by single lap shear test is generally not totally valid for the comparison of different fusion bonding techniques [30], or to establish a relationship between structural parameters and mechanical performance.

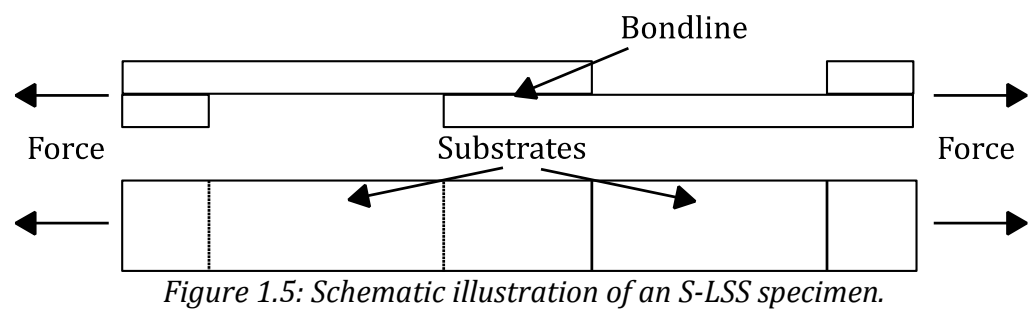

Some authors have proposed the family of fracture toughness test as an alternative to SLSS test to characterise the mechanical performance of fusion bonded samples $[15,19$, $26,31]$. Interlaminar fracture toughness or delamination resistance is one of the major design concerns for many advanced laminated composite structures, in particular for those 
structures where high-stress concentrations occur as in the case of joints. In such structures, delamination is one of the predominant failure modes [32]. Furthermore, provided that the fracture mode (mode I or II or III) is consistent, interlaminar fracture toughness measurements are independent of specimen geometry, thereby making interlaminar fracture toughness to be a valuable parameter [33]. In particular, interlaminar fracture toughness test has been found useful to quantitatively evaluate the effect of materials, processing, and environmental variables on the mechanical performance, as well as helpful to develop damage allowables for composite structures [34]. Therefore, knowledge of the interlaminar fracture toughness of composite materials is worthwhile for product development, process optimisation, and material selection.

\subsection{Problem statement and objective}

As mentioned earlier, in order to work towards more robust, reliable, and predictable fusion bonding processes and joints, a proper description of the relationship between process, structure and performance is required. In particular, a proper description of the relationship between microstructural features induced by the fusion bonding processes and performance of the joints is lacking. Therefore, the objective of this work is to identify, analyse and when possible quantify the relation between physical state and structural features induced by the fusion bonding process and the resulting mechanical performance of the joints.

\subsection{Approach}

An experimental methodology was followed to evaluate the relation between structure and performance. The structural features studied were generic and therefore relevant for any type of fusion bonding process. Processing techniques were carefully selected and manufacturing procedures were developed to vary a single feature, trying to avoid the modification of features that were not under study. Specimens were then manufactured, followed by an evaluation and quantification of the feature under investigation. Subsequently, the mechanical performance of the bond was characterised. As the aim of this work is to qualitatively understand the effect of the variation of structural features on the mechanical performance, interlaminar fracture toughness was chosen as the measured property. Testing techniques for interlaminar fracture toughness are aimed at applied well-defined loading modes. Finally, quantitative or qualitative relationships between structural features and mechanical performance were established from the observations.

Four structural features were investigated in this work, namely $i$. contamination of the bond line by the release media, ii. degree of crystallinity of the bond line, iii. matrix-rich bond line thickness, and $i v$. architecture of the reinforcement at the bond line. The reason for selecting these features is further elaborated in the outline section. Throughout this study, three different material systems were used, all supplied by TenCate Advanced 
Composites. The three aerospace material grades used are namely, unidirectional (UD) Carbon fibre reinforced Polyether-ether-ketone (PEEK), a 5 harness satin (5HS) woven Carbon fabric reinforced PEEK, and a UD Carbon fibre reinforced Polyphenylene-sulfide (PPS). The different materials were selected to highlight the structural feature under study.

\subsection{Outline}

The core content of this work comprises four chapters (Chapter 2 to 5). The chapters are reproduced from research papers, meaning that some information is repeated in every chapter. However, with this format, a single chapter can be read without losing the essential information of the problem being tackled. Figure 1.6 shows a fusion bonded specimen being fractured in opening mode. The figure also illustrates which structural features were studied in the thesis. A brief description of the content and the motivation behind each of the chapters is presented.

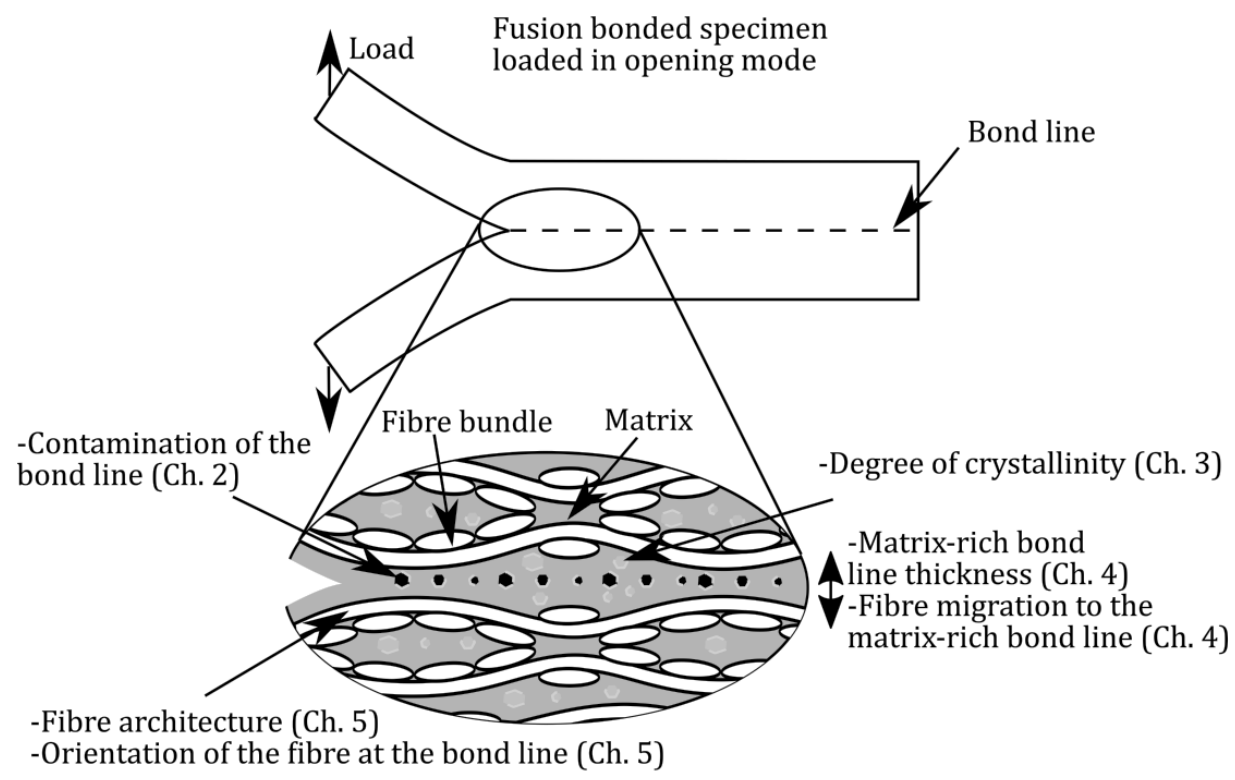

Figure 1.6: Schematic representation of a fusion bonded specimen. The structural features studied are highlighted with the chapter in which the topic was studied.

The release media, used as an ancillary material during consolidation and eventually forming of thermoplastic composites, can potentially leave contaminants on the surfaces of the substrates. These contaminants will be trapped in the bond line during the fusion bonding process and may affect the joint performance. The second chapter discusses the effect of surface contamination, caused by release media, on the toughness of fusion bonded UD Carbon/PEEK joints. Efforts were spent to correlate the physicochemical state of the substrate surface prior to bonding to the interlaminar toughness of the bond line. 
High cooling rates can be achieved during the fusion bonding process. The effect on the bond line is particularly relevant for semicrystalline polymers such as PEEK or PPS, as the cooling rate affects the degree of crystallinity as well as the crystalline morphology, which then again will influence the mechanical properties. High cooling rates are correlated with a low degree of crystallinity. In the third chapter, the influence of crystallinity on interlaminar fracture toughness of Carbon/PPS fusion bonded joints was investigated. A stamp-forming process was used in a novel way in order to obtain well consolidated specimens with a low crystallinity, which were then characterised using double cantilever beam testing. In this chapter, PPS was selected as it has slower crystallisation kinetics than PEEK, which allows the achievement of a relative lower degree of crystallinity for the same cooling rate.

It is a common practice in fusion bonding of thermoplastic composites to add a matrix layer between the two substrates to be joined. The aim of this practice is to ensure good wetting of the two substrates. Depending on the process parameters, the morphology of the matrix-rich bond line thickness will be varied, and thereby the mechanical performance of the bond. The fourth chapter presents a study on the effect of the matrix bond line thickness on the toughness of Carbon/PEEK fusion bonded specimens. Specimens were manufactured using three different processing techniques, which resulted in variations in the fibre-matrix distribution at the interface.

So far the investigation of this work was focused on unidirectional material. However, fusion bonding techniques are often applied to woven structures. The delamination behaviour of woven structures is generally more complex than for UD reinforcement, mainly due to the mesostructure of the woven reinforcement. The irregular interlaminar structure of woven fabric composites forces a delamination (crack) to interact with the matrix-rich regions and the weave structure during its propagation. In the fifth chapter a novel experimental method is introduced to characterise the fracture toughness of woven fabric reinforced laminates. The method is then applied to study the effect of crack propagation direction on the toughness of 5HS Carbon/PEEK laminates. Efforts are spent to relate the weave structure to the measured fracture toughness.

Following the core chapters two to five, the obtained results are consolidated and discussed in chapter six. First, a summary of the relation between the structural features studied and the observed interlaminar fracture toughness is presented. Second, the results are discussed from a broader viewpoint by looking at the mechanisms that govern the interlaminar fracture toughness of fusion bonded joints. Based on this, the knowledge gained is translated into practical guidelines to manufacture fusion bonded joints with high interlaminar fracture toughness for use by industry. Also, the effect of the studied features on other properties than toughness are discussed.

The last chapter of this thesis presents the conclusions as well as the recommendations for future work. 


\section{$1.7 \quad$ References}

[1] A. Kelly, "Concise encyclopedia of composite materials," Elsevier, 2012.

[2] T. G. Gutowski, "Advanced Composites Manufacturing," Wiley Inter Science, 1997.

[3] A. Offringa, "New thermoplastic composite design concepts and their automated manufacture," Jec composites magazine, pp. 45-49, 2010.

[4] A. Offringa, "Thermoplastic composites-rapid processing applications," Composites Part A: Applied Science and Manufacturing, pp. 329-336, 1996.

[5] R. C. Harper, "Thermoforming of thermoplastic matrix composites. Part I," SAMPE J., vol. 28.2, 1992.

[6] E. Wang and T. Gutowski, "Cost comparison between thermoplastic and thermoset composites," SAMPE J, vol. 26, pp. 19-26, 1990.

[7] J. W. Gillespie and L. A. Carlsson, "Buckling and growth of delamination in thermoset and thermoplastic composites," Journal of Engineering Materials and Technology, pp. 93-98, 1991.

[8] R. A. Grimm, "Welding processes for plastics," Adv Mater Process, vol. 147, pp. 27-30, 1995.

[9] B. A. Strong , "High performance and engineering thermoplastic composites," Technomic Pub., 1993.

[10] S. M. Todd, "Joining thermoplastic composites," Proceedings of the 22nd International SAMPE Technical Conference, vol. 22, pp. 383-392, 1990.

[11] E. M. Silverman and R. A. Griese, "Joining methods for graphite/PEEK thermoplastic composites," SAMPE Journal, vol. 25(5), pp. 34-38, 1989.

[12] A. Beevers, "Welding: the way ahead for thermoplastics?," Engineering, vol. 231, 1991.

[13] D. M. Maguire, "Joining Thermoplastic Composites," SAMPE Journal, vol. 25(1), pp. 11$14,1989$.

[14] V. K. Stokes, "Joining methods for plastics and plastic composites: an overview," Polymer Engineering \& Science, vol. 29, pp. 1310-1324, 1989.

[15] C. Ageorges, L. Yea and M. Hou, "Advances in fusion bonding techniques for joining thermoplastic matrix composites: a review," Composites Part A: Applied Science and Manufacturing, vol. 32(6), pp. 839-857, 2001.

[16] M. M. Schwartz, "Joining of composite-matrix materials," Materials Park - ASM International, 1994.

[17] A. P. D. Costa, E. C. Botelho, M. L. Costa, N. E. Narita and J. R. Tarpani, "A review of welding technologies or thermoplastic composites in aerospace applications," Journal of Aerospace Technology and Management, vol. 4.3, pp. 255-266, 2012.

[18] P. Davies, W. J. Cantwell, P. Y. Jar, P. E. Bourban, V. Zysman, and H. H. Kausch, "Joining and repair of a Carbon fibre-reinforced thermoplastic," Composites, vol. 22.6, pp. 425431, 1991.

[19] A. Yousefpour, M. Hojjati and J. Immarigeon, "Fusion bonding/welding of thermoplastic composites," Journal of Thermoplastic Composite Materials, vol. 17(4), pp. 303-341, 2004.

[20] A. Benatar and T. G. Gutowski, "Method for fusion bonding thermoplastic composites," 
SAMPE Q., vol. 18.1, 1986.

[21] S. C. Springer and G. S. Mantell, "Manufacturing process models for thermoplastic composites," Journal of Composite Materials, vol. 26, pp. 2348-2377, 1992.

[22] F. Yang and R. Pitchumani, "Interlaminar contact development during thermoplastic fusion bonding," Polymer Engineering and Science, vol. 42, pp. 424-438, 2002.

[23] Y. H. Kim and R. P. Wool, "A theory of healing at a polymer-polymer interface," Macromolecules, vol. 16, pp. 1115-1120, 1983.

[24] P. G. De Gennes, "Reptation of a polymer chain in the presence of fixed obstacles," Journal of Chemical Physics, vol. 55, pp. 572-579, 1971.

[25] Y. M. Boiko, G. Guérin, V. A. Marikhin and R. E. Prud'homme, "Healing of interfaces of amorphous and semi-crystalline poly(ethylene terephthalate) in the vicinity of the glass ransition temperature," Polymer, vol. 42, pp. 8695-8702, 2001.

[26] J. F. Lamèthe, P. Beauchêne and L. Léger, "Polymer dynamics applied to PEEK matrix composite welding," Aerospace Science and Technology, vol. 9, pp. 233-240, 2005.

[27] D. Stavrov and H. E. N. Bersee, "Resistance welding of thermoplastic composites-an overview," Composites Part A: Applied Science and Manufacturing, vol. 36.1, pp. 39$54,2005$.

[28] T. J. Ahmed, D. Stavrov, H. E. N. Bersee and A. Beaukers, "Induction welding of thermoplastic composites-an overview," Composites Part A: Applied Science and Manufacturing, vol. 37(10), pp. 1638-1651, 2006.

[29] J. A. Harris and R. A. Adams, "Strength prediction of bonded single lap joints by nonlinear finite element methods," International Journal of Adhesion and Adhesives, vol. 4.2, pp. 65-78, 1984.

[30] I. F. Villegas, L. Moser, A. Yousefpour, P. Mitschang and H. E. N. Bersee, "Process and performance evaluation of ultrasonic, induction and resistance welding of advanced thermoplastic composites," Journal of Thermoplastic Composite Materials, vol. 26(8), pp. 1007-1024, 2013.

[31] W. J. B. Grouve, L. L. Warnet, B. Rietman and R. Akkerman, "On the weld strength of in situ tape placed reinforcements on woven fabric reinforced structures," Composites Part A, vol. 43, pp. 1530-1536, 2012.

[32] T. E. Tay, "Characterization and analysis of delamination fracture in composites: an overview of developments from 1990 to 2001," Applied Mechanics Reviews, pp. 1-32, 2003.

[33] A. Pavan and J. G. Williams, Fracture of Polymers, Composites and Adhesives, vol. 27, Elsevier, 2000.

[34] B. R. Blackman, A. J. Brunner and P. Davies, "Delamination fracture of continuous fibre composites: Mixed-mode fracture," in Fracture Mechanics Testing Methods for Polymers, Adhesives and Composites, Elsevier, 1985, pp. 335-357. 



\title{
Chapter 2: Effects of release media on the fusion bonding of Carbon/PEEK laminates*
}

\begin{abstract}
Carbon fibre reinforced thermoplastic composite laminates have been press consolidated using various release media. The potential contamination of the laminate's surface by the release media and its effect on the performance of the joint after fusion bonding was studied. Before bonding, the physical and chemical state of the bonding surfaces were analysed by measuring the surface energy and roughness. The laminate surface's chemical composition was investigated by X-ray photoelectron spectroscopy (XPS). Subsequently, the laminates were fusion bonded through an autoclave cycle. The mechanical performance of the joints was characterised by mode-I fracture toughness and short beam strength tests. The surface of some of the composite laminates was found to contain high concentration of the release medium residues after consolidation. This contamination showed a significant effect on the mechanical performance of fusion bonded joints. It was demonstrated that the performance of the joint can be regained by employing a simple cleaning method.
\end{abstract}

${ }^{*}$ Reproduced from F. Sacchetti, W. J. B Grouve, L. L. Warnet and I. F, Villegas. "Effects of release media on the fusion bonding of Carbon/PEEK laminates", Composites Part A: Applied Science and Manufacturing, pp. 70-76, Vol. 94, 2017. 


\subsection{Introduction}

Continuous fibre reinforced thermoplastic composites (TPCs) are attracting increasing interest from the aerospace and automotive industries. Thermoplastic based composite materials have advantages over their thermoset counterparts. These advantages include a higher toughness, a better environmental resistance and improved flammability properties [1-3]. From a manufacturing point of view, the main advantage of thermoplastic composites lies in their potential for high production rates $[4,5]$. The fact that no cure reaction is needed and processing only involves softening of the matrix through heating allows for fast manufacturing and joining techniques, such as thermoforming and fusion bonding, respectively, which are also highly suitable for process automation [6-9].

The present work focuses on fusion bonding, a family of joining techniques in which thermoplastic composite parts are joined at elevated temperatures through the diffusion of thermoplastic polymer molecules across the joint interfaces followed by consolidation under pressure. Effective interdiffusion requires intimate contact, which involves polymer flow to flatten the surface asperities $[10,11]$. Fusion bonding processes are usually divided into those where the whole assembly is heated up, such as co-consolidation, where parts are consolidated and fusion bonded in the same autoclave process [9], or those where only the joining interface and its vicinity are heated, referred to as welding processes [10-15].

Contrarily to adhesive bonding, which involves careful treatment of the surfaces to be bonded [16], fusion bonding is claimed not to require any special surface treatment other than degreasing since the thermoplastic matrix melts during the process $[14,15]$. However, the release media used to treat the moulds for forming and consolidation of thermoplastic composites can potentially leave contaminants on the surfaces, which will be trapped in the bond line during the fusion bonding process. These contaminants might subsequently have an impact on the mechanical performance of the bond. It is clear that additional research on this topic is required in order to mature the fusion bonding processes.

Our previous research [17] on Carbon/PEEK has shown that the release media used during the consolidation of parts can have a significant influence on their ability to be fusion bonded. The present work is an extension of this earlier study and presents a deeper investigation to identify the nature of the contamination. For this purpose, Carbon/PEEK laminates were consolidated using three different release media. The surface state was analysed using roughness measurements, surface energy measurements and by X-ray photoelectron spectroscopy (XPS) measurements. Subsequently, the laminates were fusion bonded, after which the joint performance was characterised using short beam strength test (SBS) and mode-I fracture toughness by double cantilever beam (DCB) experiments. The experimental results showed a clear correlation between the state of the surface before welding and the mechanical performance of the joints. A solution was provided to quantify the level of contamination, based on the obtained results. Moreover, a cleaning process approach was proposed to reduce the level of contamination on the surface. 


\subsection{Experimental Methods}

\subsubsection{Materials}

Unidirectional Carbon Polyether-ether-ketone (PEEK) pre-preg material (Cetex TC1200 produced by TenCate, The Netherlands) was used in this research. Flat laminates with a $[0]_{12}$ stacking sequence were press consolidated in a 2 MN Pinette hotplaten press using a 25.4 by $25.4 \mathrm{~cm}^{2}$ picture frame mould. The press consolidation cycle suggested by TenCate was used to manufacture the laminates, and it is shown in Figure 1. The nominal laminate thickness after press consolidation was $1.5 \mathrm{~mm}$. A total of 12 laminates were manufactured using three different release media; four laminates were consolidated using each release medium. The three different release media used were: Polyimide A film, having a glass transition temperature $\mathrm{T}_{g}$ of $285^{\circ} \mathrm{C}$, which is below the processing temperature of PEEK; Polyimide B film with a $\mathrm{T}_{g}$ of around $500{ }^{\circ} \mathrm{C}$, which is well above the processing temperature of PEEK, and finally a liquid semi-permanent Silicon based release agent. The surfaces of the Polyimide films were cleaned by wiping by hand for 2 minutes with a Wypall ${ }^{\circledR}$ X60 cloth wetted with isopropyl alcohol. The commercial names of the release media used in this work are not disclosed as agreed with the manufacturers. A laminate with a configuration of $[0]_{24}$ was press consolidated as well to characterise the performance of the parent material.

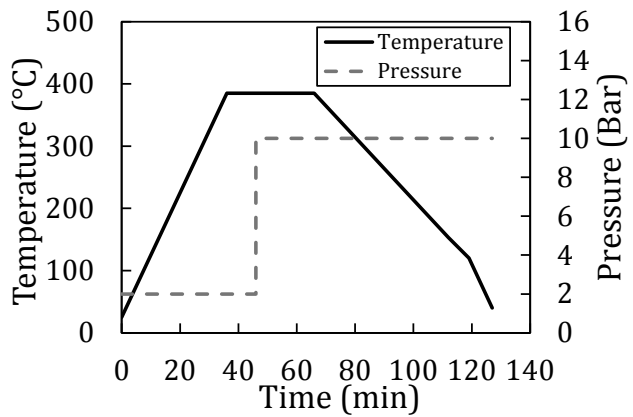

Figure 2.1: Press cycle used to manufacture flat laminates. The dashed line indicates temperature and solid line indicates pressure.

\subsubsection{Surface cleaning}

The laminates were separated into two groups after the press consolidation step. Each group was subjected to a different cleaning process. The aim of this cleaning process was to reduce the amount of potential contamination on the surface. The two different approaches used were: 
I) The surfaces of the laminates were wiped by hand for 2 minutes with a Wypall@ X60 cloth wetted with isopropyl alcohol by applying a normal force of approximately $10 \mathrm{~N}$ (this resulted in a pressure of roughly $6 \mathrm{kPa}$ ).

II) The surfaces of the laminates were vigorously wiped with the same dry cloth for 5 minutes by applying a normal force of about $80 \mathrm{~N}$ (resulting in a pressure of roughly 50 $\mathrm{kPa}$ ) by hand, followed by cleaning treatment $\mathrm{I}$.

\subsubsection{Surface analysis}

Three different experimental techniques were used to characterise the surface before joining. Firstly, the surface energy of the laminates was determined using an optical contact angle measurement device Dataphysics OCA 20. Various liquids were used at room temperature, following the Owens, Wendt, Rabel and Kaelble (OWRK) method [18]. This technique is known to be sensitive to surface contamination [19]. Figure 2.2 shows an example of a picture from which the contact angles were determined. It is important to note that the measurements were performed parallel to the fibre direction, the contact angle in the direction perpendicular to the fibres would be different due to the influence of the surface topography. The three liquids used were: demineralised water, n-Hexane, and ethylene glycol. Three specimens were tested for each laminate and five measurements were performed for each specimen, the standard deviation was calculated over the laminate.

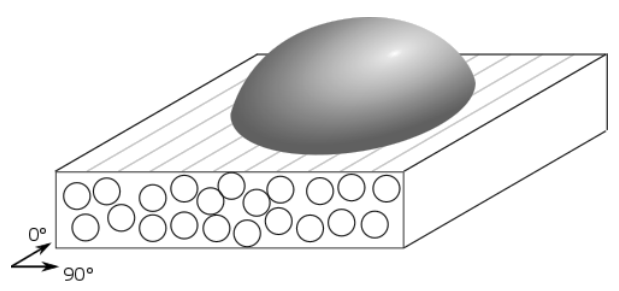

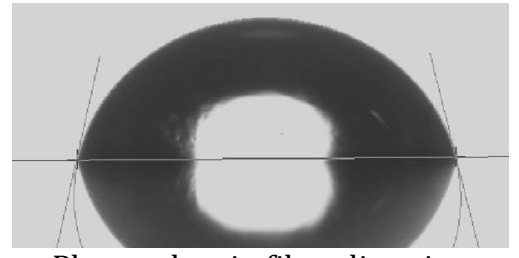

Photo taken in fibre direction (i.e. 0 deg as shown in the drawing)

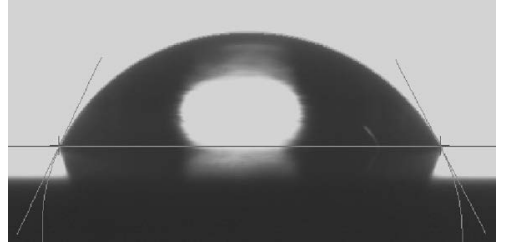

Photo taken transverse to fibre direction

(i.e. 90 deg as shown in the drawing)

Figure 2.2: Effect of fibre orientation on contact angle. 
Secondly, since contact angle measurements provide combined information about the roughness and chemical composition of the surface, roughness measurements were carried out separately using a Keyence VK 9700 confocal laser scanning microscope.

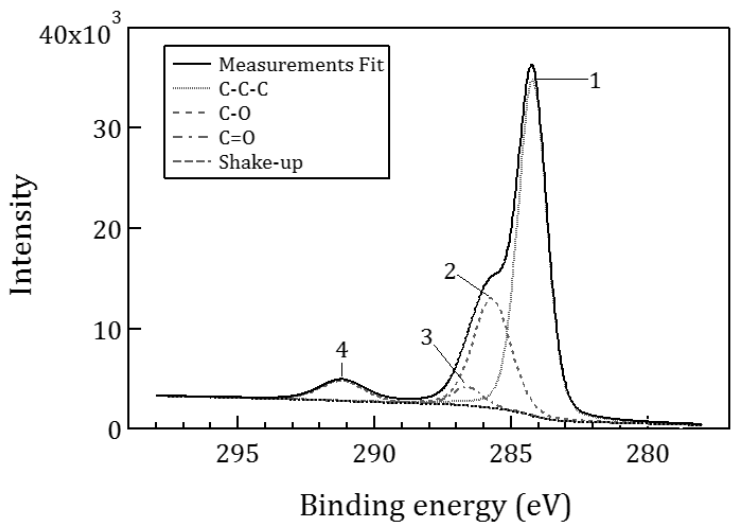

Figure 2.3: Carbon $1 S$ spectrum, deconvoluted into different peaks for different types of bonds (1: C-C-C bond at 284.7 e.V.; 2: C-O bond at 286.3 e.V., 3:C-C-C bond at 287.1 e.V. and 4: shake-up at 291 e.V)

Thirdly, the chemical composition of the surface of the composite was determined by X-ray photoelectron spectroscopy, using a Quantera SXM scanning XPS microprobe from Physical Electronics. The different peaks in an XPS spectrum can be assigned to different chemical elements, while the area under the peaks provides information on the amount of those elements on the surface. Moreover, the peaks can be deconvoluted to distinguish the types of chemical bonds that each element has and their relative levels. For example, as shown in Figure 2.3, the Carbon $1 \mathrm{~S}$ peak (denoted as "measurements fit") can be deconvoluted in several overlapping peaks attributed to $\mathrm{C}-\mathrm{C}-\mathrm{C}, \mathrm{C}-\mathrm{O}$ and $\mathrm{C}=\mathrm{O}$ bonds. Reference values are required to improve the interpretation of XPS analysis. For this purpose, the XPS spectra of the two neat polyimide (PI) films and the Carbon/PEEK prepreg were obtained. The chemical structure of the components is shown in Figure 2.4. The theoretical spectrum can be determined from the chemical structure of the material. Firstly, the elements which are expected and the amount of each element has to be identified. Secondly, the nature of the chemical bonds and the amount of them has to be identified. The theoretical PEEK spectra were compared with the measured Carbon/PEEK spectra of the material as received and a good agreement of the amounts of elements and bonds gives a conformation of the material. Thereafter, the spectra of the PI film and Carbon/PEEK samples were then compared with the spectra of the laminate surfaces after press consolidation. 
<smiles>Cc1ccc(Oc2ccc(N3C(=O)c4ccc(-c5ccc6c(c5)C(=O)N(C)C6=O)cc4C3=O)cc2)cc1</smiles>

Figure 2.4: Chemical structure of PEEK, Polyimide A, and Polyimide B.

\subsubsection{Fusion bonding}

For simplicity, the different press-consolidated laminates produced in this study were fusion bonded in an autoclave, similar to the co-consolidation process. Although not entirely realistic, autoclave fusion bonding of pre-consolidated laminates allowed us to focus solely on the effect of release media in the fusion bonded joints without any potential noise in the results caused by phenomena associated with local heating in typical welding processes, such as uneven temperature distributions or residual stresses. Consequently, sets of two laminates which had been press consolidated using the same release medium and had undergone the same cleaning procedure were stacked on top of each other, vacuum bagged and fusion bonded in an autoclave cycle. The autoclave cycle was performed following the specifications of TenCate for the consolidation of regular laminates and is illustrated in Figure 2.5. Table 2.1 shows the various combinations used.

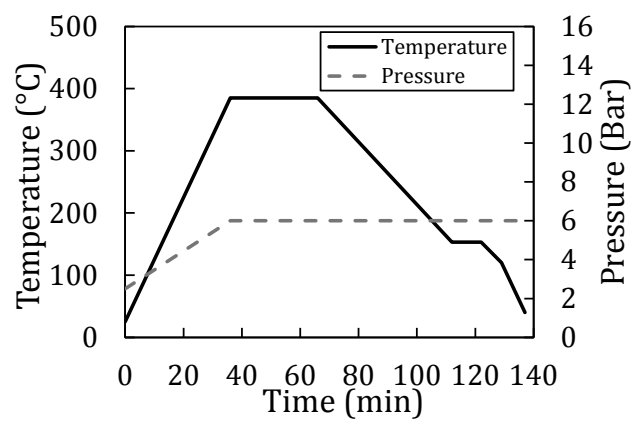

Figure 2.5: Autoclave cycle used to co-consolidate (or fusion bond) two flat laminates. The dashed line indicates temperature and solid line indicates pressure. 


\begin{tabular}{ccc}
\hline $\begin{array}{c}\text { Release agent used in the } \\
\text { press consolidation }\end{array}$ & $\begin{array}{c}\text { Cleaning treatment before } \\
\text { Co-consolidation }\end{array}$ & $\begin{array}{c}\text { Co-consolidated } \\
\text { Sample Name }\end{array}$ \\
\hline Si based release agent & Treatment I & SiI \\
Si based release agent & Treatment II & SiII \\
Poly(imide) A film & Treatment I & AI \\
Poly(imide) A film & Treatment II & AII \\
Poly(imide) B film & Treatment I & BI \\
Poly(imide) B film & Treatment II & BII \\
\hline
\end{tabular}

Table 2.1: Names of the various co-consolidation samples.

\subsubsection{Mechanical testing}

The mechanical performance of the joints was characterised using double cantilever beam (DCB) and short beam strength (SBS) testing. The DCB samples were cut from the laminates in the longitudinal direction of the fibres and then tested according to ISO 15024. The specimens were loaded in a servo-hydraulic Instron 8500 universal testing machine equipped with a $1 \mathrm{kN}$ force cell. A travelling recording camera was used to measure the crack length during testing. Corrected beam theory (CBT) data reduction analysis was implemented to analyse the data. The SBS test was performed according to ASTM D2344. The specimens were loaded in an Instron 5982 electro mechanic universal testing machine equipped with a $10 \mathrm{kN}$ force cell. The span length used was $16 \mathrm{~mm}$.

Cross-sectional micrographs were obtained with a Leica DMRX optical microscope. The micrographs were used to assess the state of the fusion bonded interface. Micrographs of the fracture surface of the DCB samples were obtained using a NeoScope JCM-5000 Scanning Electron Microscope (SEM). Fractography was used to assess the failure modes of the samples.

\subsection{Results and Discussion}

The current section presents and discusses the obtained experimental results. Firstly, the surface evaluation is described. The surface energy and roughness measurements are presented followed by the XPS spectroscopy results. Secondly, the results from DCB and SBS tests are presented followed by the microscopic analysis on the failed specimens.

\subsubsection{Surface analysis}

\subsubsection{Surface energy and roughness}

The surface energy of the laminates was calculated with the contact angle measurements after press consolidation and cleaning. Surface energy results with standard deviations are given in Table 2.2. It can be noted that the surface energy of the laminates consolidated with Polyimide A and with the Silicone based semi-permeant release media showed similar values, irrespectively of the chosen cleaning treatment. Different values were 
however observed for the laminates consolidated with Polyimide B film. For these, surface energy values similar to the other laminates were only obtained after the strong cleaning procedure (i.e. procedure II).

Differences in surface energy can be caused by differences in roughness or variations in the chemistry of the surfaces. The surface roughness of all the laminates, as measured by a confocal microscope, was found to be $R_{q}=0.25 \pm 0.05 \mu \mathrm{m}$. The scatter of the results of the six laminates was within the error of the measurement technique. Hence, the difference in the surface energy can be attributed to differences in the chemistry of the surfaces.

\begin{tabular}{ccc}
\hline \multirow{2}{*}{ Release agent } & \multicolumn{2}{c}{$\begin{array}{c}\text { Surface Energy } \\
\left(\mathrm{m} / \mathrm{m}^{2}\right)\end{array}$} \\
\cline { 2 - 3 } & Cleaning Treatment I & Cleaning Treatment II \\
\hline Si based & $29.2 \pm 1$ & $28.5 \pm 1$ \\
PolyimideA & $29.8 \pm 1$ & $30.1 \pm 1$ \\
PolyimideB & $48.5 \pm 1$ & $30.5 \pm 1$ \\
\hline Table 2. Surface energy of the different samples. The liquids used were demineralised water
\end{tabular}

Table 2.2: Surface energy of the different samples. The liquids used were demineralised water, n-Hexane, and ethylene glycol.

\subsubsection{XPS Analysis}

The XPS results are summarised in Tables 2.3 and Table 2.4. Table 2.3 shows the percentage of the main elements detected on the surface of laminates. Table 2.4 summarises the results from the deconvoluted Carbon and Oxygen peaks which gives information about the nature of the chemical bonds between the elements. The first four rows of Table 2.3 are reference values for the basic materials used, i.e. PEEK, Carbon/PEEK in pre-preg form, Polyimide A and B. The next four rows show the results for the laminates after the two cleaning processes. The percentages of Oxygen and Carbon detected in the Polyimide films and PEEK are similar, which makes this data less usable for distinguishing the components. Nevertheless, the presence of Nitrogen in the Polyimide (PI) films can be used to identify the difference between PI and PEEK. However, this information is not conclusive and additional information can be obtained from the deconvolution of the peaks and the ratios between the chemical bonds. The ratio among the Carbon bonds (i.e. C-C-C vs. $\mathrm{C}-\mathrm{O}$ vs. $\mathrm{C}=\mathrm{O})$ and Oxygen bonds $(\mathrm{C}-\mathrm{O}-\mathrm{C}$ vs. $\mathrm{C}=\mathrm{O})$ can be used to differentiate the presence of one or the other component.

In Table 2.3 it can be seen that all the laminates have some contaminating elements in comparison with the theoretical reference; even in the as-received materials. The lowest amount of contamination was observed in the laminate consolidated with the Siliconbased semi-permanent release agent. The main element detected on this laminate, apart from the constitutive elements of PEEK, is Silicon which is one of the constitutive elements of the release agent. The deconvolution of the Carbon and the Oxygen peaks remains similar to what is obtained for the pure PEEK (Table 2.4). Similar observations were made on the surface of the laminate consolidated with Polyimide A as a release medium. 
Although this shows the presence of $2 \%$ of Nitrogen, the deconvolution of the Carbon and Oxygen peaks are similar to the theoretical values of the PEEK pre-preg. However, the results from the laminate, in which Polyimide $\mathrm{B}$ was used as a release medium and cleaning treatment I was applied, are different. The data in Table 2.3 clearly shows an increased concentration of Nitrogen. Moreover, in this laminate the deconvolution of the Carbon and Oxygen peaks does not look similar to PEEK. Instead, it appears quite similar to the deconvolution of the Polyimide B film (Table 2.4). Contrary to the other release media, it seems that mostly Polyimide B remnants can be found on the Carbon/PEEK surface after consolidation and cleaning treatment I.

\begin{tabular}{cccccc}
\hline Element & $\mathrm{C}$ & $\mathrm{O}$ & $\mathrm{Si}$ & $\mathrm{N}$ & others \\
\hline Binding Energies (e.V.) & 285 & 532 & 102 & 689 & - \\
\hline Theoretical PEEK & 86.4 & 13.6 & - & - & - \\
Carbon/PEEK Pre-preg & 85.2 & 13.3 & 0.1 & - & 1.4 \\
Polyimide A & 81.5 & 13.9 & - & 4.5 & 0.1 \\
Polyimide B & 79.6 & 14.3 & - & 6.1 & - \\
\hline $\begin{array}{c}\text { Laminate - Si base - } \\
\text { Treatment I }\end{array}$ & 81.4 & 15.9 & 2.4 & - & 0.3 \\
$\begin{array}{c}\text { Laminate - Polyimide A - } \\
\text { treatment I }\end{array}$ & 82.7 & 14.7 & - & 2.0 & 0.6 \\
$\begin{array}{c}\text { Laminate - Polyimide B - } \\
\text { treatment I }\end{array}$ & 73.5 & 17.9 & - & 4.9 & 3.7 \\
$\begin{array}{c}\text { Laminate - Polyimide B - } \\
\text { treatment II }\end{array}$ & 85.1 & 13.0 & 0.1 & 1.5 & 0.3 \\
\hline
\end{tabular}

Table 2.3: XPS results, amount of each element.

The results obtained after cleaning treatment I were not expected, the lower glass transition temperature and the higher chemical affinity of Polyimide A with respect to Polyimide B would suggest that a higher level of contamination may arise when polyimide $A$ is used. To understand this better further research is required and this is beyond of the scope of this research.

\begin{tabular}{ccc}
\hline Deconvoluted Bonds & C-C-C/ C-O/C=0 & C-O-C/ C=0 \\
\hline Binding Energies (e.V.) & $284.7 / 286.3 / 287.5$ & $533.4 / 531.3$ \\
\hline Theoretical PEEK & $14 / 4 / 1$ & $2 / 1$ \\
Polyimide B & $14 / 1.6 / 2.1$ & $2 / 13.8$ \\
\hline Laminate - Si base - Treatment I & $14 / 4.8 / 0.6$ & $2 / 1.1$ \\
Laminate - Polyimide A - Treatment I & $14 / 4.5 / 0.7$ & $2 / 1.1$ \\
\hline Laminate - Polyimide B - Treatment I & $14 / 1.4 / 1.9$ & $2 / 14$ \\
Laminate - Polyimide B - Treatment II & $14 / 4.8 / 0.6$ & $2 / 1.6$ \\
\hline
\end{tabular}


After applying cleaning treatment II to the Polyimide B laminates, the XPS analysis shows a significant decrease in the amount of Nitrogen. Likewise, the Carbon and the Oxygen deconvolution after cleaning treatment II are more similar to the PEEK spectrum than to that of the Polyimide. These results indicate hence that the Polyimide B release agent leaves a residue on the surface of the laminates that is not completely removed with cleaning treatment I but can be removed from the surface using the cleaning treatment II.

Good agreement between XPS measurements, and surface energy measurements were found. When no contaminants were presented, the surface energy values were always the same. On the other hand, when contaminats were presented the values of surface energy change. Surface energy measurements were found to be a quick indicative technique of the state of the surface. Potentially, surface energy measurements could even serve as an easy quality check before fusion bonding. However, this would require additional research.

\subsubsection{Mechanical testing}

\subsubsection{Fracture toughness}

The fracture toughness in mode-I for the different samples was tested according to ISO 15024. Stable crack propagation was observed in all cases. A typical force displacement and crack length displacement curve is shown in Figure 2.6. The fracture toughness during crack propagation remains stable and fibre bridging was not observed. The fracture toughness determined for all samples is shown in Figure 2.7(a).

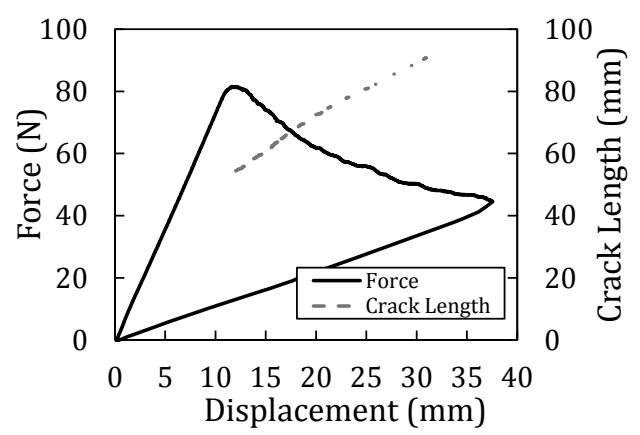

Figure 2.6: Typical force displacement and crack length displacement curve observed during testing.

The co-consolidated samples SiI and AI (see Table 2.1) show toughness values similar to the parent material, indicated by 'press' in the bar graph. This suggests that the level of surface contamination in these samples was not high enough to affect the fracture toughness of the joint. The co-consolidated sample BI shows, however, a significant drop (85\% drop with respect to the performance of the parent material) in toughness 
compared to the other samples. This correlates with the higher contamination of the laminate surface as observed in the XPS measurements. The co-consolidated sample BII again shows a fracture toughness similar to the parent material. XPS measurements have already shown the reduction of contamination due to cleaning treatment II. It can be concluded that the residual contamination on the surface after cleaning treatment II does not degrade the toughness of the Polyimide B samples.

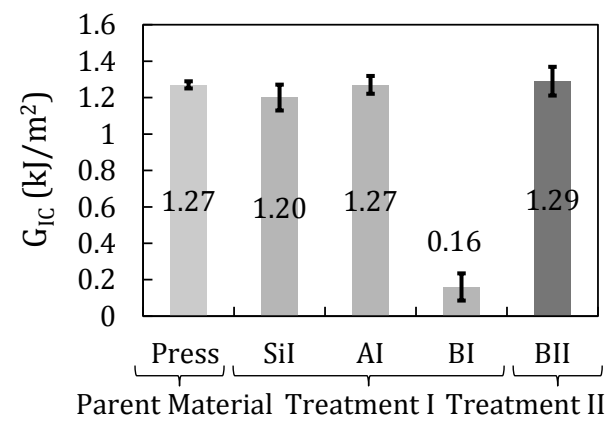

a) Delamination fracture toughness

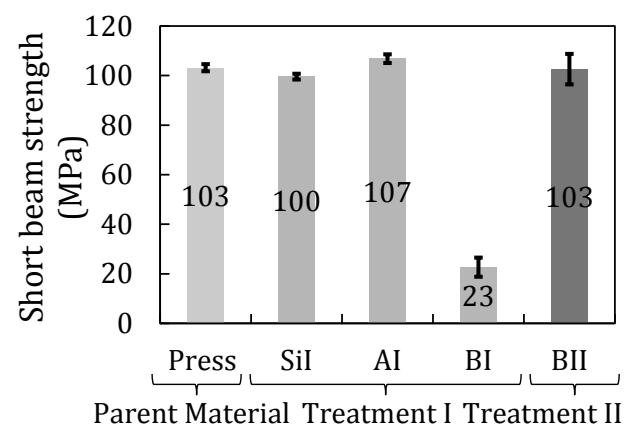

b) Short beam strength

Figure 2.7: a) Delamination fracture toughness and b) short beam strength of six samples.

\subsubsection{Short beam strength}

The short beam strength values obtained for the different types of samples considered in this study are shown in Figure 2.7(b). Similarly to the behaviour in Mode I loading, all types of samples showed a similar SBS as the parent material except for the BI samples, which showed a $80 \%$ decrease in their average SBS as compared to the average SBS of the parent material. Moreover, two different failure behaviours related to these two different strength levels were observed during short beam testing, which are illustrated in Figure 2.8. The sample with lower short beam strength, i.e. the BI sample, showed pure interlaminar shear failure. Cracks were observed on the sides of the sample and the crack was located in the midplane at the bond line. In contrast, the samples with the highest strength values showed a combination of inelastic plastic deformation and pin indentation prior to interlaminar failure. Moreover, the interlaminar cracks were found to be present in multiple planes but almost none in the midplane (or bond line). Schematic pictures of these failure modes are shown in Figure 2.8. The combination of these failure modes does not comply with the test standard. Hence, it is difficult to comparatively analyse the results of the test for the different types of samples tested. Nevertheless, for the samples that yielded the highest strength, the results can be considered to provide a lower bound for the interlaminar strength of the specimen since the interlaminar failure mode was not yet initiated at the moment of the force level off. 


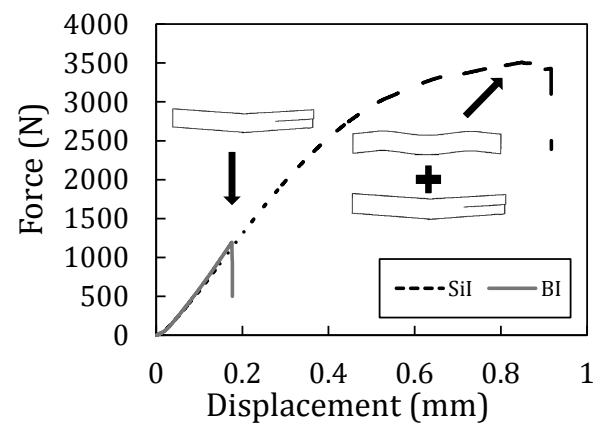

Figure 2.8: Two distinct force displacement curves observed during SBS testing and schematic pictures of the failure modes.

\subsubsection{Cross-sectional micrographs and fractography}

Cross-sectional micrographs of all the samples were analysed after manufacturing. The bonded area between adjacent plies in the press-consolidated samples look similar to the bond line between two laminates after fusion bonding (Figure $2.9(a)$ ). No significant differences were observed in such cross section irrespectively of the release medium used and the applied cleaning treatment.

The cross section of the samples as well as the fracture surfaces were analysed using optical and scanning electron microscopy after performing the fracture toughness (DCB) tests. All samples that showed a high toughness look similar, with fracture surfaces characterised by a tortuous crack path with a fibre-rich surface, some broken fibres and fibre imprints in the matrix. A completely different fracture surface was found for the sample with low toughness, i.e. the BI sample. In this case only a matrix-rich fracture surface was observed and a smooth crack path (Figure $2.9(b),(c),(d))$.
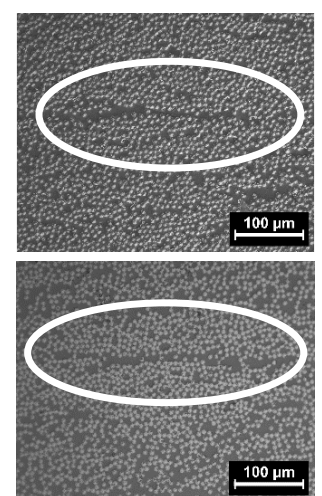

(a)
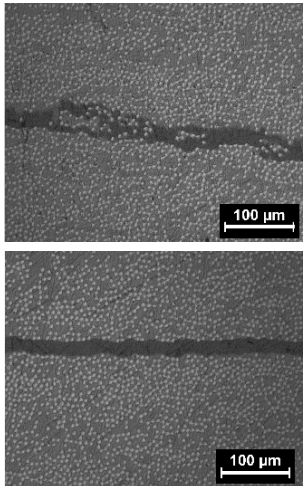

(b)
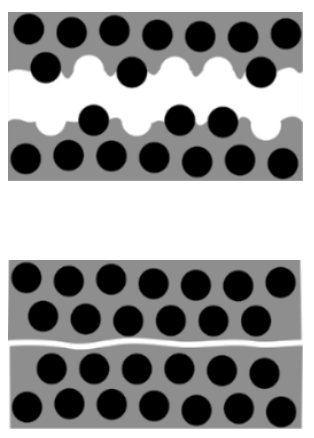

(c)

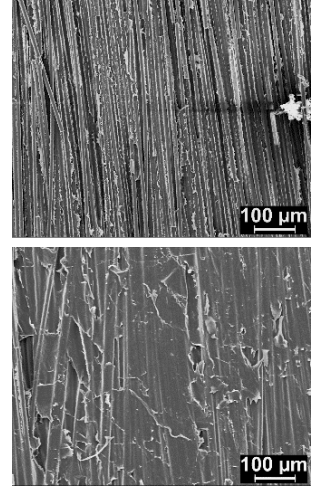

(d)

Figure 2.9: (a) Cross-sectional micrographs before testing (the white circle indicates the interfaces), (b) cross section after DCB testing, (c) schematic of the DCB failure, and (d) SEM micrograph of the DCB fracture surface. From top to bottom, parent material (one-step press consolidation of 24 layers), and co-consolidation sample BI. 
The absence of voids in the fusion bonded samples irrespectively of the release media used to obtain the press-consolidated laminates indicates that proper intimate contact was achieved. It can be noticed in Figure 2.9 (a) for the case of BI sample, which looks similar to all the other fusion bonded samples. Therefore, the lower mechanical performance of the BI sample, having the higher surface contamination, could be attributed to the contamination causing some obstruction of the interdiffusion process. However, to draw definite conclusions more research in the healing process of these interfaces would be required.

\subsection{Conclusions}

The aim of this paper was to find a correlation between the presence of contamination on the surface of unidirectional Carbon/PEEK composites due to the use of release media (two types of polyimide films and a solvent based release agent system) during their manufacturing and the drop in the mechanical performance of fusion bonded joints obtained with these composites. Firstly, the presence and nature of potential surface contamination was evaluated with different techniques. Surface energy measurements were found to be a quick indicative technique of the state of the surface, while XPS measurements were used to quantify the amount of contaminants present on the surface. It was found that one of the polyimide films investigated leaves a significantly higher level of contamination. Subsequently, SBS and DCB tests were used to evaluate the effect of the contamination on the mechanical performance of the fusion bonded joints. Both testing techniques showed the same trend: the fracture toughness and short beam strength of the co-consolidated samples were found to be similar to the performance of the parent material for low levels of surface contamination. High surface contamination, however, resulted in a severe deterioration of the joint strength and toughness. Nevertheless, these higher levels of contamination could be successfully reduced by following a proper cleaning procedure. This work shows that in certain systems the remnants of release agent on the surface limit the proper development of fusion bonding. This has to be taken seriously in some industrial applications such as automated fibre placement, welding and over-moulding techniques where fusion bonding is of fundamental importance.

\section{$2.5 \quad$ References}

[1] A. Offringa, "Thermoplastics in aerospace, new products through innovative technology," SAMPE J., vol. 41.6, pp. 19-27, 2005.

[2] D. C. Leach, "Continuous fibre reinforced thermoplastic matrix composites," Elsevier Applied Science, Advanced Composites, pp. 43-109, 1989.

[3] I. Y. Change and J. K. Lees, "Recent Development in Thermoplastic Composites: A Review of Matrix Systems and Processing Methods," J. Thermoplast. Compos. Mater., vol. 1.3, pp. 227-296, 1988.

[4] R. C. Harper, "Thermoforming of thermoplastic matrix composites. Part II," SAMPE J., 
vol. 28.2, 1992.

[5] E. Wang and T. Gutowski, "Cost comparison between thermoplastic and thermoset composites,” SAMPE J, vol. 26.6, pp. 19-26, 1990.

[6] M. Hou, L. Ye and Y. W. Mai, "An Experimental Study of Resistance Welding of Carbon Fibre Fabric Reinforced Polyetherimide (CF Fabric/PEI) Composite Material," Appl. Compos. Mater., vol. 6.1, pp. 35-49, 1999.

[7] T. G. Gutowski, "Advanced Composites Manufacturing," Wiley Inter Science, 1997.

[8] A. D. Rietman, R. Akkerman and P. Ermanni, "Pull-off strength assessment of coconsolidated AS4/PEEK T-joints," SETEC., 2013.

[9] A. Offringa, "New thermoplastic composite design concepts and their automated manufacture," Jec composites magazine, pp. 45-49, 2010.

[10] A. Benatar and T. G. Gutowski, "Methods for fusion bonding thermoplastic composites," SAMPE Quarterly, vol. 18.1, pp. 34-41, 1986.

[11] N. S. Taylor, S. B. Jones and M. Weld, "The feasibility of welding thermoplastic composite materials," Constr. Build. Mater., vol. 3.4, pp. 213-219, 1989.

[12] D. Stavrov and H. E. N. Bersee, "Resistance welding of thermoplastic composites-an overview," Compos. Part Appl. Sci. Manuf., vol. 36.1, pp. 39-54, 2005.

[13] T. J. Ahmed, D. Stavrov, H. E. N. Bersee and A. Beukers, "Induction welding of thermoplastic composites-an overview, Compos," Composites Part A: Applied Science and Manufacturing, vol. 37.10, pp. 1638-1651, 2006.

[14] A. Yousefpour, M. Hojjati and J. P. Immarigeon, "Fusion Bonding/Welding of Thermoplastic Composites," J. Thermoplast. Compos. Mater., vol. 17.4, pp. 303-341, 2004.

[15] C. Ageorges, L. Ye and M. Hou, "Advances in fusion bonding techniques for joining thermoplastic matrix composites: a review," Compos. Part Appl. Sci. Manuf., vol. 32.6, pp. 839-857, 2001.

[16] B. M. Parker and R. M. Waghorne, "Surface pretreatment of Carbon fibre-reinforced composites for adhesive bonding," Composites, vol. 12.3, pp. 280-288, 1982.

[17] F. Sacchetti, W. J. B. Grouve, L. L. Warnet and I. F. Villegas, "Influence of surface preparation on fusion bonding of thermoplastic composites," in Proceedings of 20th International Conference on Composite Materials, Copenhagen, 2015.

[18] D. K. Owens and R. C. Wendt, "Estimation of the surface free energy of polymers," J. Appl. Polym. Sci., vol. 13.8, pp. 1741-1747, 1989.

[19] W. Benenson, “Handbook of Physics," Springer Science \& Business Media, 2002. 


\title{
Chapter 3: Effect of cooling rate on the interlaminar fracture toughness of unidirectional Carbon/PPS laminates*
}

\begin{abstract}
The effect of cooling rate on the interlaminar fracture toughness of Carbon reinforced PPS laminates was investigated experimentally. A typical stamp forming process was utilised in a novel manner to achieve high average cooling rates, of up to $3500{ }^{\circ} \mathrm{C} /$ minute, while ensuring a good consolidation quality. Differential scanning calorimetry measurements were used to characterise the degree of crystallinity of the samples, while the interlaminar fracture toughness of the laminates was characterised under mode I using the Double Cantilever Beam test. Finally, micrographic analysis of the fracture surfaces was carried out to correlate the degree of crystallinity to the failure modes. A strong correlation between fracture toughness and degree of crystallinity was found. The samples with a low degree of crystallinity showed a high interlaminar fracture toughness and large plastic deformation of the matrix during fracture.
\end{abstract}

*In preparation to be submitted to: Engineering Fracture Mechanics

F. Sacchetti, W. J. B Grouve, L. L. Warnet and I. F. Villegas, "Effect of cooling rate on the interlaminar fracture toughness of unidirectional Carbon/PPS laminates". 


\subsection{Introduction}

Thermoplastic composites are of increasing interest to the aerospace and automotive industries. Compared to many metals, they provide a higher specific strength and stiffness, an increased design freedom and the ability to tailor mechanical performance to the particular application [1]. Moreover, the melt-processability of the thermoplastic matrix allows high production rates, assembly through fusion bonding and makes recycling easier as the matrix and fibres do not necessarily need to be separated [2, 3]. Arguably, the main bottleneck preventing broader application of thermoplastic composites is the final part costs. To overcome this, efforts have been made to cut manufacturing costs through automation and by reducing cycle times. This has resulted in the industrialisation of new manufacturing technologies such as stamp forming [4-6], which in some cases is found to be more cost efficient than the previously existing thermoset manufacturing processes. Moreover, new promising thermoplastic composite production techniques such as laser assisted fibre placement, over-injection moulding, pultrusion, and ultrasonic welding are under continuous development, with the aim of further reducing the manufacturing costs. All of these new processing techniques are characterised by having high cooling rates, ranging from $400{ }^{\circ} \mathrm{C} / \mathrm{min}$ for pultrusion [7] up to $24000{ }^{\circ} \mathrm{C} / \mathrm{min}$ for automated fibre placement (AFP) [8]. Changes pertaining to the large cooling rates during manufacturing are known to affect the mechanical performance of the final thermoplastic composite parts. Therefore, the interest in the effect of fast cooling rates on the mechanical performance of thermoplastic composites is becoming more relevant with the advancement of these new technologies. Unfortunately, process optimisation of the new manufacturing technologies is challenging as the characteristic processing conditions, cooling rate in particular, still lie outside the known process-property envelope. This makes it difficult to predict the mechanical performance of the final part. Clearly, there is a need to extend the known process-property envelope for a range of materials in order to fully utilise the potential of thermoplastic composites.

The effect of processing conditions, and in particular cooling rate, on the mechanical properties of Carbon fibre reinforced Polyphenylene-sulphide (Carbon/PPS) [9-13] and Carbon fibre reinforced Polyether-ether-ketone (Carbon/PEEK) composites [14-25], has received extensive attention in the literature. A common finding is that properties such as the fibre-matrix interfacial shear strength (IFSS) $[19,22]$, tensile strength $[12,13]$, tensile modulus [12, 18] and interlaminar shear strength [10,11] decrease with increasing cooling rate. However, matrix ductility and interlaminar fracture toughness increase with increasing cooling rate [20-25]. These changes in mechanical performance have been mainly correlated to a change in the degree of crystallinity of the polymeric matrix.

Among the studies mentioned in the previous paragraph, the ones focusing on continuous fibre composites utilised autoclave or hot press consolidation as manufacturing techniques, achieving maximum cooling rates of around $80^{\circ} \mathrm{C} / \mathrm{min}$. Efforts were made by 
some research groups to obtain higher cooling rates. However, cooling rates above $100{ }^{\circ} \mathrm{C} / \mathrm{min}$ and up to $2000^{\circ} \mathrm{C} / \mathrm{min}$ could only be achieved by releasing the consolidation pressure in order to bring the material in contact with a heat sink (either water or aluminium plates) $[24,25]$. The releasing of pressure affected the quality of the laminates, evidenced by the presence of voids [24]. Consequently, interpreting the results obtained from mechanical testing of these specimens was problematic since they were influenced by both the presence of voids and the change in crystallinity.

The present work focuses on extending knowledge about the influence of high cooling rates on interlaminar fracture toughness of Carbon/PPS laminates. The interlaminar fracture toughness is of interest as it is sensitive to the polymer properties and thus the processing conditions. As an alternative approach, the present work proposes using a stamp forming process to manufacture well consolidated specimens with a high cooling rate. A stamp forming process was used where the tool temperature controls the cooling rate. Three mould temperatures were used, namely $200{ }^{\circ} \mathrm{C}, 100{ }^{\circ} \mathrm{C}$ and $25{ }^{\circ} \mathrm{C}$. After manufacturing, the degree of crystallinity of the specimens was measured using Differential Scanning Calorimetry (DSC). The effect of the degree of crystallinity on the interlaminar fracture toughness was investigated using Double Cantilever Beam (DCB) testing. Finally, the fracture surfaces of the samples were analysed to correlate the degree of crystallinity with the failure modes.

\subsection{Experimental methods}

This section describes the materials used in this research, followed by the description of the processes used to manufacture the samples. After processing, DSC measurements, mode I interlaminar fracture toughness tests and SEM fractographic analysis were used to characterise the samples. The methodology followed to perform the measurments is described in this section.

\subsubsection{Materials \& laminate consolidation}

Unidirectional Carbon Polyphenylene-sulphide (Carbon/PPS) pre-preg material (Cetex TC1100 produced by TenCate Advanced Composites) was used in this research. The PPS matrix used in the pre-preg is a semicrystalline polymer with glass transition and melting temperature of $90{ }^{\circ} \mathrm{C}$ and $280{ }^{\circ} \mathrm{C}$, respectively. The composite material has a matrix content of $34 \%$ by weight. Flat laminates, with a stacking sequence of $[0]_{12}$, were press consolidated in a Pinette hot platen press to be used as blanks in a subsequent stamp forming step. A picture frame mould, with a cavity dimension of 300 by $300 \mathrm{~mm}^{2}$, was used to avoid excessive flow of the material during consolidation. The press consolidation cycle suggested by TenCate was used to manufacture the laminates and is shown in Figure 3.1. It can be seen that a nominal cooling rate of $5{ }^{\circ} \mathrm{C} / \mathrm{min}$ was used. Three types of laminates were manufactured and are schematically illustrated in Figure 3.2: 
Type I: The first type was used for temperature measurements. One type $\mathrm{K}$ thermocouple was located at the laminate's midplane to measure the temperature during stamp forming, thereby evaluating the cooling rate.

Type II: The second type was used for mechanical testing. A $13 \mu \mathrm{m}$ thick polyimide film was inserted at one of the edges of the laminate at the midplane in order to provide the pre-crack required for DCB testing.

Type III: The last type was used for DSC measurements. This laminate featured a polyimide film between each ply for the first six plies. The polyimide films allow separation of the plies after manufacturing. In this way, the degree of crystallinity through the thickness of the laminate can be evaluated. Only one laminate of this type was prepared.

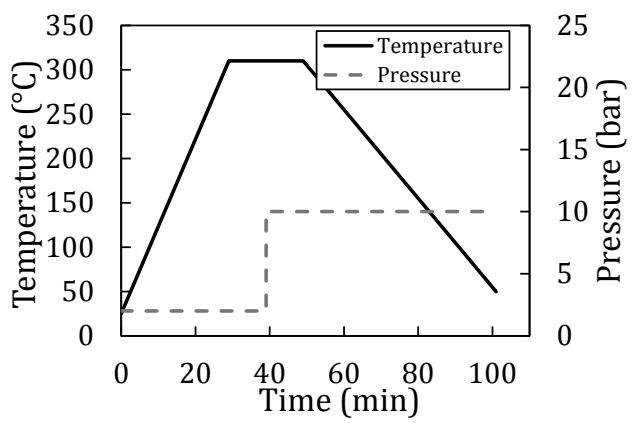

Figure 3.1: Press consolidation cycle for the Carbon/PPS laminates

One additional type II laminate was prepared but not stamp formed. Instead, it was kept as reference for the press consolidation process. The nominal laminate thickness after press consolidation was $1.8 \mathrm{~mm}$. This low thickness was intended to enable high cooling rates during the subsequent stamp forming process and, more or less, a uniform temperature distribution through the thickness of the laminate.

\subsubsection{Stamp forming process}

The Pinette hot platen press was also used for stamp forming the pre-consolidated laminates. The stamp forming setup consists of an infrared oven and a transport system to automatically transfer the blanks from a loading station to the oven, and from the oven to the forming station. During stamp forming, the laminates were pre-heated in the infrared oven to a temperature of $320^{\circ} \mathrm{C}$. Subsequently, they were transferred to the press station and stamp formed between two flat aluminium moulds measuring 250 by $250 \mathrm{~mm}^{2}$ at a pressure of 20 bar for 1 minute. The cooling rate of the laminates from a temperature of $320^{\circ} \mathrm{C}$ to the mould temperature was dictated by the mould temperature. Three mould temperatures, equal for both mould halves, were used: $200{ }^{\circ} \mathrm{C}, 100^{\circ} \mathrm{C}$ and $25^{\circ} \mathrm{C}$. It is worth noticing that the typical mould temperature for stamp forming of Carbon/PPS parts is $200{ }^{\circ} \mathrm{C}$. A LabVIEW data acquisition system was used to record the temperature from the 
(Laminate type I)

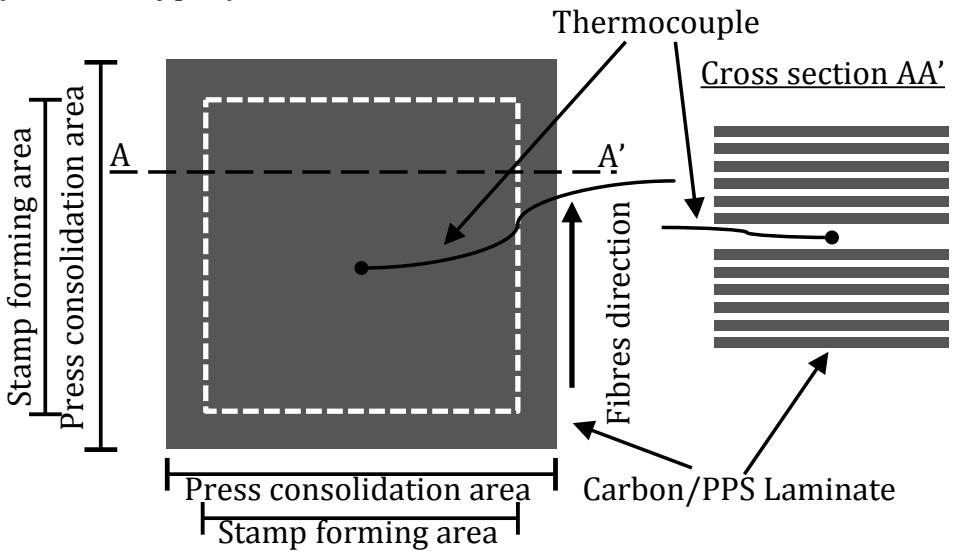

(Laminate type II)

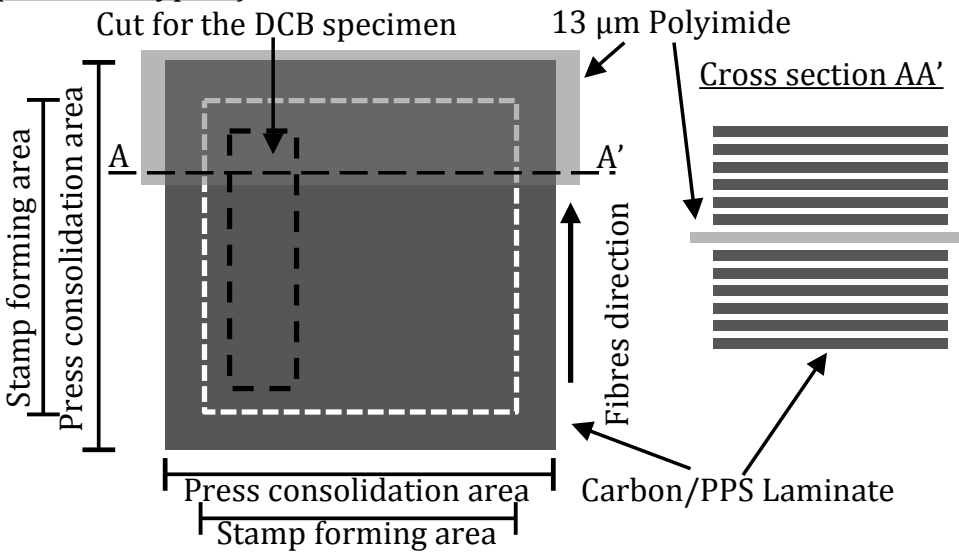

(Laminate type III)

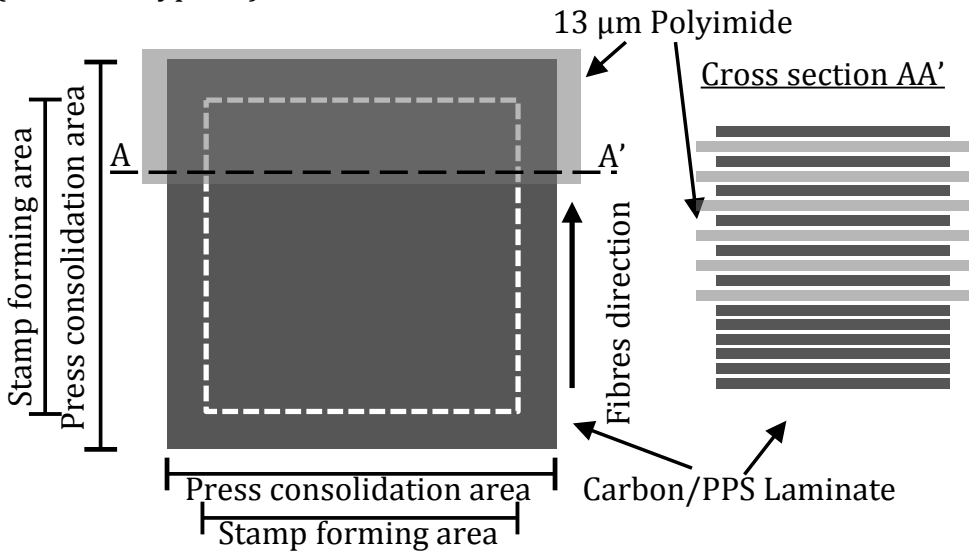

Figure 3.2: Schematic view of the lay-up of the three types of laminates produced in this study. 
thermocouples embedded in the type I laminates during the stamp forming process. After the stamp forming cycle, the laminates were allowed to further cool down from mould temperature to room temperature by natural convection.

Two laminates were manufactured for each stamping mould temperature. One laminate was used to measure the temperature (laminate type I), while the other one was used for physical and mechanical testing (laminate type II). An additional laminate with polyimide films in between the first six plies (laminate type III) was stamp formed using a mould temperature of $25^{\circ} \mathrm{C}$. Cross-sectional micrographs were obtained from all type II laminates with a Leica DMRX optical microscope. The micrographs were used to assess the presence of voids after stamp forming.

After measuring the interlaminar fracture toughness in the type II laminates stamp formed at $100{ }^{\circ} \mathrm{C}$ and $25^{\circ} \mathrm{C}$ mould temperature, the already tested specimens were subjected to an annealing treatment in order to increase their crystallinity fraction. This treatment was aimed at obtaining the same level of crystallinity as obtained in the press-consolidated samples. The annealing treatment involved placement of the specimens in a pre-heated convection oven at $180{ }^{\circ} \mathrm{C}$ for 30 minutes without the application of pressure [26]. After the annealing treatment, the degree of crystallinity and the interlaminar fracture toughness of the specimens were measured again.

\begin{tabular}{ccc}
\hline Sample name & Consolidation technique & Laminates type \\
\hline Reference & Press consolidated & II \\
S-200 & Stamp formed with moulds at $200^{\circ} \mathrm{C}$ & I,II \\
S-100 & Stamp formed with moulds at $100^{\circ} \mathrm{C}$ & I,II \\
S-25 & Stamp formed with moulds at $25{ }^{\circ} \mathrm{C}$ & I,II,II \\
S-100-a & Stamp formed with moulds at $100{ }^{\circ} \mathrm{C}$ - annealed & II \\
S-25-a & Stamp formed with moulds at $25^{\circ} \mathrm{C}$-annealed & II \\
\hline
\end{tabular}

Table 3.1: Summary of the sample names, the production technology used and the type of laminates produced for each condition.

Table 3.1 summarises all prepared samples, with their designated name, the processing technology used to manufacture the sample, and the type of laminates that were prepared. The laminate that was only subjected to press consolidation is listed as Reference sample. The name of the samples that were stamp formed start with an $S$ followed by number which indicates the temperature of the moulds during the stamp forming process (that is S-200, S-100 and S-25 for samples that were stamp formed using moulds at 200, 100 and $25{ }^{\circ} \mathrm{C}$, respectively). In the case of samples that were subjected to an annealing treatment, an "a" was added at the end of the name (S-100-a and S-25-a).

\subsubsection{Differential Scanning Calorimetry experiments}

The degree of crystallinity of each laminate was measured by differential scanning calorimetry. A Mettler Toledo differential scanning calorimeter (DSC822E) was used for this purpose. The measurements were performed in a Nitrogen atmosphere with heating 
and cooling rates of $10{ }^{\circ} \mathrm{C} / \mathrm{min}$ from room temperature to $320^{\circ} \mathrm{C}$ and vice versa. A drop of silicon paste was added between the specimen and the crucible to improve thermal contact and to hence increase the accuracy of the first heating run. For the DSC analysis, at least three specimens of at least $10 \mathrm{mg}$ were taken from the central part of each sample. Since all the laminates used in this study had a thickness of around $1.8 \mathrm{~mm}$, it was assumed, following previous works [27], that the degree of crystallinity did not vary much over the thickness of the specimen. As mentioned earlier, this assumption was crosschecked by performing DSC measurements on the individual plies from a laminate with polyimide films between the first six plies, for the laminate processed with the highest cooling rate (laminate $\mathrm{S}-25$ ).

The degree of crystallinity was calculated by analysing only the heating run using the following equation [13]:

$$
X_{c}=\frac{\Delta H_{f}+\Delta H_{c}}{\left(1-W_{f}\right) \Delta H_{f}^{0}},
$$

where, $W_{f}$ is the weight fraction of reinforcing fibre in the composite $(66 \%$ for the material used in this research), $\Delta H_{f}$ is the enthalpy of fusion, $\Delta H_{c}$ is the enthalpy of cold crystallization, and $\Delta H_{f}^{0}$ is the fusion enthalpy of $100 \%$ crystalline PPS. Values of $\Delta H_{f}^{0}$ found in the literature for PPS range from about $50 \mathrm{~J} / \mathrm{g}$ to $150.4 \mathrm{~J} / \mathrm{g}$ [13]. The latter was used in this study to calculate the degree of crystallinity, as that value was measured for TenCate material.

\subsubsection{Double cantilever beam experiments}

The interlaminar fracture toughness of the different samples was characterised using double cantilever beam testing. Four specimens were cut per sample in the longitudinal direction of the fibres and then tested according to ISO 15024. The specimens were cut such that they had an initial crack length of about $55 \pm 10 \mathrm{~mm}$. The specimens were loaded in a servohydraulic Instron 8500 universal testing machine equipped with a $200 \mathrm{~N}$ force cell. Before testing, a mode I pre-crack was created according to the procedure indicated in the ISO 15024 standard. Both pre-cracking and the DCB tests were performed at a crosshead speed of $4.8 \mathrm{~mm} / \mathrm{min}$.

The energy release rate $\left(G_{I C}\right)$ was calculated using the corrected beam theory (CBT) data reduction method as:

$$
G_{I C}=\frac{3 P \delta}{2 w(x+\Delta)} \frac{1}{N}
$$

with $w$ the specimen width, $P$ and delta the applied force and displacement, respectively, and $x$ the crack tip location as defined in Figure 3. The latter was measured during the test using an automated travelling camera system. Two correction factors $\mathrm{N}$ and $\Delta$ were used. The former accounts for the stiffening effects of the loading blocks, while the latter 
accounts for root rotation at the crack tip. There is no need for a large deformation correction factor, designated as $F$ in the standard, as the travelling camera system was used to measure $x$, as opposed to the crack length $a$ [28].

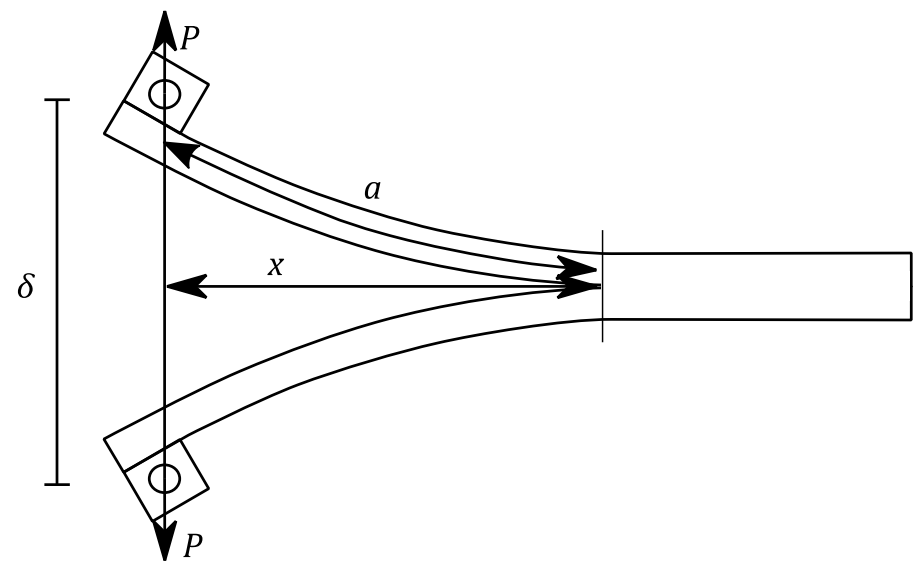

Figure 3.3 Schematic illustration of a DCB specimen undergoing large displacement. Image reproduced from Williams [28].

The interlaminar fracture toughness was calculated for both crack initiation and crack propagation. The maximum force criteria was used to evaluate the initiation point, from that point onwards the $G_{I C}$ values were considered as propagation values. An example of force vs. displacement curve for the pre-crack and for the DCB test of a press-consolidated specimen is shown in Figure 3.4.

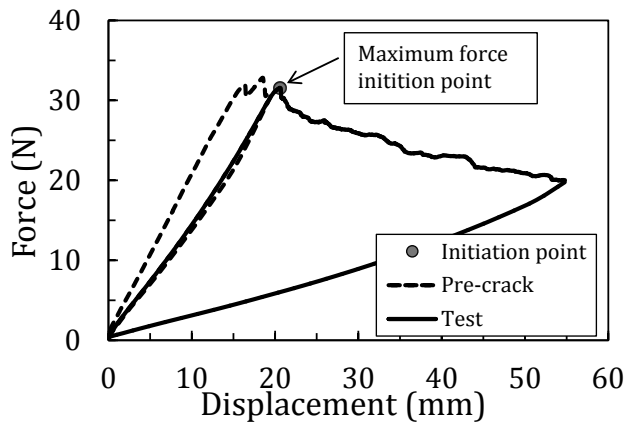

Figure 3.4: Example of a force vs. displacement curve during pre-cracking and testing of a DCB specimen.

As mentioned earlier, the specimens from samples S-100 and S-25 were subjected to an annealing treatment after testing. Before (re-)testing the annealed specimens, they were cut to have an initial crack length of $55 \pm 10 \mathrm{~mm}$. No pre-cracking was needed as these specimens already had a pre-crack from the previous test. 


\subsection{Experimental results}

The current section presents the experimental results. Firstly, the cooling rates as measured during the stamp forming process are presented, followed by cross-sectional micrographs after stamp forming. Secondly, the results of differential scanning calorimetry and the interlaminar fracture toughness measurements are provided and discussed. Finally, the fractographic analysis is presented, where the observed failure modes are correlated to the degree of crystallinity.

\subsubsection{Cooling rates during stamp forming}

The objective of using the stamp forming process in this study was to achieve cooling rates that limit the PPS crystallisation process while keeping sufficient consolidation pressure. Figure 3.5 shows the temperature at the midplane of the laminate versus time for the stamp forming process with the three mould temperatures. The temperature traces were recorded during the stamp forming of type I laminates. The graph on the right in Figure 3.5 shows a detailed view of the cooling phase. As expected, the cooling rate decreases with increasing mould temperature. For each mould temperature, the cooling rate was calculated at four different temperatures. These were the temperature at the beginning of the stamp forming stage $\left(320{ }^{\circ} \mathrm{C}\right)$, at the reported melting temperature of PPS $\left(\mathrm{T}_{\mathrm{m}}=\right.$ $280^{\circ} \mathrm{C}$ ), at the temperature at which the crystallisation rate of PPS is the highest and is approximated to $\left(\left[\left(\mathrm{T}_{\mathrm{m}}-\mathrm{T}_{\mathrm{g}}\right) / 2\right]=185^{\circ} \mathrm{C}\right)$, and at the reported glass transition temperature $\mathrm{T}_{\mathrm{g}}$ of PPS $\left(90^{\circ} \mathrm{C}\right)$. It is worth noticing that the cooling rate cannot be directly correlated to the final degree of crystallinity as isothermal crystallisation occurs above $\mathrm{T}_{\mathrm{g}}$ [26]. The cooling rates as a function of mould temperature are shown in Table 3.2. It can be noted that the cooling rates achieved are significantly higher than the ones usually observed during traditional consolidation techniques, typically $5^{\circ} \mathrm{C} / \mathrm{min}$ for press consolidation.
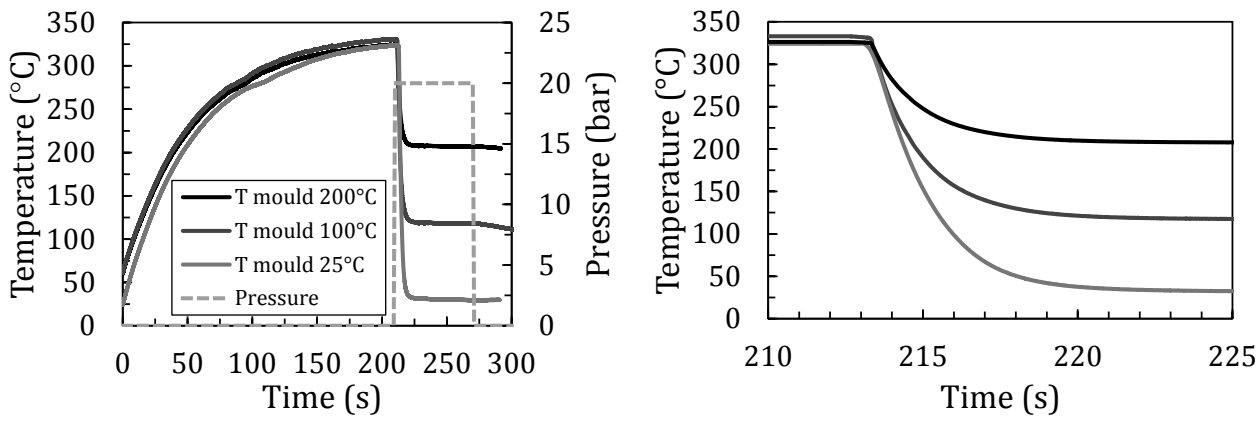

Figure 3.5: Left) Midplane laminate temperature vs. time curves for the different mould temperatures as observed during the stamp forming process. Right) A detailed look at the cooling phase. 


\begin{tabular}{ccccc}
\hline $\begin{array}{c}\text { Mould } \\
\text { temperature: }\end{array}$ & $\begin{array}{c}\text { Cooling rate at } \\
320^{\circ} \mathrm{C}\end{array}$ & $\begin{array}{c}\text { Cooling rate at } \\
280^{\circ} \mathrm{C}\left(\mathrm{T}_{\mathrm{m}}\right)\end{array}$ & $\begin{array}{c}\text { Cooling rate at } \\
185^{\circ} \mathrm{C} \\
{\left[\left(\mathrm{T}_{\mathrm{m}}-\mathrm{T}_{\mathrm{g}}\right) / 2\right]}\end{array}$ & $\begin{array}{c}\text { Cooling rate at } \\
90^{\circ} \mathrm{C}\left(\mathrm{T}_{\mathrm{g}}\right)\end{array}$ \\
\hline $200^{\circ} \mathrm{C}$ & $4200^{\circ} \mathrm{C} / \mathrm{min}$ & $3300^{\circ} \mathrm{C} / \mathrm{min}$ & - & - \\
$100^{\circ} \mathrm{C}$ & $7600^{\circ} \mathrm{C} / \mathrm{min}$ & $6500^{\circ} \mathrm{C} / \mathrm{min}$ & $2400^{\circ} \mathrm{C} / \mathrm{min}$ & - \\
$25^{\circ} \mathrm{C}$ & $7400{ }^{\circ} \mathrm{C} / \mathrm{min}$ & $6500^{\circ} \mathrm{C} / \mathrm{min}$ & $4800^{\circ} \mathrm{C} / \mathrm{min}$ & $2200^{\circ} \mathrm{C} / \mathrm{min}$ \\
\hline
\end{tabular}

Table 3.2: Cooling rates measured in the stamp consolidation process.

The stamp-formed type II laminates were checked for voids by inspecting cross-sectional micrographs. No voids were observed in any of the cross sections. Hence, consolidation was assumed to be satisfactory for all specimens. Differences in the transparency of the matrix in different samples could be observed by using dark field microscopy. Figure 3.6 shows examples of the cross-sectional micrographs. Although difficult to see from the printed micrographs, the dark field microscopy showed differences in matrix appearance. The matrix in the Reference and S-200 sample had a whitish colour, while the matrix material S-25 sample was transparent. This is a first indication of differences in degree of crystallinity.
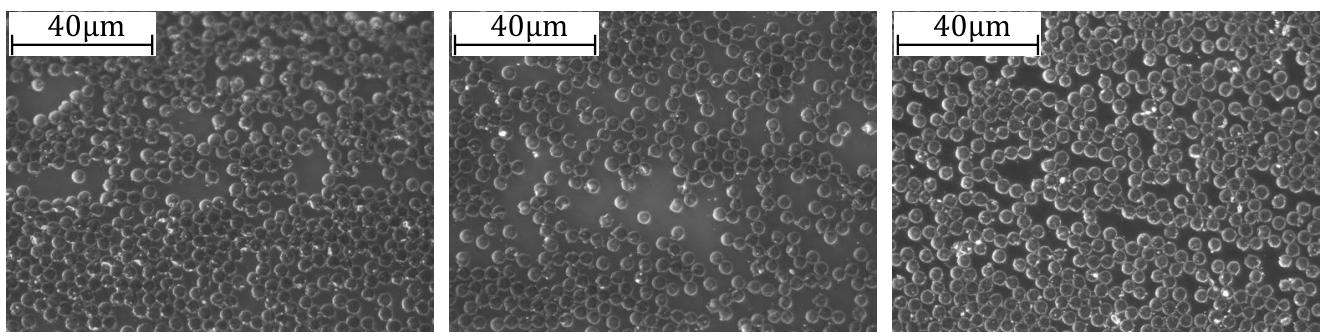

Figure 3.6: Cross-sectional micrographs. From left to right: Reference sample, stamp-formed sample with moulds at $200^{\circ} \mathrm{C}$ (S-200), and a stamp-formed sample with moulds at $25^{\circ} \mathrm{C}(\mathrm{S}-25)$.

\subsubsection{Differential scanning calorimetry measurements (DSC)}

Table 3.3 shows the average degree of crystallinity of the first six plies of the S-25 laminate (laminate type III). It can be observed that the variability in the degree of crystallinity over the thickness of the laminate is small and that it lies close to the scatter of the testing technique. These results validate the simplified approach of using a bulk measurement to represent the degree of crystallinity at the midplane of the laminates used in the rest of this study.

Figure 3.7 shows the DSC heating curves for a few specimens. The trace of a S-100-a specimen is not shown in the Figure as it is similar to the trace of a S-25-a specimen. The S100 and S-25 specimens showed an exothermic cold crystallisation peak in the temperature range from $100{ }^{\circ} \mathrm{C}$ to $140{ }^{\circ} \mathrm{C}$. This peak was not found in the other curves. The second clear peak observed is an endothermic peak which was observed in all the specimens lying in the range from $250{ }^{\circ} \mathrm{C}$ to $290{ }^{\circ} \mathrm{C}$ and corresponds to the melting of the crystalline phase. Finally, the S-200 and S-25-a specimens showed an additional small peak 
in the vicinity of $220{ }^{\circ} \mathrm{C}$ for the S-200 specimen and $190{ }^{\circ} \mathrm{C}$ for the S-25-a specimen. The bottom left graph in Figure 3.7 shows these peaks in closer detail. A similar small peak in the vicinity of $190{ }^{\circ} \mathrm{C}$ was also observed for the S-100-a specimen. These small peaks can be associated with the melting of a small fraction of a secondary population of lamella formed when crystallisation occurs at a temperature below $280{ }^{\circ} \mathrm{C}[29,30]$. Such secondary fusion peaks are known to appear at a temperature just above the temperature at which the secondary crystallisation occurred $[29,30]$. It means close to $180{ }^{\circ} \mathrm{C}$ for both annealed specimens (S-100-a and S-25-a) and close to $200{ }^{\circ} \mathrm{C}$ for the S-200 specimen.

\begin{tabular}{|c|c|}
\hline Sample & $\begin{array}{c}\text { Degree of } \\
\text { crystallinity (\%) }\end{array}$ \\
\hline S-25-1 st ply & $9.8 \pm 1.0$ \\
\hline S-25-2nd ply & $11.6 \pm 1.2$ \\
\hline S-25-3 ${ }^{\text {rd }}$ ply & $13.6 \pm 1.4$ \\
\hline S-25-4th ply & $13.7 \pm 2.1$ \\
\hline S-25-5th ply & $12.1 \pm 1.5$ \\
\hline S-25-6 th ply & $11.9 \pm 1.8$ \\
\hline
\end{tabular}

Table 3.3: Through thickness crystallinity for the $S$-25 sample, with the $1^{\text {st }}$ ply being the outermost ply of the laminate and the $6^{\text {th }}$ ply at the centre of the laminate. The reported values correspond to the average and the standard deviation of three measurements for each separate ply.
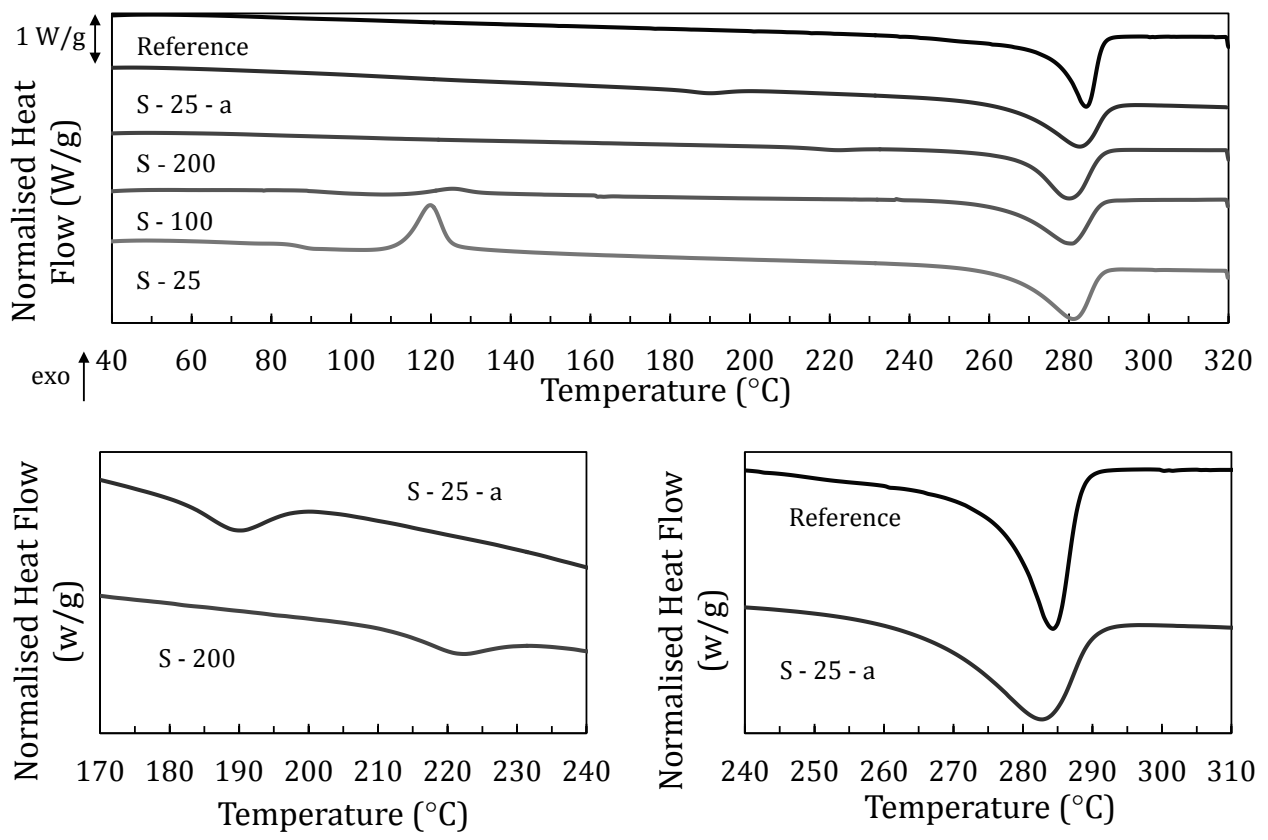

Figure 3.7: Upper figure) DSC trace for the first heating run of the different samples. From top to bottom: Reference specimen, S-25-a, S-200, S-100, S-25. Bottom left) Close-up look at the secondary fusion peak. Bottom right) Close-up look at the main fusion peak. The curves have been shifted along the vertical axis for clarity. 
Table 3.4 shows the average degree of crystallinity with its standard deviation based on the measurements on three specimens per sample. The press-consolidated Reference sample showed the highest degree of crystallinity, followed by the two annealed samples and the S-200 sample. Although the degree of crystallinity increased significantly after annealing, it did not reach the same value as that in the Reference sample. Probably the already existing, less perfect, lamella formed at lower temperature during cooling constrain the development of further crystallinity during the annealing treatment. The stamp-formed samples showed a close relation between the mould temperature and the degree of crystallinity, where the higher mould temperature resulted in a higher degree of crystallinity.

\begin{tabular}{cc}
\hline Sample & $\begin{array}{c}\text { Degree of } \\
\text { crystallinity (\%) }\end{array}$ \\
\hline Reference & $33.3 \pm 1.3$ \\
S-200 & $28.1 \pm 1.4$ \\
S-100 & $22.4 \pm 1.9$ \\
S-25 & $12.1 \pm 2.1$ \\
S-100-a & $27.3 \pm 0.8$ \\
S-25-a & $27.4 \pm 0.8$ \\
\hline
\end{tabular}

Table 3.4: Degree of crystallinity for the different samples. The reported values correspond to the average and the standard deviation of three specimens per sample.

A final observation can be made from the shape of the melting peak, in particular when comparing the Reference specimen with the stamp-formed specimen. The bottom left graph in Figure 3.7 illustrates that the press-consolidated specimen showed a narrow peak with a peak melting temperature of $285^{\circ} \mathrm{C}$, while the stamped-formed specimens before and after annealing showed a wider melting peak with a somewhat lower peak melting temperature. This can be explained by considering the relation between lamella thickness and the melting temperature. Firstly, a narrow melting peak indicates a narrow distribution of lamella thickness [31]. Secondly, the lamella thickness can be related to the cooling rate, with higher cooling rates resulting in a thinner lamella [30]. The lamella in the press-consolidated Reference specimens were formed from the melt at relatively high temperature. The slow cooling rate means that there is plenty of time to form near-perfect, and relatively thick, lamella with a similar size, resulting in a narrow melting peak in the DSC trace when melted. The lamella present in the stamp-formed specimens, both annealed and not annealed, were formed at high cooling rate or as a result of cold crystallisation. These lamella were formed in a less ideal condition, which results in less perfect crystals with a wider distribution of lamella thicknesses, which is reflected in the wider and lower melting peak. 


\subsubsection{Interlaminar fracture toughness}

The mode I interlaminar fracture toughness of the different samples was characterised for both crack initiation and crack propagation. A few examples of typical force versus displacement curves are shown in the left graph of Figure 3.8. All specimens showed an initial linear loading behaviour. Nevertheless, the specimens that reached higher forces showed a deviation from the linear behaviour with an increase in the apparent stiffness. This deviation from the linear behaviour was correlated to the low thickness of the specimen which results in large displacements of the bending arms. It should be noted that, even though a large displacement of the bending arms was observed during the tests, the interlaminar fracture toughness is still expected to be properly calculated as during the experiments the moment arm $(x)$ was measured instead of the crack length $(a)$. A stable crack propagation was observed in all specimens. During unloading of the specimens that reached higher forces, some residual displacement was still observed at zero force, which indicates the occurrence of plastic deformation or damage (besides the delamination) during the test. This second observation indicates a deviation from the linear elastic behaviour of the specimen, possibly resulting in a small error in the calculated fracture toughness values. Nevertheless, as the residual displacement is very small, the results are considered valid for comparison purpose.

The fracture toughness as a function of the crack length (R-curves) is shown in the right graph of Figure 3.8 for a Reference, a S-25, S-100 and a S-25-a specimen. The Reference specimens presented a small increase in the interlaminar fracture toughness along with the crack propagation, which could be due to fibre bridging, which was visually observed to occur in an approximately $10 \mathrm{~mm}$-long area behind the crack tip. Although stable crack propagation was observed for all the stamp-formed specimens, some variability of the fracture toughness along the crack length was observed within each specimen.
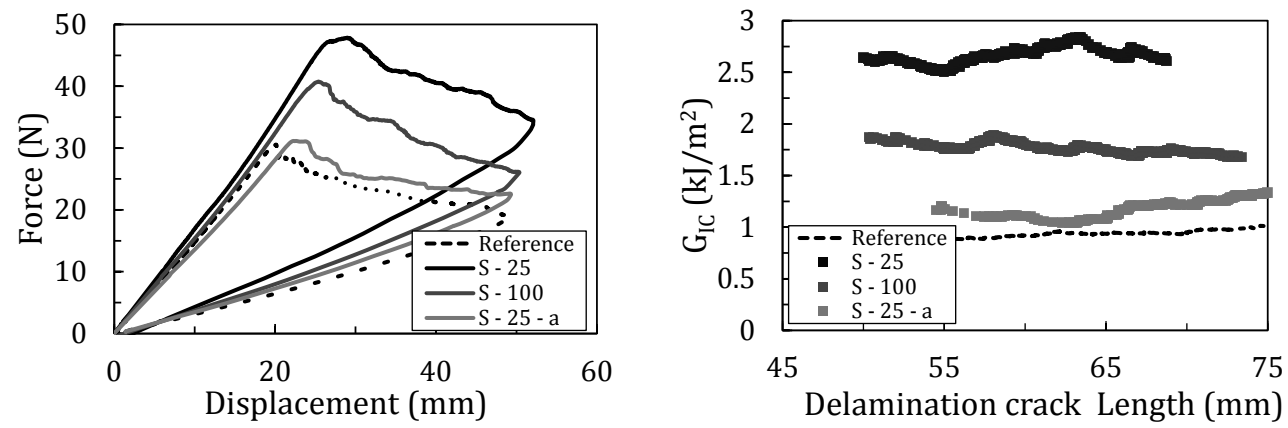

Figure 3.8: Left) Example of force vs. displacement curves. The difference in the initial compliance among the specimens was attributed to a different initial crack length. Right) An example of Rcurves for different specimens. For the name of the specimens the reader is referred to Table 1.

Table 3.5 shows the average initiation and propagation toughness values with their corresponding standard deviation for all the samples. The average initiation value of each 
sample was calculated by averaging the initiation values of the specimens within that sample. The average propagation value per sample was determined by averaging the mean propagation value of each specimen within that sample. The initiation fracture toughness values were found to be lower than the propagation values. For the Reference specimens, this difference was associated with an increasing R-curve. In the case of the stamp-formed specimens, the effect of a possible increasing R-curve may be hidden behind the higher variability. The S-25 and S-100 samples showed the largest variability in propagation values as can be seen from Table 3.5.

\begin{tabular}{cccc}
\hline Sample & $\begin{array}{c}\mathrm{G}_{\mathrm{IC}} \text { initiation } \\
\left(\mathrm{kJ} / \mathrm{m}^{2}\right)\end{array}$ & $\begin{array}{c}\mathrm{G}_{\mathrm{IC}} \text { propagation } \\
\left(\mathrm{kJ} / \mathrm{m}^{2}\right)\end{array}$ & $\begin{array}{c}\text { Degree } \\
\text { of crystallinity }(\%)\end{array}$ \\
\hline Reference & $0.95 \pm 0.10$ & $1.10 \pm 0.11$ & $33.3 \pm 1.3$ \\
S-200 & $1.11 \pm 0.17$ & $1.26 \pm 0.19$ & $28.1 \pm 1.4$ \\
S-100 & $1.48 \pm 0.30$ & $1.68 \pm 0.33$ & $22.4 \pm 1.9$ \\
S-25 & $2.22 \pm 0.41$ & $2.41 \pm 0.59$ & $12.1 \pm 2.1$ \\
S-100-a & $1.25 \pm 0.18$ & $1.26 \pm 0.20$ & $27.3 \pm 0.8$ \\
S-25-a & $1.17 \pm 0.19$ & $1.18 \pm 0.22$ & $27.4 \pm 0.8$
\end{tabular}

Table 3.5: Values measured for interlaminar fracture toughness initiation and propagation.

A small increase of around $10 \%$ in the interlaminar fracture toughness, both in initiation and propagation, was observed when comparing the Reference sample and the S-200 sample. This reflects that the Processing conditions have an effect in the interlaminar fracture toughness. Moreover, an increase in the interlaminar fracture toughness of more than $100 \%$ between the press sample and the S-25 sample was observed. This shows that the mould temperature has a large effect in the interlaminar fracture toughness.

\subsubsection{Fractographic analysis}

The fracture surfaces of the specimens after DCB testing were investigated in order to correlate features of the fracture surface, the interlaminar fracture toughness values and the degree of crystallinity. Figure 3.5 shows the two extreme cases of the fractographic images obtained by scanning electron microscope (SEM). The images correspond to a press-consolidated (Reference) specimen, left figure, and the right figure corresponds to a stamp-formed specimen, with mould temperature of $25{ }^{\circ} \mathrm{C}$ (S-25). The images were selected to highlight the most significant differences. It can be observed that the plastic deformation of the matrix in the right figure is higher with respect to the left figure. This is evidenced by increased out of plane drawing of the matrix forming long lips at the edge of the fibres in the S-25 specimen; this fractographic feature is known as "shear lips" in the literature [32]. As expected, the plastic deformation of the matrix increases with decreasing degree of crystallinity. 

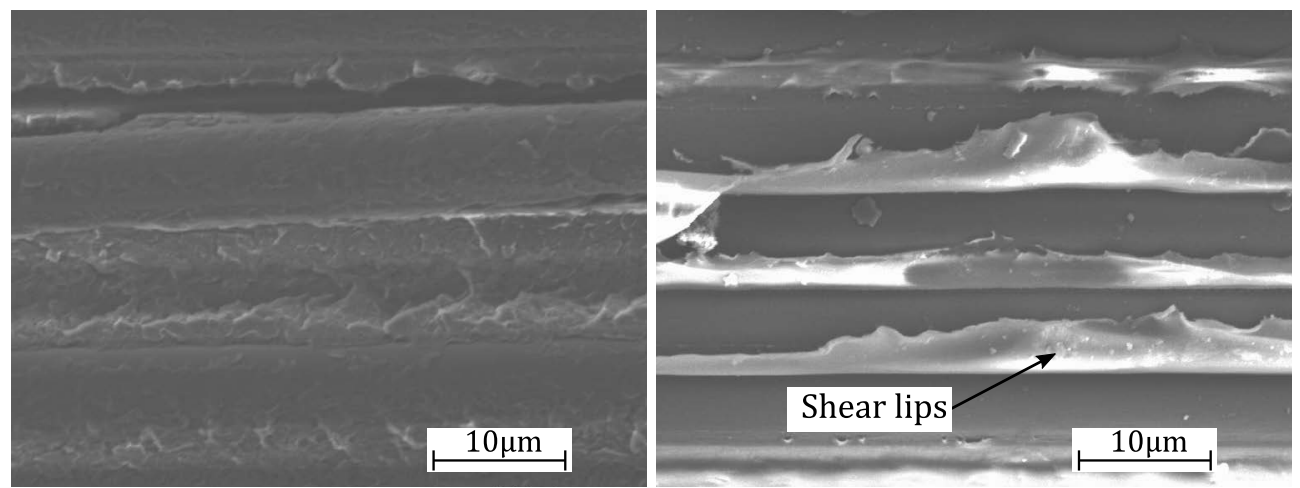

Figure 3.9: SEM micrographs of two fracture surfaces. Left) Reference specimen. Right) Stampformed specimen with moulds at $25^{\circ} \mathrm{C}(\mathrm{S}-25)$ specimens.

Literature reports that the interface adhesion strength between the matrix and the fibres decreases with a decreasing degree of crystallinity [23]. In the presented SEM images, it can be seen that for the Reference specimens, the surface of some fibres is covered by matrix, thus some adhesion between fibre and matrix is shown. In the case of the S-25 specimen, however, the fibres show a smooth surface, which suggests that the matrix was separated from the fibres during fracture. Hence apart from showing that crystallinity has an effect on the ductility of the matrix, the results presented in this study show some indications of an effect of the crystallinity on the fibre-matrix interface.

\subsection{Discussion}

This section first combines the results from the DSC and DCB experiments to investigate and discuss the interrelation between the degree of crystallinity and fracture toughness. Subsequently, at the end of the section the experimental procedure followed is critically reviewed.

Figure 3.10 shows a plot of the mode I interlaminar fracture toughness (initiation and propagation values) as a function of the degree of crystallinity. The samples with a lower degree of crystallinity show higher scatter in the interlaminar fracture toughness. This high scatter may possibly be attributed to a variation in the degree of crystallinity between the different specimens from the same laminate. This idea is reinforced by the observation that the scatter in the interlaminar fracture toughness is significantly reduced after annealing.

Despite the high scatter in the data on the left side of the graph, a linear correlation can be observed between the interlaminar fracture toughness and the degree of crystallinity, with the interlaminar fracture toughness decreasing with increasing degree of crystallinity. In the most extreme case, an increase of the degree of crystallinity from 12 to $33 \%$ results in a drop of $50 \%$ in interlaminar fracture toughness. Arguably more relevant to the industry is the difference between 'standard' stamp forming, for which mould temperature around 
$200{ }^{\circ} \mathrm{C}$ is used, and slow press consolidation. The small difference in crystallinity of $28 \%$ vs. $33 \%$ already results in a difference of roughly $10 \%$ in toughness. The aforementioned linear relation between crystallinity and toughness is somewhat surprising as the thermal history not only affected the degree of crystallinity, but also the crystalline morphology, as was evidenced by the variations in melting peaks between the samples. The obtained linear relation may suggest that toughness is mainly influenced by the degree of crystallinity, while the actual morphology has a negligible influence.
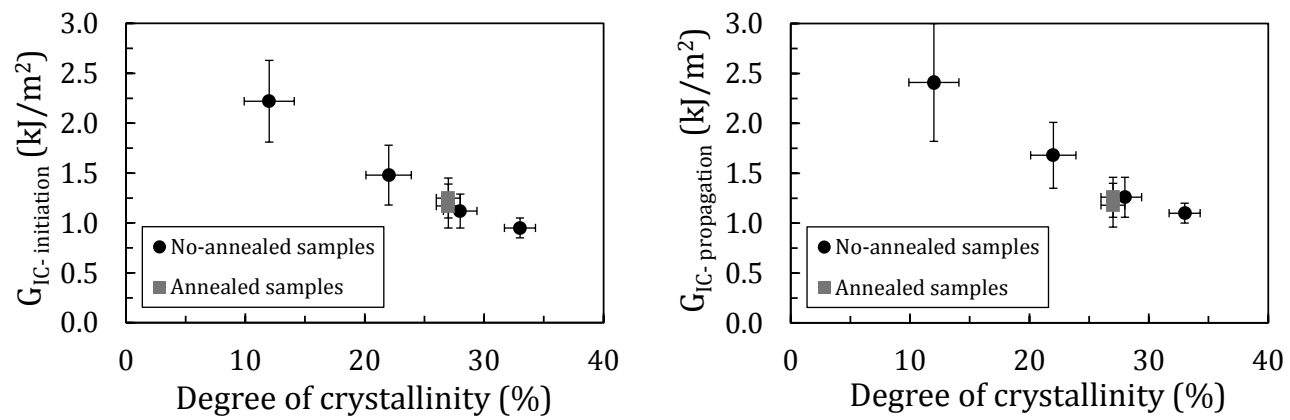

Figure 3.10: Initiation (left) and propagation (right) interlaminar Fracture toughness vs. degree of crystallinity.

The fractographic analysis showed an increase in the plastic deformation of the matrix with a decrease in the degree of crystallinity of the matrix. Moreover, an indication of a reduction of the matrix fibre bond quality with decreasing degree of crystallinity was observed. The interlaminar fracture toughness was reported to depend on both the ductility of the matrix and on the strength of the fibre-matrix interface [33]. In the range tested, the increase in matrix ductility seems to be the dominant mechanism. The large plastic deformation observed in the fractographic images is localised only at the fracture surface. The global linear elastic behaviour of the specimen during testing was almost not affected by the presence of this plasticity. As such, the tests performed in this research are considered to still comply with the LEFM assumption, which makes the comparison of the values obtained for the different samples acceptable. Lastly, in this study only the interlaminar fracture toughness was evaluated. Nevertheless, from the literature, it is clear that other mechanical properties such as short beam strength, tensile strength or modulus will decrease with decreasing degree of crystallinity. Given the emergence of new and faster processing techniques, it would be interesting and worthwhile to evaluate the effect of a low degree of crystallinity, even lower than the levels investigated in this work, on other mechanical properties as well. 


\subsection{Conclusions}

The effect of the degree of crystallinity on the interlaminar fracture toughness of UD Carbon/PPS laminates was investigated experimentally. A stamp forming process was successfully used to obtain well consolidated laminates, i.e. without the presence of voids, at different cooling rates by changing the mould temperature. A maximum average cooling rate of $3500{ }^{\circ} \mathrm{C} / \mathrm{min}$ was achieved for a mould temperature of $25^{\circ} \mathrm{C}$. The crystallinity and interlaminar toughness were characterised using DSC and DCB tests, respectively.

Laminates stamp formed with a mould temperature of $200{ }^{\circ} \mathrm{C}$, which is typical industrial procedure for this material system, had a high degree of crystallinity (28\%) but not as high as that in the reference press-consolidated sample (33\%). The small decrease in the degree of crystallinity from $33 \%$ to $28 \%$ was observed to result in roughly a $10 \%$ increase in the interlaminar fracture toughness. A lower degree of crystallinity was obtained for lower mould temperatures. For the extreme case of a mould temperature of $25{ }^{\circ} \mathrm{C}$, a degree of crystallinity as low as $12 \%$ was obtained. The interlaminar fracture toughness was observed to increase more than $100 \%$ with a change in degree of crystallinity from $33 \%$ to $12 \%$. Microscopy on the fracture surfaces showed that the main mechanism increasing the interlaminar fracture toughness was the larger local plastic deformation that the PPS can undergo with lower degree of crystallinity.

Clearly, the effect of the degree of crystallinity on the mechanical performance, and more particularly the toughness, has to be taken into account when designing components to be manufactured with processing technologies which have fast cooling rates. This is especially true for relatively new processes such as ultrasonic welding or AFP, for which even higher cooling rates are observed than those studied in this work.

\subsection{References}

[1] A. Kelly, “Concise encyclopedia of composite materials," Elsevier, 2012.

[2] R. C. Harper, "Thermoforming of thermoplastic matrix composites. Part II," SAMPE J., vol. 28, n. 2, 1992.

[3] E. Wang and T. Gutowski, "Cost comparison between thermoplastic and thermoset composites," SAMPE J, vol. 26, pp. 19-26, 1990.

[4] T. G. Gutowski, “Advanced Composites Manufacturing," Wiley Inter Science, 1997.

[5] A. Offringa, "New thermoplastic composite design concepts and their automated manufacture," Jec cinoisute magazine, no. Jun- Jul., pp. 45-49, 2010.

[6] A. Offringa, "Thermoplastic composites-rapid processing applications," Composites Part A: Applied Science and Manufacturing, pp. 329-336., 1996.

[7] J. J. Tierney and J. W. Gillespie Jr., "Crystallization kinetics behavior of PEEK based composites exposed to high heating and cooling rates," Composites Part A: Applied Science and Manufacturing, vol. 35.5, pp. 547-558, 2004.

[8] W. J. B. Grouve, L. L. Warnet, B. Rietman, H. A. Visser, and R. Akkerman, “Optimization 
of the tape placement process parameters for Carbon-PPS composites," Composites Part A: Applied Science and Manufacturing, vol. 50, pp. 44-53, 2013.

[9] P. Davies, M. L. Benzeggagh and F. X. De Charentenay, "Delamination behavior of Carbon-fiber-reinforced PPS," SAMPE, 1987.

[10] D. Traudel-broucher, A. L. Esquirol and M. N. Bureau, "Influence of cooling rates on microstructure and mechanical performance of continuous fiber reinforced PPS composites," SAMPE International Symposium and Exhibition-Emerging Opportunities, 2012.

[11] N. L. Batista, P. Olivier, G. Bernhart, M. C. Rezende, and E. C. Botelho, "Correlation between degree of crystallinity, morphology and mechanical properties of PPS/Carbon fiber laminates," Materials Research AHEAD, 2016.

[12] J. Deporter and D. G. Baird, "The effects of thermal history on the structure/property relationship in polyphenylene-sulfide/Carbon fiber composites," Polymer Composites, vol. 14(3), pp. 201-213, 1993.

[13] J. E. Spruiell, "A review of the measurement and development of crystallinity and its relation to properties in neat poly (phenylene sulfide) and its fiber reinforced composites," No. ORNL/TM-2004/304. ORNL, 2005.

[14] P. T. Curtis, I. K. Partridge and J. P. Sainty, "Cooling rate effects in PEEK and Carbon fibre-PEEK composites," Elsevier Proceedings of the sixth international conference on composite materials (ICCM 6/ECCM 2), vol. 4, pp. 401-12, 1987.

[15] M. F. Talbott, G. S. Springer and L. A. Berglund, "The effects of crystallinity on the mechanical properties of PEEK polymer and graphite fibre reinforced PEEK," Journal Compos Mater, vol. 21, pp. 1056-1081, 1987.

[16] G. Ostberg and J. C. Seferis, "Annealing effects on the crystallinity of polyetheretherketone (PEEK) and its Carbon fibre composite," Journal Appl Polym Sci, vol. 33, pp. 29-39, 1987.

[17] P. Davies, W. J. Cantwell, C. Moulin and H. H. Kausch, "A study of the deladelamination resistance of IM6/PEEK composites," Compos Sci Technol, vol. 36, pp. 153-166, 1989.

[18] A. Lustiger, F. S. Uralil and G. M. Newaz, "Processing and structural optimisation of PEEK composites," Polym Compos, vol. 11, pp. 65-75, 1990.

[19] P. Vautey, "Cooling rate effects on the mechanical properties of a semicrystalline thermoplastic composite," SAMPE Q; pp. 23-28, 1990.

[20] P. Davies, W. J. Cantwell, P. Y. Jar, H. Richard, D. J. Neville and H. H. Kausch, "Cooling rate effects in Carbon fibre/PEEK composites," ASTM STP - Composite Materials: Fatigue and Fracture, vol. 1110, pp. 70-80, 1991.

[21] J. Denault and T. Vu-Khanh, "Crystallisation and fibre/matrix interaction during the molding of PEEK/Carbon composites," Polym Compos, pp. 361-71, 1992.

[22] T. Vu-Khanh and J. Denault, "Effect of molding parameters on the interfacial strength in PEEK/Carbon composites," Journal Reinforced Plast Compos, pp. 916-31., 1993.

[23] S. L. Gao and J. K. Kim, "Cooling rate influences in Carbon fibre/PEEK composites. Part II: interlaminar fracture toughness," Composites Part A: Applied Science and Manufacturing, pp. 763-774, 2001.

[24] A. Beehag, and L. Ye, "Influence of cooling rate on interlaminar fracture properties of unidirectional commingled CF/PEEK composites," Applied Composite Materials, pp. 
135-151, 1995.

[25] S. L. Gao and J. K. Kim, "Correlation among crystalline morphology of PEEK, interface bond strength, and in-plane mechanical properties of Carbon/PEEK composites," Journal of Applied Polymer Science, pp. 1155-1167, 2002.

[26] L. C. López and L. W. Garth, "Crystallization kinetics of poly (p-phenylene sulphide): effect of molecular weight," Polymer, pp. 106-113, 1988.

[27] W. I. Lee and G. S. Springer, "A model of the manufacturing process of thermoplastic matrix composites," Journal of Composite Materials, pp. 1017-1055, 1987.

[28] J. G. Williams, "Large displacement and end block effects in the 'DCB' interlaminar test in modes I and II," Journal of Composite Materials, pp. 330-347, 1987.

[29] M. Bonnet, K. D. Rogausch and J. Petermann, "The endothermic "annealing peak" of poly (phenylene sulphide) and poly (ethylene terephthalate)," Colloid and Polymer Science, pp. 513-518, 1999.

[30] P. Cebe and S. Chung, "Melting behavior of high performance composite matrix polymers: Poly (phenylene sulfide)," Polymer Composites, pp. 265-273, 1990.

[31] J. I. Lauritzen Jr and J. D. Hoffman, "Extension of theory of growth of chain-folded polymer crystals to large undercoolings," Journal of Applied Physics, vol. 44.10, pp. 4340-4352, 1973.

[32] D. Purslow, "Matrix fractography of fibre-reinforced thermoplastics, Part 1. Peel failures," Composites, pp. 365-374, 1987.

[33] L. Drzal and M. Madhukar, "Fibre-matrix adhesion and its effect on composite mechanical properties," Compos Mater, vol. 41, pp. 333-378, 1991. 



\title{
Chapter 4: Effect of resin-rich bond line thickness and fibre migration on the toughness of UD Carbon/PEEK joints*
}

\begin{abstract}
It is a common practice in fusion bonding of thermoplastic composites to add a matrix layer between the two substrates to be joined. The aim is to ensure good wetting of the two parts. The effect of this additional matrix layer on the mechanical performance was studied by mode I fracture toughness measurements. The additional matrix was inserted at the interface in the form of films of various thicknesses. Three different manufacturing techniques, namely autoclave consolidation, press consolidation and stamp forming, were used to prepare different sets of specimens with varying resinrich bond line thickness. The occurrence of fibre migration towards the matrix-rich interface was induced by the manufacturing techniques used due to their different processing times. The interlaminar fracture toughness was observed to increase with increasing amount of extra-matrix at the interface, while no effects of the fibre migration on the fracture toughness were observed.
\end{abstract}

${ }^{*}$ Submitted to: Composites Part A: Applied Science and Manufacturing F. Sacchetti, W. J. B Grouve, L. L. Warnet and I. F. Villegas, "Effect of resin-rich bond line thickness and fibre migration on the toughness of UD Carbon/PEEK joints". 


\subsection{Introduction}

Fusion bonding can be considered as an affordable way to assemble thermoplastic composite parts [1]. From a practical viewpoint, the process involves heating of the interface between the parts, followed by application of pressure and cooling down. There are many fusion bonding techniques available, all differing in the way heat and pressure are applied to the interface [2,3]. Two groups of fusion bonding techniques can be distinguished by the size of the area heated, namely bulk heating and welding, which is characterised by local heating. The first group consists of bringing the entire parts to melt and using the tooling to maintain pressure throughout the process. Consequently, this technique is characterised by a relatively long processing time (1-2 hours) [4]. The second group is characterised by local heating, and sometimes by local application of pressure, which means that short processing times can be achieved (minutes or seconds).

From a physical viewpoint, the fusion bonding process involves intimate contact development between the two surfaces (also known as wetting), followed by interdiffusion of polymer chains across the interface (also known as healing) [5]. Proper wetting may be a challenge for thermoplastic composites with a high fibre volume fraction due to the lack of matrix material at the interface; this may result in poor bond performance [6]. To solve this problem, an additional layer of neat polymer can be inserted (interleave) at the interface in order to promote wetting [7-9]. Moreover, some welding techniques may, in any case, require such an additional resin layer at the interface. For example, a resin layer is added as an energy director in the case of ultrasonic welding, while resistance welding requires a metal mesh embedded in a matrix layer at the interface $[5,10]$. This additional layer of pure polymer may lead to a matrix-rich bond line which in turn may affect the joint performance. A proper understanding of the interrelation between the matrix-rich bond line thickness and the joint performance is required to enable optimisation of the joint design.

Earlier research showed that the interlaminar fracture toughness of Carbon/PEEK increases with interleaving thickness (i.e. with increasing thickness of the matrix-rich bond line) $[9,11]$. This is in line with the work on other material systems [12-15] and adhesives joints $[16,17]$ and is generally related to the size of the plastic yielding zone in front of the crack tip. An increase in matrix interface thickness allows for a larger plastic yielding zone, resulting in a higher interlaminar fracture toughness. It is proposed that the interlaminar toughness eventually reaches a plateau value equal to the matrix toughness for larger matrix interleaved thicknesses $[16,18]$. To the best of the authors' knowledge, the aforementioned studies were all performed on samples manufactured using a typical (bulk heating) consolidation technique, i.e. either autoclave or press consolidation. These techniques are characterised by a long processing time, which allows fibres to migrate into the matrix-rich area at the interface. The long processing times are not representative of what happens during welding. In this case, the short processing times are expected to 
significantly reduce fibre migration. It is not clear how this fibre migration affected the measured toughness values reported in the literature. Two effects may play a role. On the one hand, fibre migration leads to more fibre-fibre contact, which effectively reduces the plastic zone size and, hence, the fracture toughness $[13,19]$. On the other hand, fibre migration may also lead to fibre nesting, resulting in so-called fibre bridging which causes an increase in toughness $[20,21]$.

In this research, the effect of interleaving thickness and fibre migration on the interlaminar fracture toughness of unidirectional Carbon fibre reinforced poly-ether-ether-ketone (Carbon/PEEK) fusion bonded samples was studied. The interleave thickness was varied by adding unreinforced PEEK films of varying thickness at the interface between the laminates, while the extent of fibre migration was varied by using different processes. Two slow processes, autoclave consolidation and press consolidation, and one fast process, stamp forming, were used to prepare interleaved fusion bonded samples. The slow processes are expected to yield samples with a high degree of fibre migration, while the fast process should prevent significant fibre migration. A mode I DCB test was used to evaluate the fracture toughness of the joint. Fractographic analysis of the samples was performed after mechanical testing to investigate the failure behaviour of the different samples.

\subsection{Experimental methods}

Sample preparation consisted of two steps. First, laminates were press consolidated following the procedure described below. Second, these laminates were used as substrates for a fusion bonding step in which two substrates were joined to form a sample. The substrates were fusion bonded using three processing technologies as described in this section. Subsequently, the physical state and the interlaminar fracture toughness of the samples was characterised by cross-sectional microscopy and DCB test respectively. The procedures followed to perform these measurements are described in the following subsections.

\subsubsection{Materials and substrate manufacturing}

Press consolidation was used to prepare unidirectional Carbon/PEEK laminates with a stacking sequence of [0]12. The material was provided by TenCate and is known as Cetex® TC1200. The fibre used in the pre-preg is a T300 JB 3K while the polymer is a Victrex PEEK 150. The pre-preg was stacked in a picture frame mould of 300 by $300 \mathrm{~mm}^{2}$ and subsequently consolidated using a static Pinette Emidacau Industries press following the consolidation cycle suggested by TenCate, which is shown in Figure 4.1. To ensure deboning of the laminates from the mould, Marbocote CC223, a silicon based release agent was used as a release media. These laminates were then used as the substrates for the fusion bonding processes. 


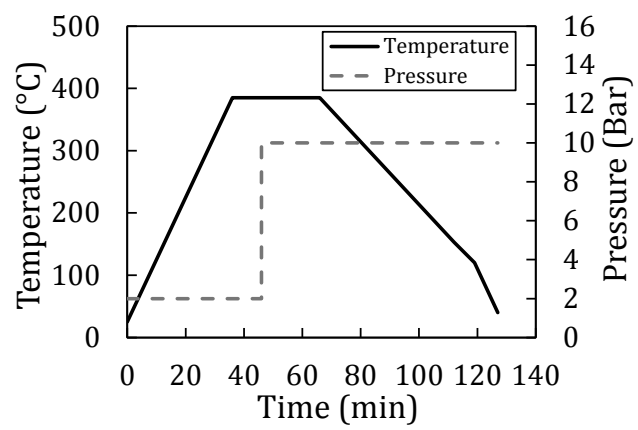

Figure 4.1: Press cycle used to manufacture the laminates.

\subsubsection{Fusion bonding processes}

Three different processing techniques were used to prepare the fusion bonded samples, i.e. autoclave consolidation, press consolidation and stamp forming. Regardless of the processing method, a sample was prepared by stacking two substrates on top of each other with optionally additional PEEK film inserted at the interface. The film was manufactured by Victrex and is known under the trade name APTIV. It was available in two different thicknesses, namely $38 \mu \mathrm{m}$ and $100 \mu \mathrm{m}$. Moreover, a $13 \mu \mathrm{m}$ thick polyimide film was also inserted between the substrates prior to fusion bonding in order to introduce the precrack required for DCB testing. It is worth to noticing that in the area where the polyimide film was inserted the additional PEEK films were not inserted. The remainder of this section describes each of the aforementioned processing techniques.

\subsubsection{Autoclave consolidation}

An autoclave consolidation process was used to fusion bond the first sample set. Seven samples were prepared. The first sample was prepared without an additional film at the interface, while for the other six samples, one to six layers of film with a thickness of $38 \mu \mathrm{m}$ were inserted at the interface prior to consolidation.

A schematic illustration of the autoclave table preparation can be found in Figure 4.2. The press-consolidated substrates were cut into square sections of 150 by $150 \mathrm{~mm}^{2}$ and subsequently stacked together with the required film material. Brass picture frames with different thicknesses were used as a shim at the interface to maintain the distance between substrates and thereby to prevent the added matrix from being squeezed out. A $10 \mathrm{~mm}$ thick aluminium caul sheet was used to ensure the flatness of the laminate. After wrapping the table in a vacuum bag, the substrates were fusion bonded in an autoclave at 6 bar pressure and a temperature of $380{ }^{\circ} \mathrm{C}$ based on the process cycle recommended by TenCate, which is shown in Figure 4.3. 


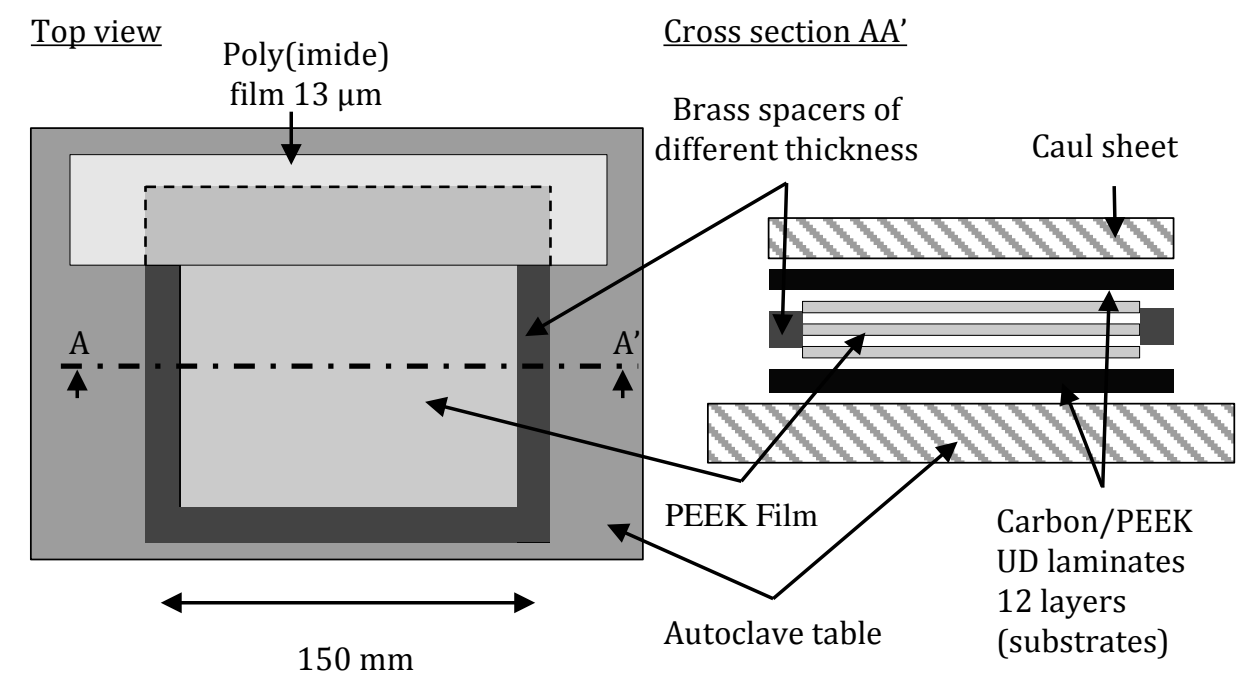

Figure 4.2: Sketch of the preparation of the autoclave table. In the top view, the upper substrate was removed for clarity.

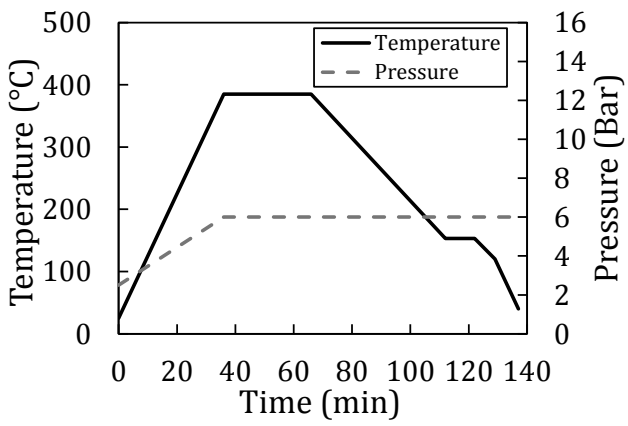

Figure 4.3. Autoclave consolidation cycle used to fusion bond the substrates.

\subsubsection{Press consolidation}

A second sample set was prepared by press consolidation of two substrates in a press using a 300 by $300 \mathrm{~mm}^{2}$ picture frame mould. A total of three samples were prepared: one without an additional polymer film, one with a $38 \mu \mathrm{m}$ PEEK film and one with a $100 \mu \mathrm{m}$ PEEK film. Contrary to the autoclave consolidation process, no shims or spacers were added as any squeeze flow was restricted by the picture frame mould. The consolidation cycle was the same as the one used to manufacture the substrates i.e. the cycle as shown in Figure 4.1. 


\subsubsection{Stamp forming}

The last sample set was prepared by using a Pinette Emidacau Industries stamp forming setup to fusion bond two substrates. Two substrate laminates were stacked and placed on a polyimide film of $50 \mu \mathrm{m}$ thickness, meant for carrying the laminates from the material loading position to the infrared oven and from the oven to the pressing/stamping position. The infrared oven was set at a temperature of $450{ }^{\circ} \mathrm{C}$. The substrates were heated up to complete melting (the temperature at the interface between the two laminates was measured to be $400{ }^{\circ} \mathrm{C}$, taking around 4 minutes of heating time). Then, the substrates were transferred to the stamping station where they were fusion bonded and consolidated between two flat aluminium moulds with a dimension of 250 by $250 \mathrm{~mm}^{2}$. The mould temperature was set to $220^{\circ} \mathrm{C}$. The mould halves were quickly closed and a pressure of 10 bar was applied for 1 minute. The measured temperature and pressure during stamp forming are illustrated in Figure 4.4. Three samples were prepared: one without extra polymer, one with a $38 \mu \mathrm{m}$ PEEK polymer film and one with a $100 \mu \mathrm{m}$ PEEK polymer film at the interface between the two laminates. Table 4.1 summarises all the samples that were prepared.

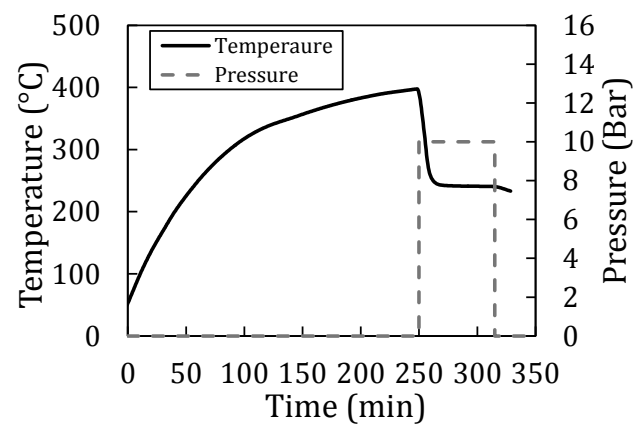

Figure 4.4: Measured temperature and pressure during stamp forming process.

\begin{tabular}{|c|c|c|c|}
\hline \multirow{2}{*}{$\begin{array}{l}\text { Number and thickness }(\mu \mathrm{m}) \\
\text { of PEEK film plies }\end{array}$} & \multicolumn{3}{|c|}{ Fusion bonding technique/ Sample name } \\
\hline & Autoclave & Press & Stamp forming \\
\hline None & A-None & P-None & S-None \\
\hline $1 \times 38 \mu \mathrm{m}$ & $A-1 \times 38$ & P-1x38 & S-1x38 \\
\hline $2 \times 38 \mu \mathrm{m}$ & $A-2 \times 38$ & - & - \\
\hline $1 \times 100 \mu \mathrm{m}$ & - & $P-1 \times 100$ & S-1x100 \\
\hline $3 \times 38 \mu \mathrm{m}$ & A-3×38 & & \\
\hline $4 \times 38 \mu \mathrm{m}$ & $A-4 \times 38$ & & \\
\hline $5 \times 38 \mu \mathrm{m}$ & $A-5 \times 38$ & - & - \\
\hline $6 \times 38 \mu \mathrm{m}$ & $A-6 \times 38$ & & \\
\hline
\end{tabular}

Table 4.1: Sample description, the thickness of interleaving, and fusion bonding technology used. 


\subsubsection{Characterisation}

After fusion bonding, cross-sectional micrographs of the samples were prepared. Subsequently, double cantilever beam (DCB) tests were performed followed by a fractography analysis.

\subsubsection{Cross-sectional microscopy}

The consolidation quality of the fusion bonded samples was characterised using thickness measurements and cross-sectional microscopy. The micrographs were taken close to the edge of the fusion bonded laminates, while the centre was kept for mechanical testing, as it is shown in Figure 4.5. The microscopy images were also used to evaluate, in a qualitative manner, the thickness of the matrix-rich bond line and the degree of fibre migration at the interface.

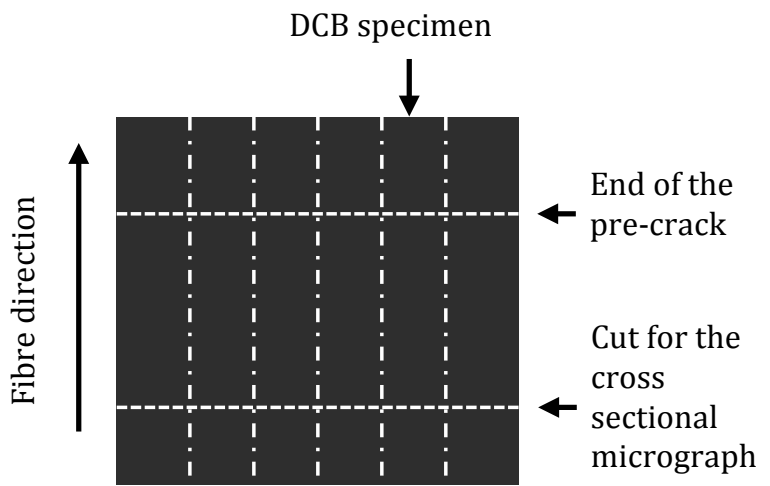

Figure 4.5: Sketch of the location of the cross-sectional sample preparation and the position of the DCB samples.

\subsubsection{Double cantilever beam experiments}

The interlaminar fracture toughness of the bond line was evaluated using the double cantilever beam (DCB) test method. DCB specimens were cut from the fusion bonded samples in the longitudinal direction of the fibres and then tested according to ISO 15024 [22]. The ISO Standard 15024 is based on the linear elastic fracture mechanics (LEFM). As such, the conformance of the linear elastic behaviour of the specimens during testing was evaluated. Figure 4.5 shows schematically the location of the test specimens cut to a width of $20 \mathrm{~mm}$ from the fusion bonded laminates. The specimens were loaded in a servohydraulic Instron 8500 universal testing machine equipped with a $1 \mathrm{kN}$ force cell. A mode I pre-cracking procedure was performed for all the specimens according to the standard. A travelling recording camera was used to measure the delamination crack length during testing. The corrected beam theory (CBT) was used to analyse the data. The interlaminar fracture toughness was calculated as: 


$$
G_{\text {IC }}=\frac{3 P \delta}{2 w(a+\Delta)}\left(\frac{F}{N}\right),
$$

where $P$ is the force, $\delta$ is the displacement, $a$ is the crack length, $w$ is the width of the specimen, $F$ is a correction factor for large displacement, $N$ is a correction factor for the loading blocks and $\Delta$ is a correction factor for the rotation of the beam at the crack tip. Since the delamination length was measured using the horizontal position of the travelling camera system, there is no need for a large-displacement correction factor $(F)$ to be applied to the measurements [22] (i.e. $F$ can be considered equal to one). The interlaminar fracture toughness was calculated both for initiation and propagation. The initiation values were calculated following the procedure called $5 \%$ / MAX point in the ISO 15024 standard. From that point on the values measured were considered as propagation values.

\subsubsection{Fractography analysis}

Two cross-sectional optical micrographs were prepared after testing. One with a sectioning plane perpendicular to the crack propagation direction and the other with a sectioning plane at $20^{\circ}$ with respect to the crack propagation direction. A schematic view of how these cross-sectional cuts were taken is shown in Figure 4.6. All the specimens were embedded in epoxy and then polished. A Leica DMRX and a Keyence VHX optical microscope were used to obtain the optical micrographs. Moreover, SEM micrographs of the fracture surface were made with a Jeol Neoscope JCM-5000. The cross-sectional and fractography images were analysed in order to determine the crack propagation path and to identify the main failure modes.

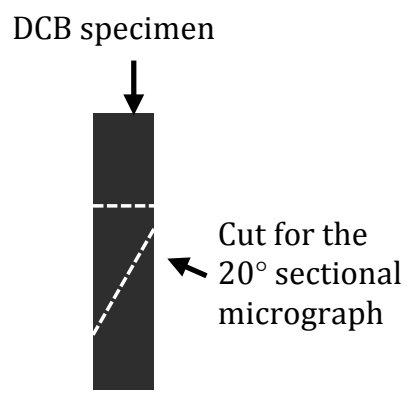

Figure 4.6: Sketch of the location of cross-section micrograph cuts for the fractography analysis.

\subsection{Experimental results}

The experimental results are elaborated in the present section. First, the physical state of the samples and bond line microstructure will be evaluated. Subsequently, the fracture toughness data is provided, followed by the fractographic analysis. 


\subsubsection{Physical state of the samples}

The fusion bonded samples prepared using the autoclave consolidation process showed non-uniform thickness, with the centre of the laminates being thicker than the edges. Despite their thickness $(10 \mathrm{~mm})$, the aluminium caul sheets were bent and permanently deformed during the autoclave cycle as a result of the high pressure applied. In some case, the difference in thickness between the edge and the centre was up to $0.15 \mathrm{~mm}$. The quality of the samples manufactured using press consolidation and stamp forming process, in terms of variation in sample thickness, was superior to the autoclaved samples with the variation in thickness being always less than $0.05 \mathrm{~mm}$.
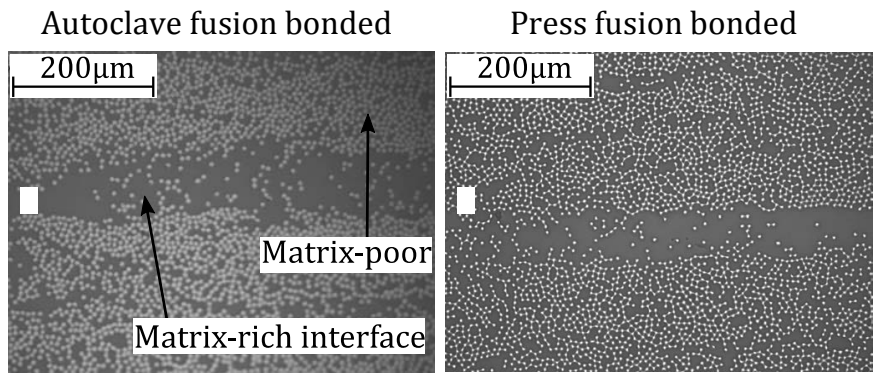

Stamp fusion bonded
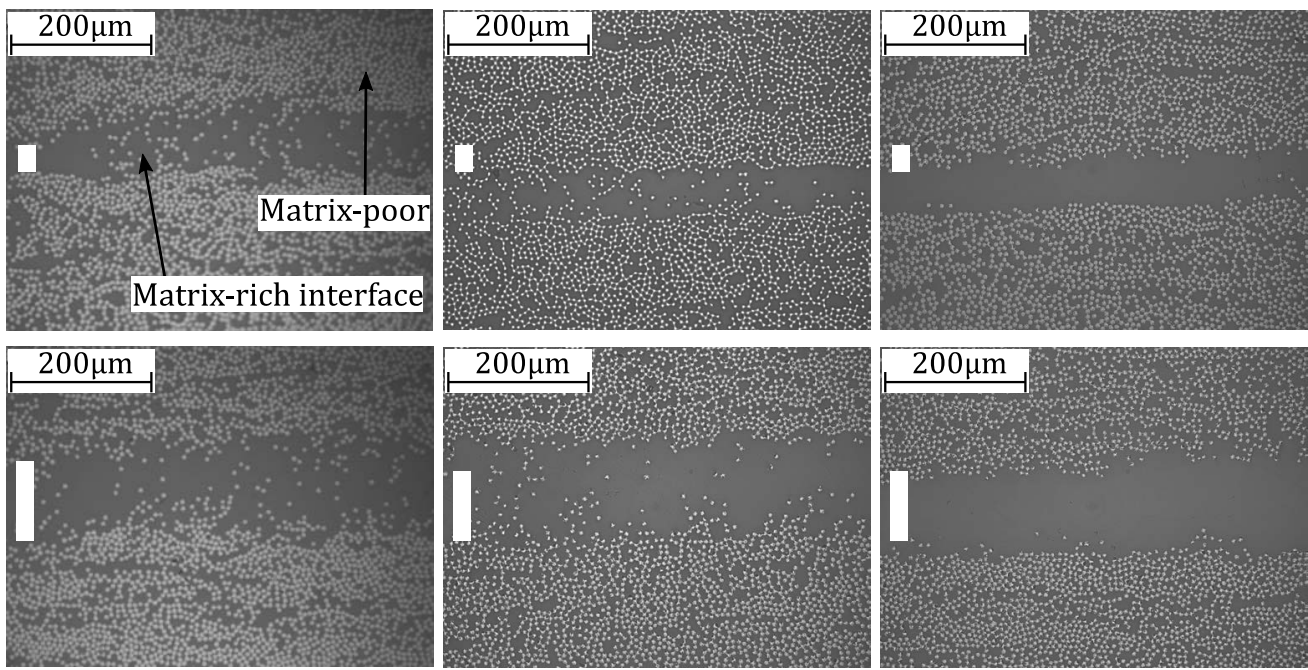

Figure 4.7: Cross-sectional micrographs of 6 different specimens close to the interface. Left to right) Autoclave-consolidated specimen, press-consolidated specimen, and stamp-formed specimen. Top row) Specimen interleaved with a $38 \mu \mathrm{m}$ thick film. Bottom row) Specimen interleaved with $100 \mu \mathrm{m}$ film in the case of press consolidation and stamp forming, specimen interleaved with 3 layers of $38 \mu \mathrm{m}$ thick films in the case of autoclave consolidation. The white bar on the left of the micrograph indicates the thickness of the interleaved films before processing.

Typical cross-sectional micrographs for the three fusion bonding techniques and with different interleave thicknesses are presented in Figure 4.7. All micrographs showed good consolidation quality with no voids in the substrates or the interface. For the cases in which a PEEK film was inserted between the laminates prior to fusion bonding, two different regions can be distinguished in all the micrographs shown in Figure 4.7, i.e. a matrix-poor region mainly in the substrates, and a matrix-rich region at the bond line. Besides, two different morphologies can be identified in the matrix-rich region. The first is characterised by matrix material in which many fibres are randomly distributed as shown in the first and second columns in Figure 7. This morphology arises when fibres migrate, 
during processing, from the substrates into the interleaved film at the interface. This happened during the slower processes, i.e. during autoclave and press consolidation. The second morphology is characterised by matrix material with very few or no fibres. This is evident in the stamp-formed samples (last column in Figure 4.7), for which there is not enough time for the fibres to migrate during processing.

The thickness of the matrix-rich region was not uniform along the cross-sectional plane for the autoclaved specimens, which was associated with significant matrix flow during processing. The effect of this non-uniformity on toughness will be further elaborated on in the next section. On the contrary, the press consolidated and the stamp formed samples showed a more uniform thickness of the matrix-rich region.

\subsubsection{Double cantilever beam experiments}

This section presents the results of the DCB experiments. First, the issues encountered during testing are described and examples of force vs. displacement curves are shown. At the end of this section, the results from all the samples tested are combined together to generate a plot of fracture toughness as a function of interleaving thickness.

\subsubsection{General observations during DCB testing.}

Five DCB specimens were tested for each sample. Nevertheless, several issues were encountered during DCB testing which made the analysis difficult and reduced the number of specimens kept for the analysis. The main problems encountered were instability of crack propagation and the presence of a non-flat resistance curve (toughness vs. crack length). The former leads to a small number of propagation values, making the specimen less statistically relevant, while the latter indicates possible variations in crack propagation mechanisms, such as for example fibre bridging. As both complicate data reduction, two criteria were implemented to obtain a set of specimen data for analysis. A specimen was kept for analysis in case it showed i. at least $10 \mathrm{~mm}$ of stable crack propagation, and ii. less than $20 \%$ deviation in its R-curve over $10 \mathrm{~mm}$ of crack length. An exception to the second criteria was made for the stamp-formed specimens. The threshold was changed to $50 \%$ in order to have enough specimens for analysis. It is worth to noticing that only a few stamp-formed specimens were kept for the analysis which were close to the second criterion. These criteria led to only three to four consistent specimens from an initial lot of five specimens per sample. An exception was the sample from the autoclave which was interleaved with three $38 \mu \mathrm{m}$ films. Out of the five specimens tested, only two were kept for the analysis. Table 4.2 summarises the number of specimens discarded and the reason for not using the data. The last column shows the number of specimens kept for the analysis. From the table, it can be noted that the standard samples, i.e. the autoclave and press consolidation samples without interleaving, did not present any problem during testing and all the specimens were kept for the analysis, while all the samples that were manufactured by a nonconventional procedure, i.e. stamp forming or 
consolidation with interleaving, showed at least one discarded specimen.

\begin{tabular}{|c|c|c|c|c|}
\hline \multirow[b]{2}{*}{$\begin{array}{l}\text { Sample } \\
\text { Name }\end{array}$} & \multicolumn{4}{|c|}{ Number of specimens } \\
\hline & $\begin{array}{l}\text { Presented at least } \\
\text { one point of } \\
\text { unstable crack } \\
\text { propagation }\end{array}$ & $\begin{array}{c}\text { Did not show at least } \\
10 \text { mm of stable crack } \\
\text { propagation }\end{array}$ & $\begin{array}{l}\text { More than } 20 \% \\
\text { or } 50 \% \\
\text { derivation in R- } \\
\text { curve }\end{array}$ & $\begin{array}{l}\text { Used for } \\
\text { the } \\
\text { analysis }\end{array}$ \\
\hline \multicolumn{5}{|l|}{ Autoclave } \\
\hline A-None & 0 & 0 & \multirow{7}{*}{0} & 5 \\
\hline A-1x38 & 1 & 1 & & 4 \\
\hline$A-2 \times 38$ & 5 & 2 & & 3 \\
\hline A-3x38 & 4 & 3 & & 2 \\
\hline A-4x38 & 4 & 1 & & 4 \\
\hline$A-5 \times 38$ & 3 & 1 & & 4 \\
\hline A-6x38 & 3 & 2 & & 3 \\
\hline \multicolumn{5}{|l|}{ Press } \\
\hline P-None & 0 & 0 & \multirow{3}{*}{0} & 5 \\
\hline P-1x38 & 3 & 1 & & 4 \\
\hline $\mathrm{P}-1 \times 100$ & 2 & 1 & & 4 \\
\hline \multicolumn{5}{|l|}{ Stamp } \\
\hline S-None & 2 & 0 & 1 & 4 \\
\hline S-1x38 & 4 & 0 & 1 & 4 \\
\hline$S-1 \times 100$ & 4 & 0 & 2 & 3 \\
\hline
\end{tabular}

Table 4.2: Overview of the number of specimens discarded and the reason for not using the data. The last column shows the number of specimens used for analysis.

Two characteristic force - displacement and crack length - displacement curves are shown in the upper graphs of Figure 4.8. The left graph corresponds to a specimen which showed stable crack propagation, while the right graph belongs to a specimen which showed a combination of stable and unstable crack propagation. During the evaluation of the initiation point, the maximum force point occurs almost always before the $5 \%$ point. Furthermore, almost no residual displacement was observed after the specimens were unloaded. The previous two observations means that the material can be analysed according to LEFM by following the ISO15024 standard. Fibre bridging was not observed during testing.

The R-curves corresponding to the two specimens are shown in the bottom row of Figure 8. As shown, only the stable part was used to calculate the interlaminar fracture toughness. The first point of the R-curve corresponds to the initiation value for interlaminar fracture toughness. It can be noted that stable crack propagation is correlated with a continuous Rcurve, whereas in the presence of an unstable crack propagation the R-curve is interrupted and therefore shows separate segments. 

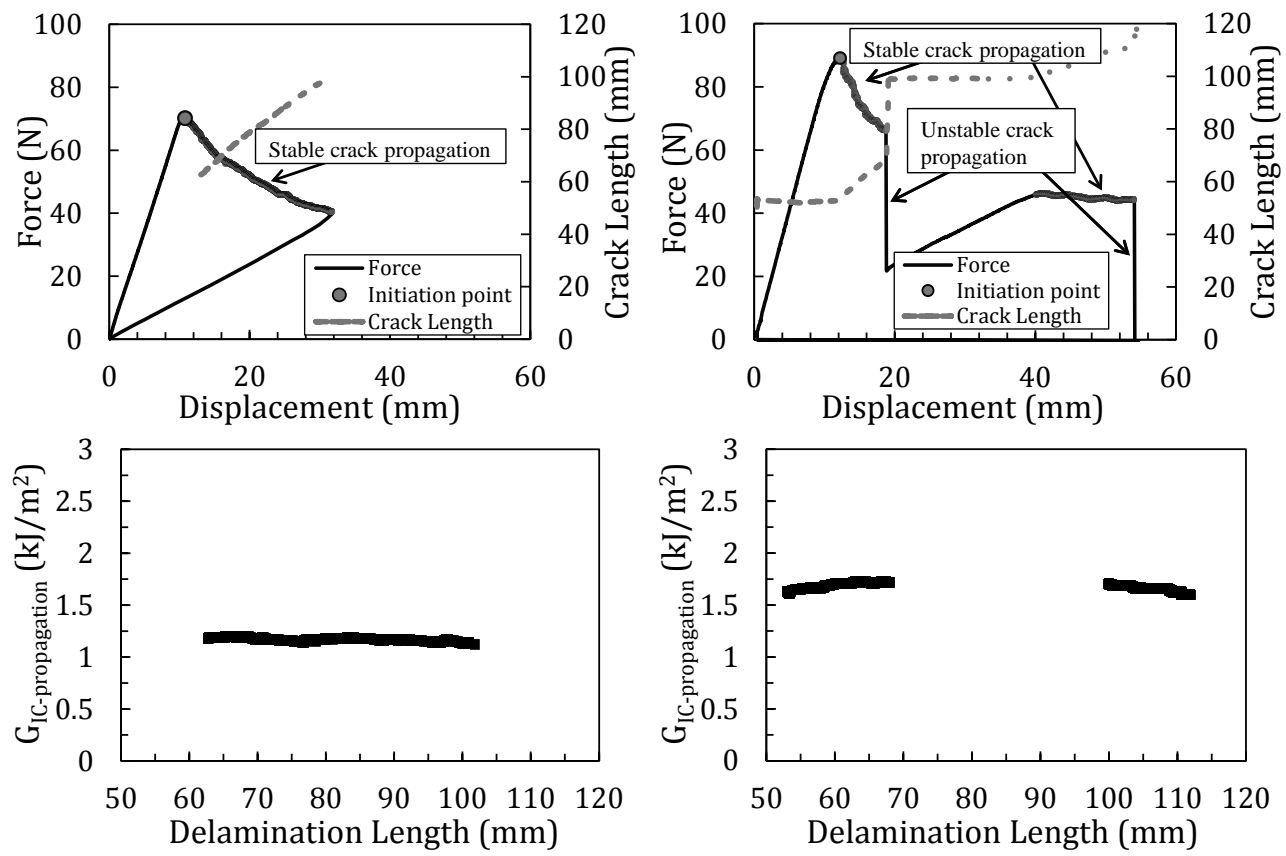

Figure 4.8: Top row) Force-displacement curve and crack length vs. displacement. Bottom row) Interlaminar fracture toughness as a function of crack length (R-curves). Left) Specimen that showed only stable crack propagation. Right) Specimen that showed a combination of stable and unstable crack propagation.

Many of the autoclave consolidated specimens suffered from unstable crack propagation as was illustrated in Table 2. Moreover, some of the specimens showed non-uniform toughness along the crack length. In those cases, the trend of the R-curve was mostly decreasing. Although the press-consolidated specimens also suffered from unstable crack propagation, they showed a longer path of stable crack propagation compared to the autoclave consolidated samples. Moreover, the R-curves observed in press-consolidated specimens were flatter than the ones observed for the autoclave consolidated samples. Finally, the stamp-formed samples, despite several cases of unstable crack propagation, showed a long path of stable crack propagation. Some of these specimens showed a rising R-curve, which in some cases was too large (more than $50 \%$ ), leading to the rejection of these specimens for the analysis.

\subsubsection{Fracture toughness vs. interleaved thickness}

The results of all the samples tested are summarised in Table 4.3. Average initiation and propagation fracture toughness values were calculated for all the samples. The average initiation value of each sample was calculated by averaging the initiation values of all the specimens within one sample. The average propagation value per sample was determined by averaging the mean propagation value of each specimen within that sample. 
The last column of Table 4.3 shows the overall trend of the R-curve for each sample, i.e. whether the R-curve was observed to be flat (-), ascending (/) or descending ( $\backslash$ ). It can be seen that the trend of the R-curve is closely related to the relation between initiation and propagation. In the cases of a flat R-curve the initiation and propagation values are similar, whereas with an ascending R-curve initiation values are lower than propagation, and the opposite occurs with a descending R-curve.

\begin{tabular}{cccc}
\hline \multirow{2}{*}{$\begin{array}{c}\text { Sample } \\
\text { type, name }\end{array}$} & \multicolumn{2}{c}{ Fracture Toughness (GIC) } & $\begin{array}{c}\text { R-curve } \\
\text { trend }\end{array}$ \\
\cline { 2 - 3 } Autoclave & Initiation $\left(\mathrm{kJ} / \mathrm{m}^{2}\right)$ & Propagation $\left(\mathrm{kJ} / \mathrm{m}^{2}\right)$ & - \\
\hline A-None & $1.28 \pm 0.10$ & $1.30 \pm 0.10$ & - \\
A-1x38 & $1.59 \pm 0.10$ & $1.55 \pm 0.10$ & - \\
A-2x38 & $1.87 \pm 0.16$ & $1.89 \pm 0.12$ & - \\
A-3x38 & $1.93 \pm 0.20$ & $2.05 \pm 0.16$ & $\backslash$ \\
A-4x38 & $2.46 \pm 0.30$ & $2.22 \pm 0.18$ & \\
A-5x38 & $2.74 \pm 0.15$ & $2.61 \pm 0.15$ & - \\
A-6x38 & $2.85 \pm 0.28$ & $2.66 \pm 0.20$ & - \\
\hline Press & & & \\
\hline P-None & $1.17 \pm 0.10$ & $1.19 \pm 0.10$ & / \\
P-1x38 & $1.54 \pm 0.10$ & $1.51 \pm 0.10$ & $/$ \\
P-1x100 & $2.06 \pm 0.17$ & $2.12 \pm 0.18$ & $/$ \\
\hline Stamp & & & \\
\hline S-None & $1.10 \pm 0.37$ & $1.25 \pm 0.25$ & \\
S-1x38 & $1.57 \pm 0.15$ & $1.60 \pm 0.10$ & \\
S-1x100 & $1.80 \pm 0.20$ & $1.84 \pm 0.25$ & \\
\hline
\end{tabular}

Table 4.3: Fracture toughness values for initiation and propagation for all the samples tested. The error was calculated as one standard deviation of the set of values within one sample.

Initiation and propagation fracture toughness as a function of the interleaved PEEK film thickness is shown in Figure 4.9 for the three different process technologies used. It is worth noticing that the x-axis is the nominal thickness of the added films and not the actual matrix-rich bond line thickness after processing, which in some cases may be smaller due to outflow of matrix. Measurements of the actual matrix-rich bond line thickness were difficult to perform from the micrograph and therefore not used. The trend is similar for all three processes, where the fracture toughness increases with increasing interleave thickness. No significant differences can be observed between the three processes and between initiation and propagation. Despite the similar average toughness values, the stamp forming process resulted in a higher scatter within the sample. This may be due to a non-uniform pressure and temperature distribution during fusion bonding, which may locally have resulted in incomplete wetting or healing. 


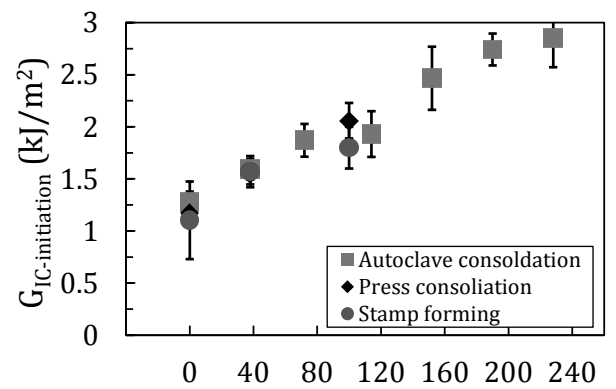

Interleaved PEEK film thickness $(\mu \mathrm{m})$

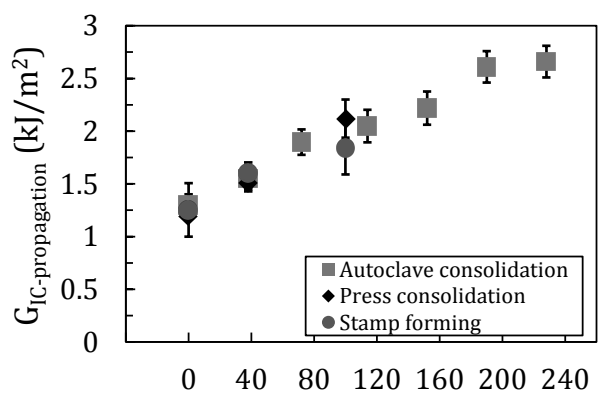

Interleaved PEEK film thickness $(\mu \mathrm{m})$

Figure 4.9: Interlaminar fracture toughness as a function of interleaved thickness for the three processes, autoclave consolidation, press consolidation, and stamp forming.

\subsubsection{Fractography}

The fracture behaviour of the different samples is compared in this section using crosssectional micrographs and fractography analysis. First, a comparison between samples without film interleaving and with film interleaving is shown. Later, the comparison between samples with fibre migration and without fibre migration is presented. Three types of images were used for the analyses. Figure 4.10 shows cross-sectional micrographs perpendicular to the crack propagation direction. These micrographs show the position of the crack at a single instant, though they do not give information about how the crack propagates along the length of the specimen. Figure 4.11 shows pictures of the optical cross-sectional micrographs with the cross-sectional plane oriented at $20^{\circ}$ with respect to the crack propagation direction. These pictures show how the crack propagates through the specimen. Finally, Figure 4.12 shows the SEM micrographs of the fracture surfaces where the interaction between fibre and matrix and the deformation of the matrix after testing can be observed.

The comparison between samples without and with PEEK film interleaving is presented here. Due to the similarity among the images within each test group, only one representative micrograph per group is shown. The left micrograph in Figure 4.10 shows a specimen without interleaving. It can be seen that the crack is located at the centre plane of the specimen. The right micrograph shows a specimen with interleaving. In this case, the crack is located close to the interface between the fibre-rich and the matrix-rich region, slightly out of the centre of the specimen. Other images in the same cross-sectional plane, thus to the left or right of the presented image, showed the same crack at the interface between matrix-rich region and the matrix-poor region of the upper substrate. 

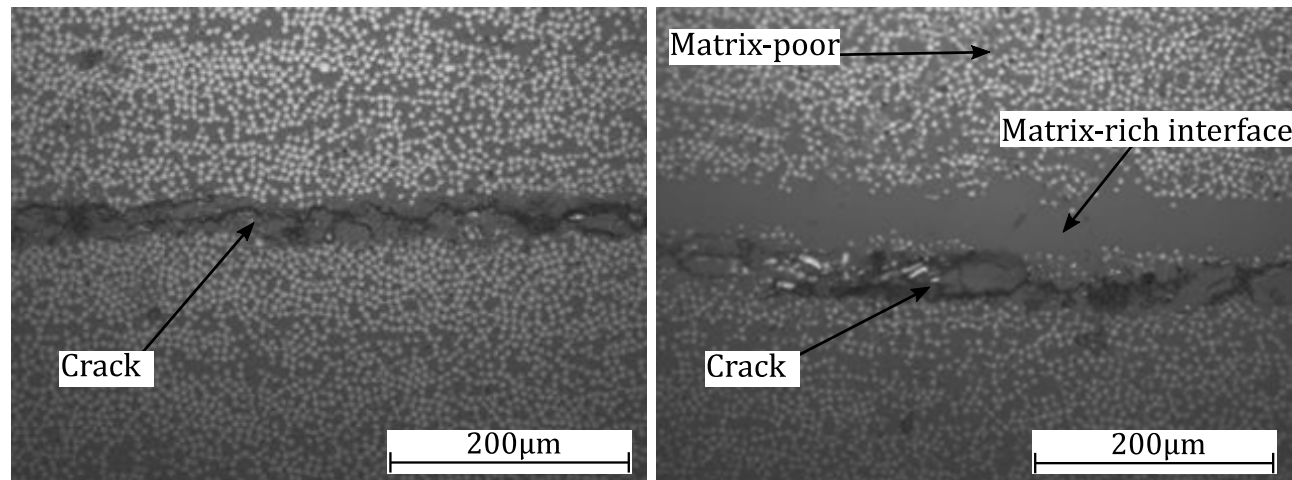

Figure 4.10: Cross-sectional micrographs perpendicular to the crack propagation direction. Left) autoclave-consolidated specimen without interleaving. Right) stamp-formed specimen with interleaving.

The straightness of the crack along the propagation direction was analysed using the $20^{\circ}$ cross-sectional micrographs. The top micrograph in Figure 4.11 shows a non-interleaved specimen, while the bottom shows an interleaved specimen. It can be noted that the crack path remains flat when the specimens are not interleaved as is shown in the top. However, the crack propagates with some waviness, seemingly avoiding the matrix-rich region in the centre, and this is the case for interleaved specimens shown in the bottom image.
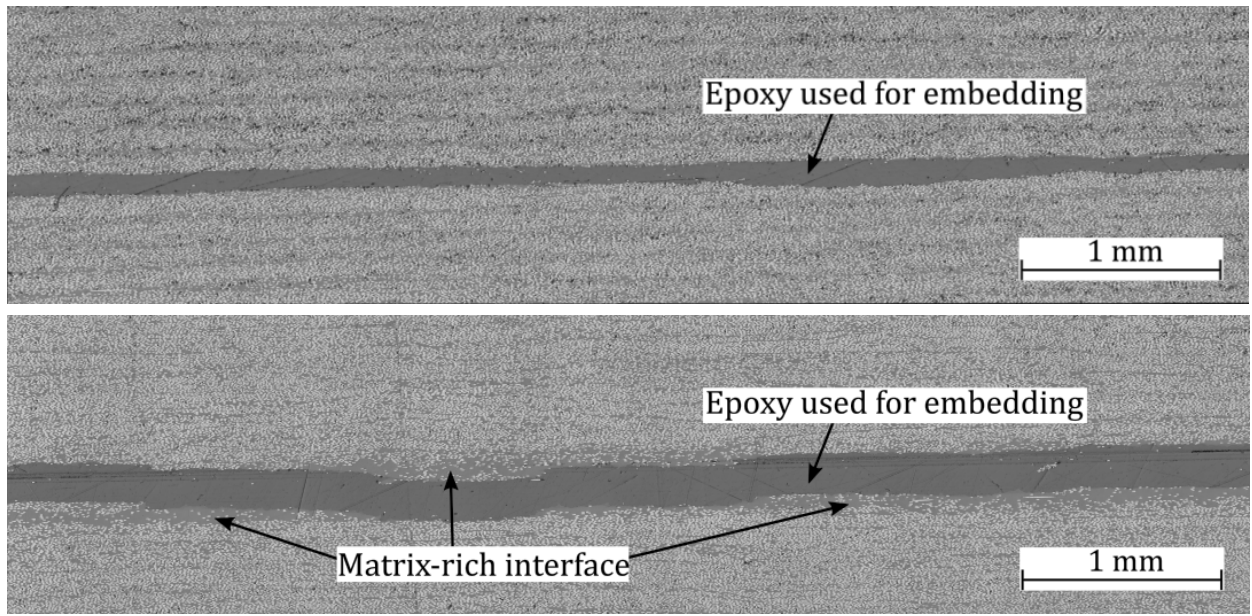

Figure 4.11: Cross-sectional micrographs taken at $20^{\circ}$ with respect to the crack propagation direction. Top: Non-interleaved stam-formed specimen. Bottom: $100 \mu \mathrm{m}$ interleaved pressconsolidated specimen.

A comparison between the fracture surface of an interleaved and a non-interleaved specimen is shown in Figure 4.12, while Figure 4.13 shows a schematic illustration of the accompanying cross section. The SEM image on the left shows that the fracture surface of a non-interleaved specimen is characterised by fibre imprints in the matrix and bare fibres. Also, microscale out of fracture plane plastic deformation of the matrix can be observed, 
which is a typical feature of the fracture surface of Carbon/PEEK laminates tested in mode I [23]. This deformation is present at the edges of the fibres in the schematic view. The SEM micrograph on the right shows that the fracture surface of an interleaved specimen is characterised by two distinct regions. The first region shows a combination of fibre imprints in the matrix and bare fibres, similar to the case of the non-interleaved sample. The second region is characterised by a matrix-rich area where large microscale plastic deformation of the matrix can be observed as evidenced by the white polymer regions.
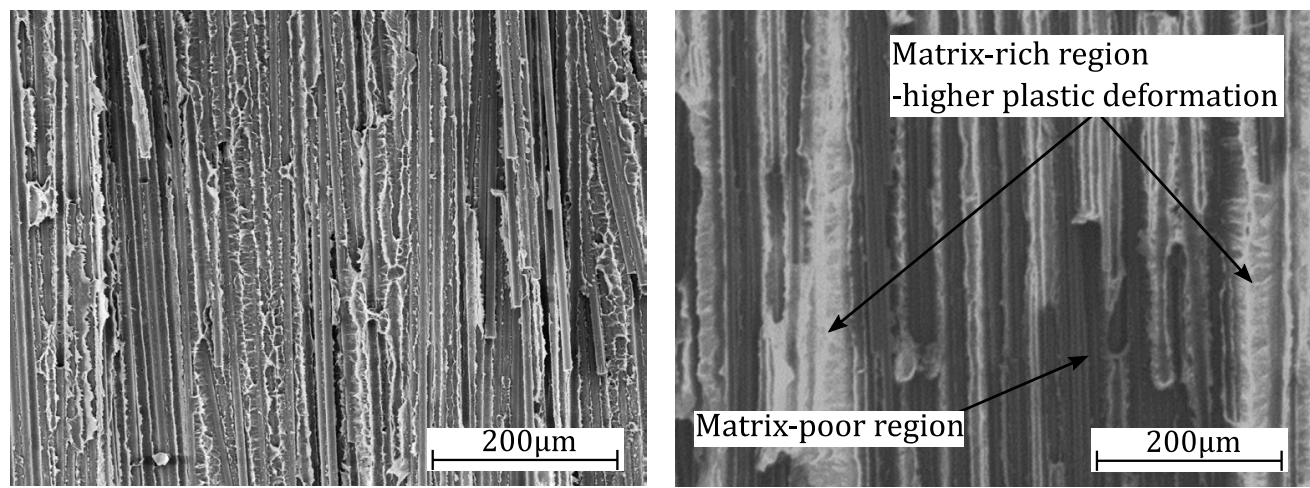

Figure 4.12: Scanning electron micrograph of the fracture surfaces. Left: Autoclave consolidated specimen with no interleaving. Right: interleave press-consolidated specimen.

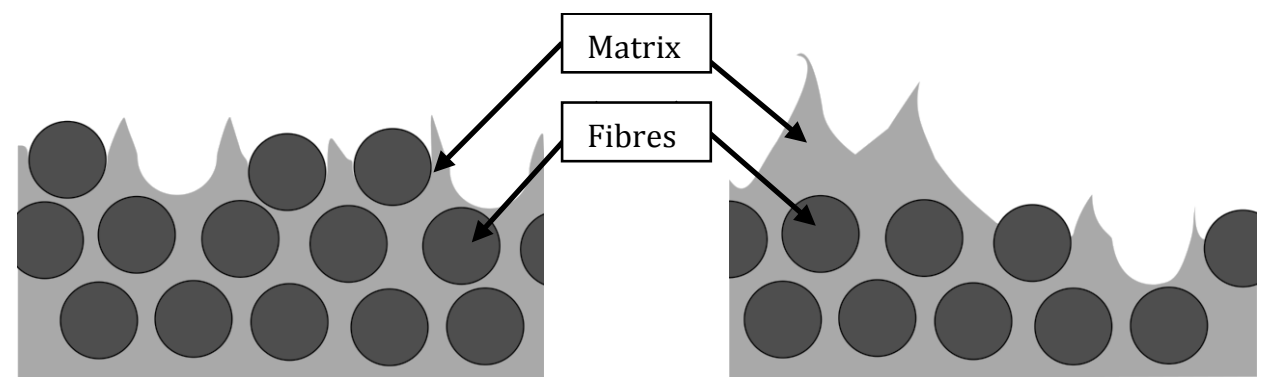

Figure 4.13: Schematic view of a cross section of a fracture surface. Left: Sample without matrix interleaving. Right: Sample with matrix interleaving.

The interleaved samples can be subdivided into two groups. The first comprises the samples prepared using a slow process (autoclave and press consolidation), while the second group consists of samples manufactured using the fast process (stamp forming). Figure 4.14 and Figure 4.15 show the cross-sectional micrographs and their schematic illustration for both groups, respectively. The crack shape and location look similar for both cases, irrespectively of whether fibre migration occurred or not. The crack seems to remain at the interface between the matrix-rich and matrix-poor region. The crack path was observed to alternate between the top and the bottom substrate trying to minimise the crack path length through the matrix-rich region, similar to what is observed in Figure 4.11 . 

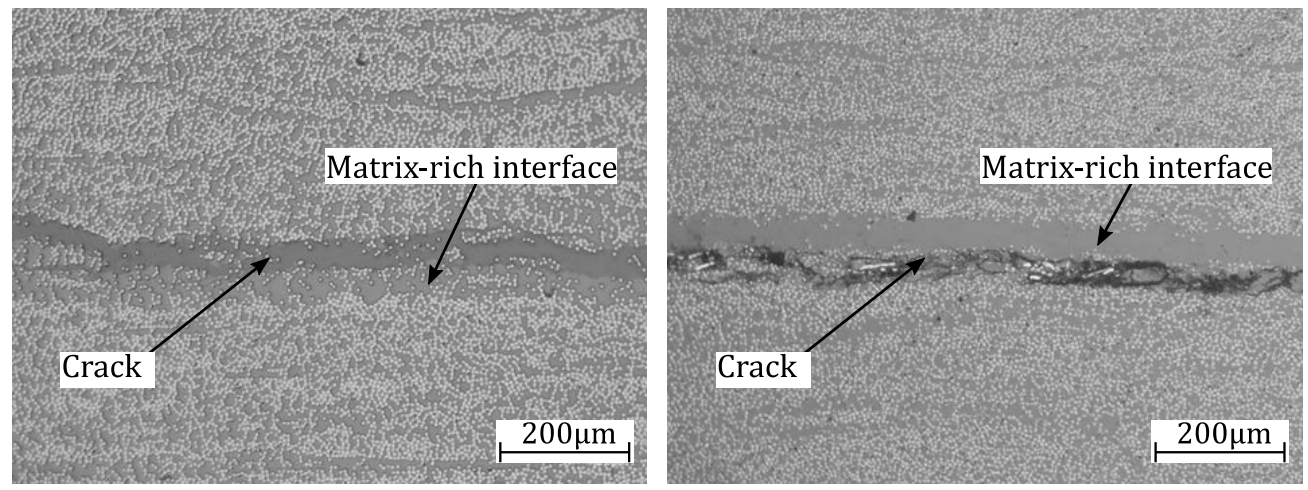

Figure 4.14: Cross-sectional micrographs perpendicular to the crack propagation direction. Left) Autoclave consolidated specimen with interleaving. Right) Stamp-formed specimen with interleaving.
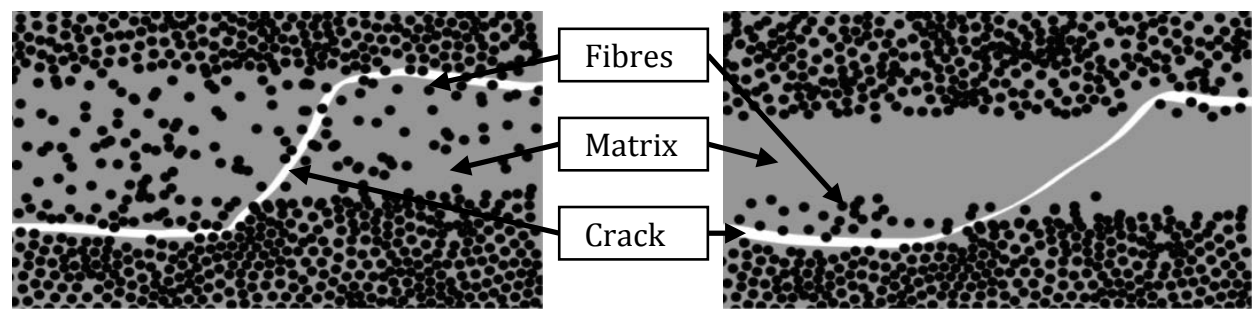

Figure 4.15: Schematic view of a cross section micrograph of an interleaved specimen.

Left) Specimen with fibre migration as obtained using autoclave or press fusion bonding.

Right) Specimen without fibre migration as obtained using stamp fusion bonding.

\subsection{Discussion}

In this section, the results obtained are combined and discussed with the purpose of getting a deeper understanding of the mechanisms that govern the interlaminar fracture toughness of fusion bonded joints that present a matrix-rich bond line.

The interlaminar fracture toughness improves by increasing the matrix-rich bond line thickness, as was expected. This is true even if the crack does not propagate through the matrix-rich area but through the matrix-poor area or the interface between the matrixpoor (one of the two substrates) and matrix-rich (the interleave) regions. This phenomenon was explained by Hojo et al. [13] for interleaved laminates, who reasoned that by increasing the interleave thickness, even if the crack does not propagate fully through the matrix-rich area, the plastic yield zone in front of the crack tip is still less constrained by the fibres and is therefore allowed to increase in size. Moreover, it was proposed that when the matrix-rich region is smaller than the maximum plastic yield zone size, the crack path migrates towards the weakest region, i.e. the boundary between matrix-poor and matrix-rich regions, resulting in adhesive failure [13]. However, when the 
thickness of the matrix-rich region increases further than the plastic yield zone, the crack will remain within this region resulting in a cohesive failure of the interleave [13]. The change in plastic zone size and the position of the crack propagation path is schematically represented in Figure 4.16. A larger plastic yield zone area means that more energy will be dissipated, which is reflected by a higher interlaminar fracture toughness. The SEM fractography, as presented in Figure 4.12, confirmed that more plastic deformation is observed in the interleaved samples compared to the samples without additional matrix at the interface. Besides, the tortuosity of the crack path, as shown in the lower micrograph in Figure 4.11, may also contribute to an increased fracture toughness.

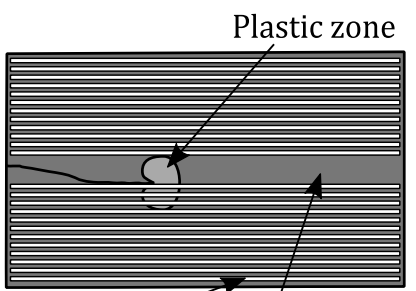

Fibre Matrix
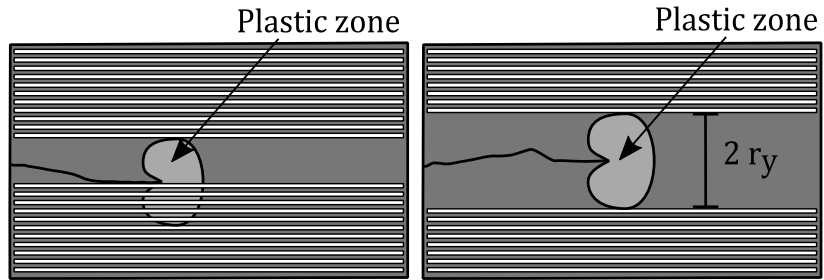

Figure 4.16: A schematic explanation of crack growth behaviour and plastic zone development having a radius $r_{y}$. Left) Base material, no interleaved. Centre) Material with an interleaving thickness below maximum plastic yield zone (2ry). Right) Material interleaved with a thickness above the maximum plastic yield zone. Figure adapted from [1].

Plastic deformation of the matrix was found to be the main mechanism to increase the interlaminar fracture toughness of the interleaved specimens. Nevertheless, as the plasticity is localised only at the fracture surface, the global linear elastic behaviour of the specimen during testing was retained. As such, the tests still comply with the LEFM assumption, which makes the comparison of the values obtained for the different samples acceptable.

It was suggested that the maximum theoretical toughness of an interleaved system is the toughness of the pure polymer, which is reached when the interleave thickness is equal or larger than two times the plastic yield radius (Figure 4.16 right) $[16,18]$. A first approximation of the plastic zone radius $\left(r_{y}\right)$ of a polymer can be calculated by applying the Irwin equation (Equation (4.2)).

$$
r_{y}=\frac{1}{2 \pi}\left(\frac{K_{I C}}{\sigma_{y}}\right)^{2},
$$

where $K_{I C}$ is the stress intensity factor which relates to the fracture toughness of the polymer, and $\sigma_{y}$ is the tensile yield stress of the polymer. The following expression can be used to relate the stress intensity factor $K_{I C}$ to the energy release rate $G_{I C}$ in case of a plane strain situation:

$$
G_{I C}=\frac{K_{I C}{ }^{2}}{E\left(1-v^{2}\right)},
$$


where $E$ is the elastic modulus of the polymer and $v$ is the Poisson's ratio. Material data from the literature is required to calculate the maximum theoretical fracture toughness of this system. The following values were reported in the data sheet of Victrex PEEK 150, which is used as matrix in the pre-pregs; tensile yield point $\left(\sigma_{y}\right)$ of $105 \mathrm{MPa}$, an elastic modulus $(E)$ of $3.5 \mathrm{GPa}$ and a Poisson's ratio $(v)$ of 0.4 . The stress intensity factor $K_{I C}$ for Victrex PEEK 450G, a similar grade of the polymer use for interleaving, is reported in literature to lie between 3 to $6 \mathrm{MPa} \cdot \mathrm{m}^{1 / 2}$ [24]. An average value of $4.5 \mathrm{MPa} \cdot \mathrm{m}^{1 / 2}$ will be used for the following analysis. Using Equation (4.2) and Equation (4.3) a plastic radius of $0.3 \mathrm{~mm}$ and an energy release rate of $6.8 \mathrm{~kJ} / \mathrm{m}^{2}$ can be calculated for this polymer. The result shows that the pure polymer has a more than two times higher toughness than the interlaminar fracture toughness measured in the experiments in this study. Nevertheless, the theoretical matrix-rich bond line thickness required to develop the fracture toughness $(0.6 \mathrm{~mm})$ was not tested in the experiments reported in this work, where a maximum matrix-rich bond line thickness of $0.2 \mathrm{~mm}$ was tested. Thus, the fracture toughness is expected to keep increasing by increasing matrix-rich bond line thickness.

The matrix-rich bond line thickness after processing was observed to be not uniform, this is particularly true for the autoclaved samples where material flow occurs during processing. This non-uniformity and the difficulty to distinguish between the matrix-rich and matrix-poor region makes it difficult to evaluate the actual matrix-rich bond line thickness after processing. This non uniformity may, moreover, also be one of the causes for the unstable crack propagation observed as it most probably resulted in a non-uniform interlaminar fracture toughness along the crack path. It is known that the unstable crack propagation may occur when the crack propagates from a region of higher toughness to a region of lower toughness, as the elastic energy stored in the specimen is more than required for making the crack to propagate in a stable manner [25].

The high cooling rates observed during stamp forming may have induced a different level of crystallinity compared to the other two (slower) processing techniques, possibly affecting the measured toughness values. DSC experiments showed, however, that a noninterleaved press consolidated specimens and non-interleaved stamp-formed specimens have the same level of crystallinity of approximately $35 \%$ using an enthalpy of crystallisation value of $130 \mathrm{~J} / \mathrm{g}$ [26] and a matrix weight fraction of $34 \%$. Although the difference in thermal history may have resulted in different crystal morphologies, this seemed to have no effect on the measured toughness.

In conclusion, it seems that the interlaminar fracture toughness is independent of the three processes used in this work. It solely depends on the interleave thickness and is not affected by fibre migration. The amount of fibres, in the fibre migration region, is too small to constrain the plastic zone, nor does it result in excessive fibre bridging. 


\subsection{Conclusions}

The effect of a matrix-rich interface and fibre migration on the fracture toughness of fusion bonded samples was studied. For this purpose, samples were prepared using manufacturing technologies having different characteristic processing times, namely: autoclave consolidation, press consolidation, and stamp forming. Autoclave and press consolidation were considered as slow processes, while stamp forming was considered as a fast process with conditions similar to those in many welding techniques. Matrix-rich bond lines with different thicknesses were obtained by interleaving matrix films at the interface between two adherents prior to fusion bonding.

Microscopy showed that two regions can be identified in the interleaved samples, namely the matrix poor adherents and a matrix-rich bond line. The processing time, moreover, affected the matrix-rich bond line morphology. On the one hand, fibre migration from the adherents into the matrix-rich bond lines was observed during (the slower) press and autoclave consolidation, resulting in a matrix-rich zone with many loose fibres. On the other hand, fibre migration was prevented during (the faster) press forming, resulting in a bond line with very few or no fibres. Double cantilever beam experiments were performed and showed that the increase in the matrix-rich bond line improves the fracture toughness. This increase is attributed to the development of microscale matrix plastic deformation. Moreover, it was shown that fibre migration has a negligible effect on the interlaminar fracture toughness, i.e. the toughness only depends on the matrix interleave thickness.

\subsection{References}

[1] A. Benater and T. G. Gutowski, "Methods for fusion bonding thermoplastic composites," S.A.M.P.E. Quarterly, vol. 18(1), pp. 35-42, 1986.

[2] A. P. D. Costa, E. C. Botelho, M. L. Costa, N. E. Narita and J. R. Tarpani, "A review of welding technologies or thermoplastic composites in aerospace applications," Journal of Aerospace Technology and Management, vol. 4.3, pp. 255-266, 2012.

[3] P. Davies, W. J. Cantwell, P. Y. Jar, P. E. Bourban,V. Zysman and H. H. Kausch, "Joining and repair of a Carbon fibre-reinforced thermoplastic," Composites, vol. 22.6, pp. 425431, 1991.

[4] S. M. Todd, "Joining Thermoplastic Composite," Proceedings of the 22nd International SAMPE Technical Conference, vol. 22, pp. 383-392, 1990.

[5] A. Yousefpour, M. Hojjati and J. Immarigeon, "Fusion bonding/welding of thermoplastic composites," Journal of Thermoplastic Composite Materials, vol. 17(4), pp. 303-341, 2004.

[6] M. M. Schwartz, "Joining of composite-matrix materials," Materials Park - ASM International, 1994.

[7] I. Da Baere, K. Allaer, S. Jacques, W. Van Paepegem and J. Degrieck, "Interlaminar behavior of infrared welded joints of Carbon fabric-reinforced polyphenylene sulfide," Polymer Composites, vol. 33, pp. 1105-1113, 2012. 
[8] W. J. Cantwell, P. Davies, P. E. Bourban, P. Y. Jar, H. Richard, and H. H. Kausch, "Thermal joining of Carbon fibre reinforced PEEK laminates," Composite Structures, vol. 16.4, pp. 305-321, 1990.

[9] J. C. Fish, M. L. Vitlip, S. P. Chen, and K. S. Shin, "Interlaminar fracture characteristics of bonding concepts for thermoplastic primary structures," AIAA journal, vol. 30.6, pp. 1602-1608, 1992.

[10] C. Ageorges, L. Ye and M. Hou, "Advances in fusion bonding techniques for joining thermoplastic matrix composites: A review," Composites - Part A: Applied Science and Manufacturing,, vol. 32(6), pp. 839-857, 2001.

[11] R. Fracasso, M. Rink, A. Pavan and R. Frassine, "Effects of strain-rate and temperature on the interlaminar fracture toughness of interleaved PEEK/CF composites," Composites Science and Technology, vol. 61(1), pp. 57-63, 2001.

[12] O. Ishai, H. Rosenthal, N. Sela and E. Drukker, "Effect of selective adhesive interleaving on interlaminar fracture toughness of graphite/epoxy composite laminates," Composites, vol. 19(1), pp. 49-54, 1988.

[13] M. Hojo, T. Ando, M. Tanaka, T. Adachi, S. Ochiai and Y. Endo, "Modes I and II interlaminar fracture toughness and fatigue delamination of CF/epoxy laminates with self-same epoxy interleaf," International Journal of Fatigue, 2006.

[14] K. Shivakumar and R. Panduraga, "Interleaved polymer matrix composites - A review," 54th AIAA/ASME/ASCE/AHS/ASC Structures, Structural Dynamics, and Materials Conference, 2013.

[15] S. F. Chen and B. Z. Jang, "Fracture behaviour of interleaved fiber-resin composites." Composites Science and Technology, vol. 41.1, pp. 77-97, 1991.

[16] A. J. Kinloch and S. J. Shaw, "The fracture resistance of a toughened epoxy adhesive," The Journal of Adhesion, vol. 12(1), pp. 59-77, 1981.

[17] M. D. Banea, L. F. Da Silva and R. D. Campilho, "The effect of adhesive thickness on the mechanical behavior of a structural polyurethane adhesive," The Journal of Adhesion, vol. 91.5, pp. 331-346, 2015.

[18] S. Singh and I. K. Partridge, "Mixed-mode fracture in an interleaved Carbonfibre/epoxy composite," Compos Sci Technol, vol. 55, pp. 319-327, 1995.

[19] F. Ozdil and L. A. Carlsson, "Plastic zone estimates in mode I interlaminar fracture of interleaved composites," Engineering Fracture Mechanics, vol. 41(5), pp. 645-658, 1992.

[20] W. S. Jojnso and P. D. Mangalgiri, "Investigation of fiber bridging in double cantilever beam specimens," Journal of Composites Technology and Research, vol. 9(1), p. 10, 1987.

[21] G. B. Murri, "Effect of data reduction and fiber-bridging on Mode I delamination characterization of unidirectional composites," Journal of Composite Materials, vol. 48.19, pp. 2413-2424, 2014.

[22] "ISO 15114- Fibre-reinforced plastic composites - Determination of the mode II fracture resistance for unidirectionally reinforced materials using the calibrated endloaded split (C-ELS) test and an effective crack length approach," 2014.

[23] D. Purslow, "Matrix fractography of fibre-reinforced thermoplastics, Part 1. Peel failures," Composites, pp. 365-374, 1987. 
[24] R. Gensler, P. Béguelin, C. J. Plummer, H. Kausch and H. Münstedt, "Tensile behaviour and fracture toughness of poly(ether ether ketone)/poly(ether imide) blends.," Polymer Bulletin, vol. 37(1), pp. 111-118, 1996.

[25] T. W. Aifantis and E. C. Webb, "Crack growth resistance curves and stick-slip fracture instabilities," Mechanics Research Communications, vol. 24, pp. 123-130, 1997.

[26] A. A. Mehmet-Alkan and J. N. Hay, "The crystallinity of PEEK composites," Polymer, vol. 34(16), pp. 3529-3531, 1993. 


\title{
Chapter 5: Interlaminar fracture toughness of 5HS Carbon/PEEK laminates. A comparison between DCB, ELS and mandrel peel
} tests*

\begin{abstract}
The present work focuses on the applicability of the mandrel peel test to quantify the interlaminar fracture toughness of 5 harness satin woven fabric Carbon/PEEK composites. For this purpose, the Mandrel Peel (MP) test was compared to the Double Cantilever Beam (DCB) and End-Loaded Split (ELS) test in terms of experimental procedure and obtained results. The interlaminar toughness of the 5 harness Carbon/PEEK was measured both parallel and perpendicular to the predominant fibre direction at the interface. While stable crack propagation was observed in the ELS test, unstable crack propagation (stick-slip) was observed during both the DCB and the mandrel peel tests. In the case of the mandrel peel test, however, the unstable propagation was immediately arrested by the mandrel, limiting the instability and providing numerous crack re-initiation values per unit of crack length. This effect is expected to increase the statistical relevance of a single test and thereby to increase the reliability of the measured values as compared to DCB tests. A fractographic analysis was performed to study the nature of the crack propagation for the different testing techniques. The mandrel peel test was found to be a potentially plausible alternative to the DCB test for woven fabric reinforced composites.
\end{abstract}

\footnotetext{
* In preparation to be submitted to: Polymer Testing
}

F. Sacchetti, W. J. B Grouve, L. L. Warnet and I. F. Villegas, "Interlaminar fracture toughness of 5HS Carbon/PEEK laminates. A comparison between DCB, ELS and mandrel peel tests". 


\subsection{Introduction}

Woven fabric composites are sometimes preferred to unidirectional tape materials for their simpler handling and better drapability. Woven fabric composites are also known to be more damage tolerant than their unidirectional counterparts in the presence of a delamination [1]. The higher damage tolerance is often explained by the irregular interlaminar structure of woven fabric composites which forces a delamination (crack) to interact with the matrix regions and the weave structure during its propagation, leading to a more tortuous crack path $[2,3]$. The fracture toughness of woven fabric composites is determined by a number of factors, which include the structure of the weave, referred to as weave index [2-5], the stacking sequence and the direction of crack propagation [4, 6-8].

Although interlaminar failure of composite materials is a well-known problem, limited data is available on the toughness of woven fabric reinforced composites. This is partly caused by the difficulty associated with experimental characterization. Various test methodologies, all based on Linear Elastic Fracture Mechanics (LEFM), have been developed for unidirectional fibre reinforced composites. Some of the more accepted ones are the Double Cantilever Beam test (DCB) for mode I, and the End-Loaded Split (ELS) or End Notch Flexure (ENF) for mode II. Figure 5.1 schematically represents the DCB and ELS tests. The existence of ISO and ASTM standards for both methods, although restricted to unidirectional composites in the longitudinal direction, illustrates some maturity of these testing techniques. While the DCB test for mode I is well accepted, this is not (yet) the case for the ELS and ENF tests for mode II, as the introduction of the standards is relatively new. Besides, both tests suffer from some experimental difficulties such as the inability to accurately measure crack length and the lack of a clear method to account for the friction between the arms of the specimen. Moreover, crack propagation is not always stable which further complicates the analysis. $[9,10]$.

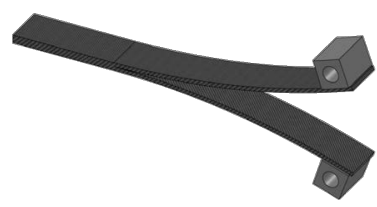

Mode I - DCB

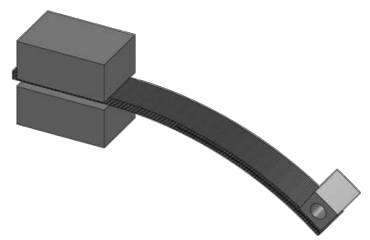

Mode II - ELS

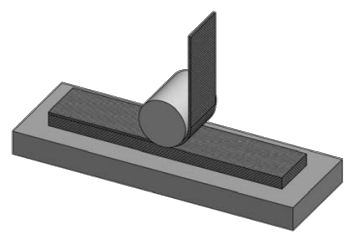

Mixed mode - Mandrel Peel Figure 5.1: DCB, ELS, and Mandrel Peel test scheme.

Although standardised for UD laminates, some difficulties arise when the DCB test method is used to characterise woven fabric composite laminates. In particular, woven fabric reinforced composites often show unstable crack propagation (stick-slip). This is true both for thermoset [2, 6-8] and thermoplastic [11-13] composites. The unstable crack propagation yields only a few GIC values per test specimen. Therefore, GIC-unstable propagation values for woven fabric reinforced laminate specimens are statistically less reliable than Gic-stable propagation values for UD specimens [14]. Moreover, the unstable 
crack propagation makes the interpretation of the test results rather difficult and the comparison with unidirectional materials questionable. The stick-slip behaviour has been treated from a theoretical point of view by different researchers such as in [15-19]. Hine et al. reported that unstable crack propagation in woven fabric composites is caused by local regions of high toughness [20]. When the crack tip reaches one of these tougher regions, crack propagation is slowed down until the stored elastic energy is sufficient to propagate the crack further. Once this region is passed, the elastic energy stored is higher than required for stable propagation. As a result the crack propagation rate increases, resulting in unstable crack propagation. For woven fabrics, the tougher regions have been correlated to the areas where the crack passes over a transverse fibre bundle [7].

The observed stick-slip behaviour and the tedious test procedure make the DCB test unattractive for woven fabric reinforced composites. The Mandrel Peel (MP) test is investigated as an alternative test to measure the interlaminar fracture toughness of woven fabric thermoplastic composites, in the present work. The mandrel peel test is an adaptation of the standard peel test, which is used to measure the bond strength of an assembly of two adherents where one adherent is flexible and the other is rigid [21]. The adherents are pulled apart at a steady rate in such a way that separation occurs progressively along the length of the bonded adherents. When the peel test is used for tough composite materials the radius of the peel arm near the crack tip becomes too small during the loading phase of the test, resulting in the fracture of the peel arm before crack propagation. The mandrel peel test was first proposed by Kawashita et al. [22], as an adaptation of the peel test, in order to measure the fracture toughness of a metal-epoxymetal peel specimen. Previous research showed that this test can also be used to characterise the fracture toughness of UD-UD [23, 24], UD-woven [24], and UD-metal [25] interfaces. The peel arm, which was a UD tape in these cases, was forced to conform to a mandrel by using an alignment force. The radius of the mandrel was chosen such that the maximum strain in the peel arm does not exceed its failure strain. It should be noted that the fracture toughness evaluated using the mandrel peel test corresponds to a mixed mode propagation. Although the exact mode mixity is unknown, it is reported to be mainly mode I [22]. This means that the interlaminar fracture toughness values measured from the mandrel peel test are expected to lie between the values measured by the DCB test (pure mode I) and the ELS test (pure mode II), though closer to DCB values than ELS ones.

The present work focuses on assessing the applicability of the mandrel peel test to quantify the fracture toughness of woven fabric based composites. A 5 Harness-Satin (HS) woven fabric Carbon/PEEK laminate was chosen as a basis material. DCB and ELS test results were compared to mandrel peel test results for the same material system. Two directions of crack propagation were investigated. In the first case, the crack propagates parallel to the predominant fibre direction at the interface, while in the second case the crack propagates perpendicular to the predominant fibre direction. Finally, a microscopy analysis was performed to study the fracture surfaces of the different samples. The 
fractographic features observed in the test coupons were compared in order to identify the dominant failure modes during the mandrel peel test.

\subsection{Experimental methods}

The present section describes the specimen preparation, as well as the procedures, followed to characterise the interlaminar fracture toughness.

\subsubsection{Specimen preparation}

The material used in this research was a CETEX ${ }^{\circledR} 5$ HS woven Carbon fabric reinforced PEEK powder coated semi-preg supplied by TenCate. The fabric comprises 3K T300JB Carbon fibre bundles with an equal amount of bundles in the warp and weft direction. The resulting repetitive unit cell has a dimension of $7.5 \times 7.5 \mathrm{~mm}^{2}$, as shown in Figure 5.2. The figure also illustrates that a satin weave structure has a predominant fibre direction on each side of the fabric. On one side, e.g. the top view in Figure 5.2, this predominant fibre direction corresponds to the warp bundles, while on the other side the predominant fibre direction corresponds to the weft bundle direction.

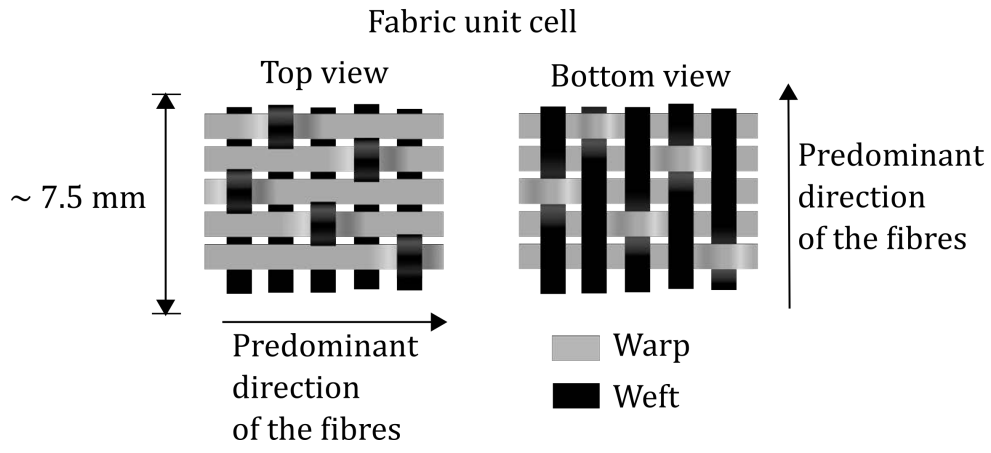

Figure 5.2: Schematic view of a unit cell for a 5 harness satin top and bottom view.

A stacking sequence of $\left[(0 / 90) /(0 / 90)_{r}\right]_{4 s}$ was used, in which $r$ indicates a flipped or reversed ply, to prepare a single laminate from which all specimens were cut. As mentioned earlier two crack propagation directions were tested, parallel $(/ /)$ and perpendicular $(\perp)$ to the predominant fibre direction. Thus, two sets of specimens were prepared for each one of the three testing techniques (DCB, ELS, and MP tests). All the test specimens required a pre-crack, which was in this case made by inserting a $13 \mu \mathrm{m}$ thick Polyimide (PI) film (Upilex-S from UBE) during semi-preg stacking. The PI films were inserted in four locations as illustrated in Figure 5.3. The PI films were added at the midplane to obtain the ELS and DCB specimens, while the films were added between the first and second ply for the mandrel peel specimens. The laminate was subsequently press 
consolidated in a Pinette press at 10 bar and $380{ }^{\circ} \mathrm{C}$, following the processing recommendations from the material supplier. Figure 5.4 shows the press cycle used to consolidate the laminate. A diamond-coated and water-cooled blade saw was used to cut the specimens from the laminate. Specimens of $20 \mathrm{~mm}$ width were cut for the DCB and ELS tests following the standards. The mandrel peel specimens were cut to a width of $10 \mathrm{~mm}$, which is larger than the representative unit cell of the woven fabric.

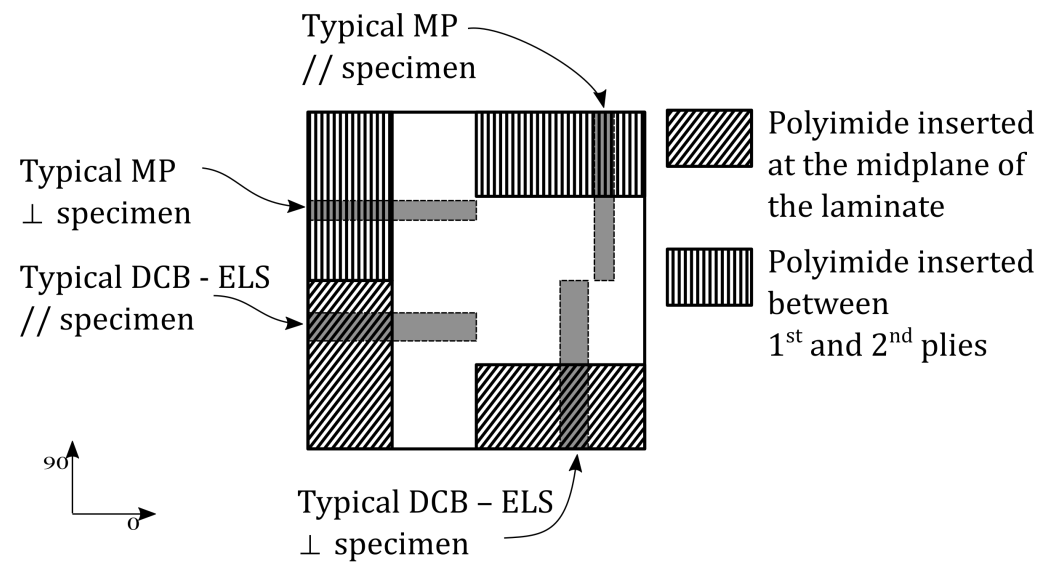

Figure 5.3: Schematic view of the position of the polyimide films placed before consolidation. The $0^{\circ}$ corresponds to the Warp direction. MP: Mandrel Peel, DCB: Double Cantilever Beam, ELS: EndLoaded Split. //: Parallel. $\perp$ : Perpendicular.

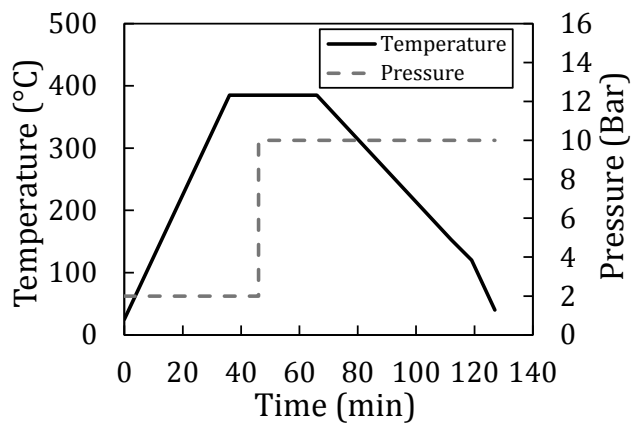

Figure 5.4: Schematic representation of the press consolidation cycle.

Figure 5.5 shows a schematic representation of the crack location for the different specimens. It can be seen that, technically, the mandrel peel interfaces are not exactly similar to the DCB and ELS interfaces when all the specimens are extracted from the same laminate. While the interface of DCB and ELS specimens predominantly comprises warp bundles, the interface of mandrel peel specimens predominantly comprises weft bundles. This choice was made in order to keep a symmetric lay-up. The authors believe, however, that this choice will have a negligible effect on the measured results, given the fact that the woven fabric is balanced in terms of properties according to the manufacturer technical 
data sheet [26]. Moreover, any influence of variations in processing conditions are prevented by extracting all specimens from the same laminate.

Laminate top view

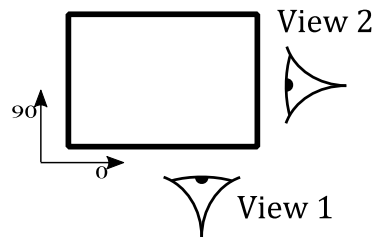

$\square$ Warp

View 1:

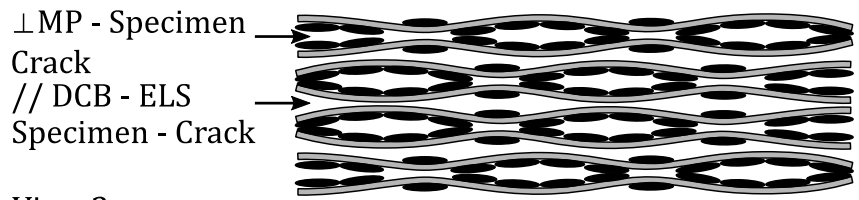

View 2:

// MP - Specime

Crack

$\perp$ DCB - ELS

Specimen - Crack

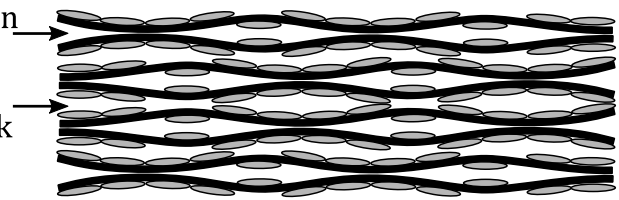

Figure 5.5: Schematic view of the stacking sequence and the position and direction of propagation of the crack. For the sake of clarity half of the plies are not shown. MP: Mandrel Peel, DCB: Double Cantilever Beam, ELS: End-Loaded Split. //: Parallel. L: Perpendicular.

\subsubsection{Double Cantilever Beam (DCB) test}

The double cantilever beam tests were performed according to the ISO 15024 standard [27]. The Corrected Beam Theory (CBT) analysis was applied to calculate the mode I fracture toughness. According to this method, the critical energy release rate $G_{\text {IC }}$ is given by:

$$
G_{\mathrm{IC}}=\frac{3 P \delta}{2 w(a+\Delta)}\left(\frac{F}{N}\right),
$$

where $w$ is the width of the specimen, $P, \delta$ and $a$ are the force, displacement and crack length during crack propagation, respectively. Furthermore, $F$ is a correction factor for the large displacement of the test specimen arms, $N$ is a correction factor for the stiffening of the specimen by the load blocks and $\Delta$ is a correction for crack tip rotation and deflection.

The specimens were tested on a servohydraulic Instron 8500 universal testing machine, at a displacement rate of $1.2 \mathrm{~mm} / \mathrm{min}$. The testing machine was equipped with a HBM $200 \mathrm{~N}$ force cell and a $150 \mathrm{~mm}$ built-in Linear Variable Displacement Transducer (LVDT). The crack length was measured using an automated camera system engineered to follow the crack tip during the test using image recognition techniques. The camera was fitted with a 20x magnification lens. Since the delamination length was measured using the horizontal position of the travelling camera system, there is no need for a large-displacement correction factor, i.e. $F$ can be considered equal to one [27]. The applied force $P$, the displacement $\delta$, as well as the crack length $a$, were measured during the test. All DCB 
specimens showed unstable crack propagation. The first instability was not used to measure the fracture toughness, as the crack tip is affected by the manufacturing process and the crack initiation film. Unloading and reloading the specimens provided the initiation value, while the subsequent crack re-initiations were used to calculate the propagation fracture toughness values.

\subsubsection{End-Loaded Split (ELS) test}

The end-loaded split test was performed according to the ISO 15114 standard [28]. The Instron 8500 servohydraulic universal testing machine mentioned earlier was fitted with a HBM $500 \mathrm{~N}$ force cell to perform the ELS test. Attempts to measure the crack length using the travelling camera system were unsuccessful, as it was difficult to identify the crack tip location accurately. Consequently, an apparent crack length was calculated from the compliance of the specimens following the procedure described in the ISO 15114 standard. According to this method, the compliance of the ELS specimen is expressed as:

$$
C=\frac{\delta}{P}=\frac{\left(L+\Delta_{\text {clamp }}\right)^{3}+3\left(a_{\mathrm{app}}\right)^{3}}{2 w h^{3} E_{1}},
$$

where $a_{\text {app }}$ is the apparent crack length, $E_{1}$ is the apparent bending modulus, $L$ is the span length, $w$ is the width of the specimen and $h$ half of the specimen thickness. The parameter $\Delta_{\text {clamp }}$ was introduced by Hashemi [29] to consider the beam root deflection and rotations at the clamp point. The apparent crack length can be calculated from Equation (5.2) at any moment of the test as:

$$
a_{\mathrm{app}}=\left(\frac{1}{3}\left\{2 w C h^{3} E_{1}-\left(L+\Delta_{\text {clamp }}\right)\right\}\right)^{\frac{1}{3}} .
$$

The $G_{I I C}$ values were determined using the Irwin-Kies equation:

$$
G_{\mathrm{IIC}}=\frac{P^{2}}{2 w} \frac{\mathrm{d} C}{\mathrm{~d} a} .
$$

Substituting Equation (5.2) into Equation (5.4) yields:

$$
G_{\mathrm{IIC}}=\frac{9 P^{2}\left(a_{\mathrm{app}}\right)^{2}}{4 w^{2} h^{3} E_{1}} .
$$

The parameters $\Delta_{\text {clamp }}$ and $E_{1}$ were measured according to the compliance calibration, also called 'clamp correction', described in the ISO 15114 standard.

Crack initiation was defined via the $5 \%$ criterion, i.e. by a $5 \%$ increase in initial compliance. For this purpose, the initial compliance $C_{0}$ was determined from a linear fit of initial force vs. displacement curve. The number of points used was such that the fit had an $\mathrm{R}^{2}$ equal to 0.999 . Following the standard, a new line was drawn with a compliance equal to $1.05 C_{0}$. The intersection of this new line with the load-displacement curve yields the initiation load and displacement. During ELS testing all the specimens showed stable crack 
propagation. Initiation and propagation values of fracture toughness were calculated.

\subsubsection{Mandrel Peel (MP) test}

The mandrel peel setup is schematically represented in Figure 5.6. The setup used in this work had a mandrel with a radius of $10 \mathrm{~mm}$. A constant displacement rate was applied using a Zwick universal testing machine on which the peel setup was mounted. The

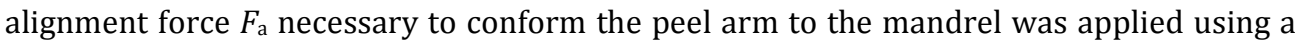
pneumatic actuator.

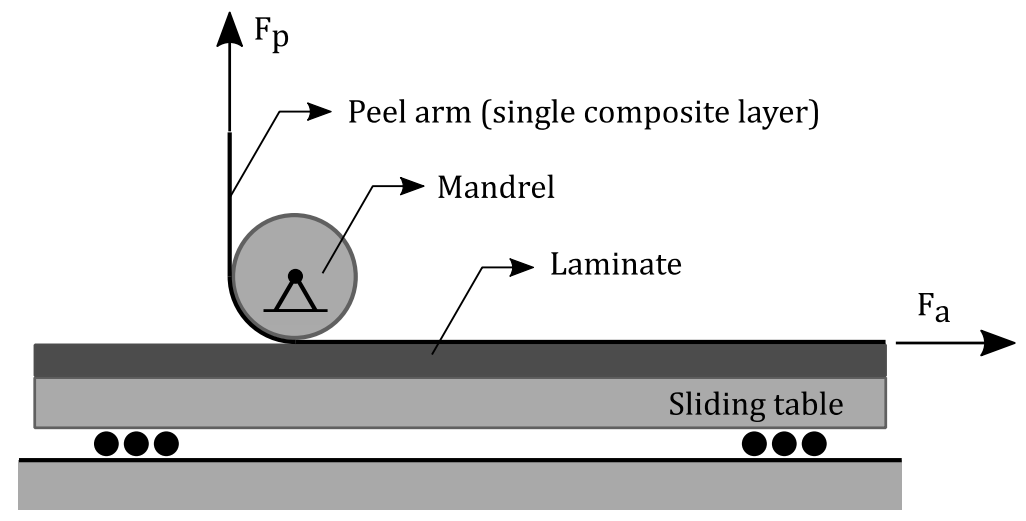

Figure 5.6: Schematic view of the mandrel peel test.

The effect of the alignment force [25], sample width and test speed [30] was investigated in previous research. No significant influence of these parameters on the test results was observed in the range of alignment force, sample width, and displacement speed tested. Following the result of the previously mentioned research, a constant peel rate of 30 $\mathrm{mm} / \mathrm{min}$ and alignment force of $60 \mathrm{~N}$ were used in this work. Two HBM $200 \mathrm{~N}$ load cells were used to measure the alignment force $F_{\mathrm{a}}$ and peel force $F_{\mathrm{p}}$. The critical energy rate can be calculated from the measured forces using Equation (5.6) [25],

$$
G_{\mathrm{c}}=\frac{1}{w}\left(F_{\mathrm{p}}(1-\mu)-F_{\mathrm{a}}\right),
$$

in which $\mu$ represents the friction coefficient in the setup. The test consists of two steps. First, the top ply is peeled from the laminate while measuring the peel force and the alignment force. Secondly, the cross head of the testing machine is returned to the initial position, and the test is performed again on the now de-bonded specimen (i.e. $G_{c}$ is equal to zero), where the peel force and the alignment force are measured again. The friction coefficient can be obtained from this second step as:

$$
\mu=\frac{F_{p}-F_{a}}{F_{p}} .
$$

An average friction coefficient $(\mu)$ value was calculated per each specimen. Subsequently 
an average friction coefficient was calculated for each sample as the mean of the specimen friction coefficients. Once the sample friction coefficient has been calculated, the fracture toughness of the specimens can be calculated using the friction coefficient of the sample and Equation (5.6). Four specimens were tested for each sample. All mandrel peel test samples showed unstable crack propagation. As with the DCB test, the first instability was not taken into account in the analysis. Only the subsequent crack re-initiations were used to calculate the fracture toughness values. The $G_{\text {IC }}$ values for DCB and mandrel peel test are not referred as stable crack propagation values as the values are unstable crack propagation.

It is worth to noticing that the peel arm of the mandrel peel specimens showed a certain curvature before testing as shown schematically in Figure 5.7. The curvature of the peel arm is caused by process-induced residual thermal stresses present in the non-symmetric peel arm (which is a single 5HS woven fabric reinforced PEEK ply). These residual thermal stresses are released during crack propagation and need to be taken into account for accurate fracture toughness measurements [31]. Nevertheless, the contribution of the residual stresses to the interlaminar fracture toughness was estimated to be $1 \%$ for an interlaminar fracture toughness of $1 \mathrm{~kJ} / \mathrm{m}^{2}$. As such the residual stresses were neglected in this research. The derivation of this estimation can be found in Appendix 5.A.

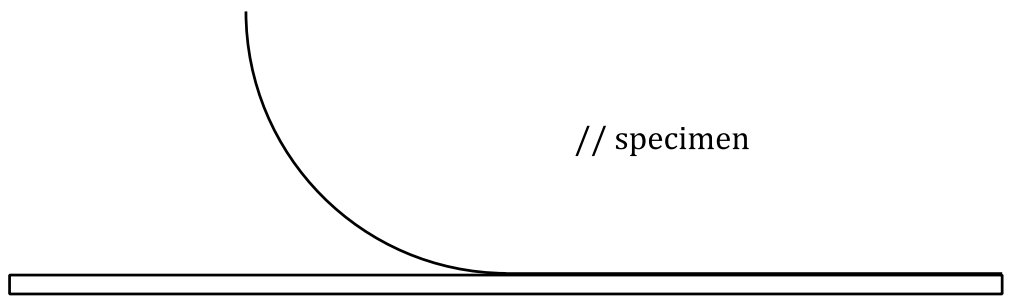

$\perp$ specimen

Figure 5.7: Schematic view of the mandrel peel specimens showing a typical curvature of the peel arm before testing. //: Parallel. $\perp$ : Perpendicular.

\subsection{Results}

The results of the different mechanical tests are presented in this section. Typical examples of force-displacement curves and R-curves (toughness vs. crack length) are shown for all the tests. The measured interlaminar fracture toughness values for the two types of samples (i.e. propagation parallel and perpendicular to the predominant fibre orientation) are presented. Finally, the results of the fractographic analysis of the different samples are described at the end of this section. 


\subsubsection{Double cantilever beam experiments}

A typical force-displacement curve measured during the DCB test is shown in the left graph in Figure 5.8. A linear force vs. displacement behaviour can be observed during the initial loading phase until the crack suddenly initiates. This is accompanied by an abrupt and significant drop in force. The remainder of the test shows a similar repeated behaviour with a linear loading phase, followed by a sudden drop in force due to crack propagation. On average, such unstable crack propagation (stick-slip) is observed 5 to 6 times per specimen, corresponding to a total crack length of about $100 \mathrm{~mm}$. The values of force, displacement, and crack length just before the unstable crack propagation were used to calculate the $G_{\text {Ic. }}$ The average crack propagation (or slip) distance for each instability was about $20 \mathrm{~mm}$ for the parallel specimens (i.e. crack propagation parallel to the predominant fibre orientation) and $16 \mathrm{~mm}$ for the perpendicular specimens (i.e. crack propagation perpendicular to the predominant fibre orientation). The linear force vs. displacement traces allows the use of linear elastic fracture mechanics. It is worth adding in this context that no significant permanent deformations of the specimens were observed after unloading. Nevertheless, the validity of analysis by energy release rate is questionable as no stable crack propagation was observed.
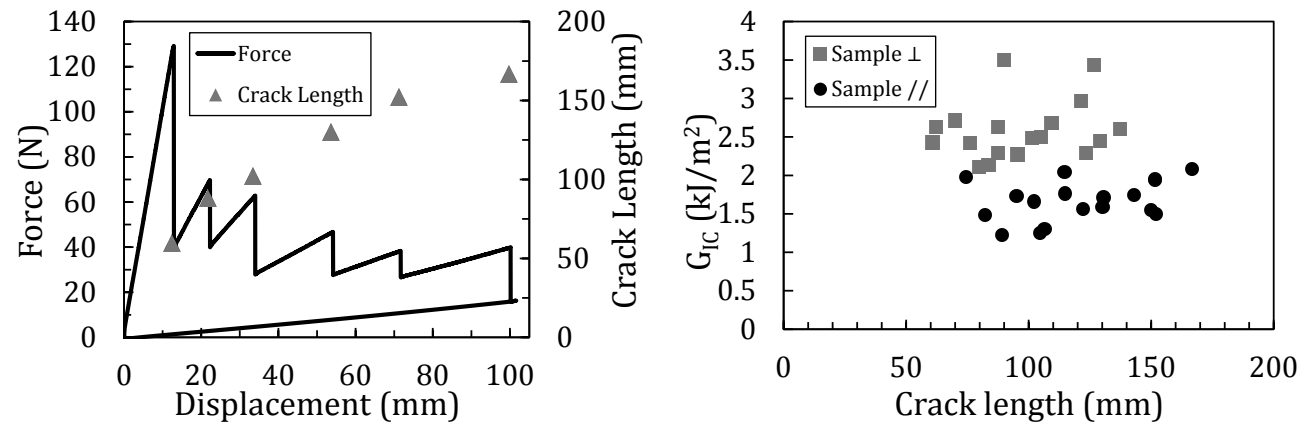

Figure 5.8: Left) The black line shows a typical force-displacement curve for a DCB test (// specimen). The grey triangles represent the crack lengths just before the unstable crack propagation starts. Right) Fracture toughness vs. crack length for all the DCB specimens. //: Parallel. $\perp$ : Perpendicular.

The right graph in Figure 5.8 shows the resistance points (fracture toughness) versus crack length produced by all specimens. Even though the scatter of the values is quite large, it can be observed that the R-curves for both samples can be considered as flat. The average values and standard deviations were calculated for each specimen. The average value for a single specimen was then used to calculate the average $G_{\text {IC }}$ value of the sample and its standard deviation. The results of the DCB tests on a specimen level and sample level are shown in Figure 5.9. It can be seen that both the fracture toughness of the perpendicular $\perp$ specimens and sample exceeds that of the parallel // specimens and 
sample.
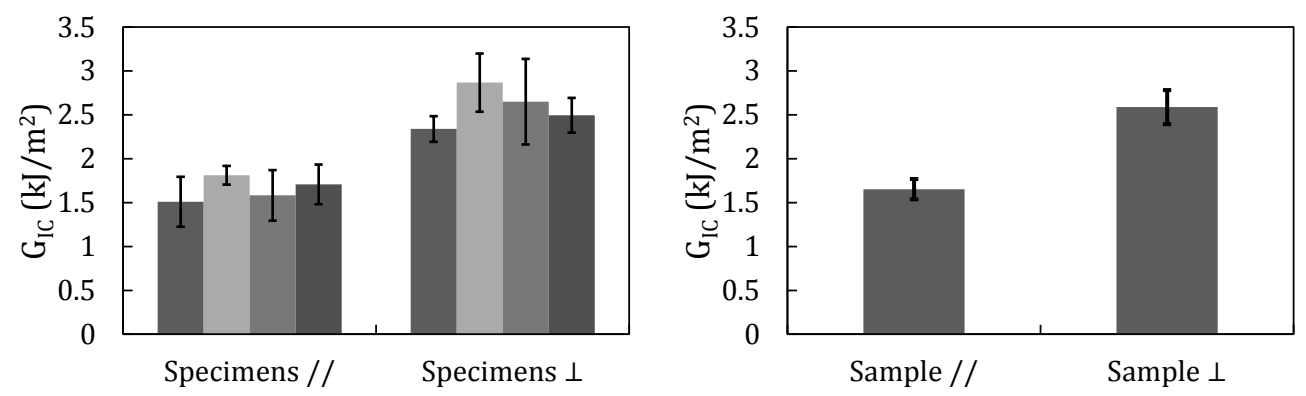

Figure 5.9: Left) Average toughness values for the different specimens with standard deviation. Right) Average toughness values for the different samples with standard deviation.

\subsubsection{End-loaded split experiments}

According to the procedure outlined in the standard, a compliance calibration test was performed prior to the ELS test. The resulting values for the apparent bending modulus $E_{1}$ as well as the correction factor $\Delta$, required to calculate the fracture toughness, can be found in Table 5.1.

\begin{tabular}{ccc}
\hline Sample & $\begin{array}{c}\text { Modulus } \boldsymbol{E}_{\mathbf{1}}(\mathrm{GPa}) \\
\text { Compliance calibration }\end{array}$ & $\begin{array}{c}\Delta \text { factor }(\mathrm{mm}) \\
\text { Compliance calibration }\end{array}$ \\
\hline Parallel $(/ /)$ & 55 & 5.5 \\
Perpendicular $(\perp)$ & 52 & 7.2 \\
\hline
\end{tabular}

Table 5.1: Results from the compliance calibration test.

Typical force-displacement curves measured during the ELS test for the parallel and perpendicular samples are shown in Figure 5.10 left. The force vs. displacement traces show a linear behaviour almost until the maximum force is reached. The star symbol in the left graph in Figure 5.10 represents the crack initiation point according to the $5 \%$ criterion, as described in the experimental section. Stable crack propagation was observed during the test, as can also be observed from the measurements of the apparent crack length. Finally, the left graph in Figure 5.10 indicates that the specimens showed slight residual deformation after testing, which can be caused by plastic deformation or damage (besides the measured delamination) during the test. The nonlinear loading stage and the residual displacement after unloading makes application of a LEFM approach somewhat questionable. 

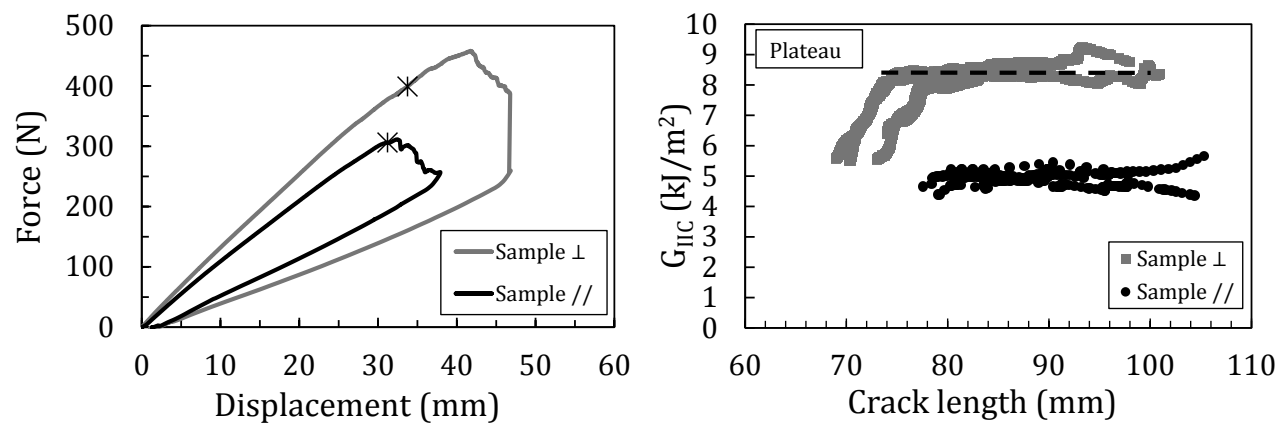

Figure 5.10: Left) Force vs. displacement curve. The star symbol represents the position of the crack initiation. Right) Fracture toughness vs. crack length for all the specimens.
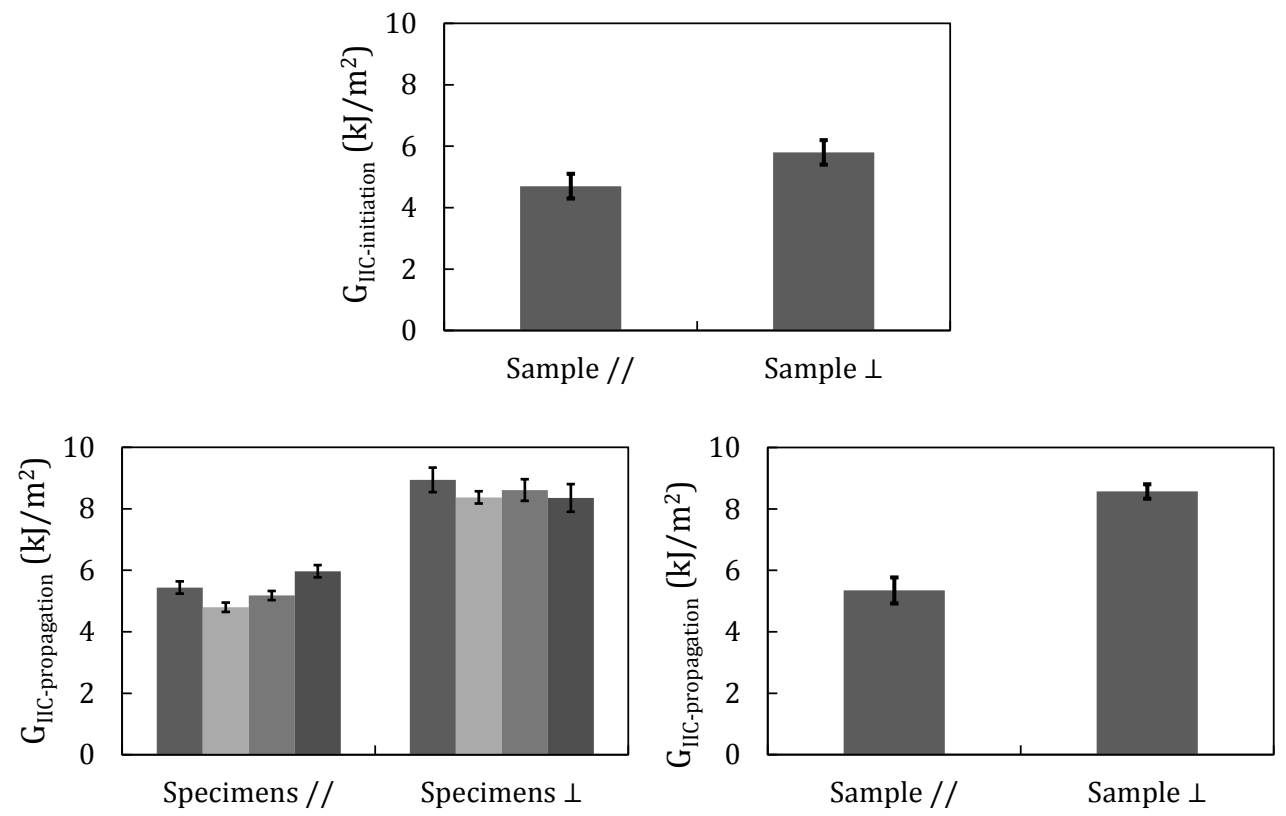

Figure 5.11: Upper) Initiation toughness values for the different samples with standard deviation. Bottom-left) Average propagation toughness values for the different specimens with standard deviation. Bottom-right) Average propagation toughness values for the different samples with standard deviation.

The right graph in Figure 5.10 shows the R-curves for all the specimens. The curves with lower $G_{\text {IIC }}$ values correspond to the specimens from the parallel sample, while the curves with a higher toughness correspond to the specimens from the perpendicular sample. The specimens from the parallel sample show a flat R-curve and the propagation values for this sample were calculated as an average $G_{\text {IIC }}$ along the R-curve. The R-curves of the perpendicular specimens initially show an increasing trend until they level off to a plateau. 
This behaviour could be associated with the development of a damage zone in front of the crack tip as the crack starts to propagate $[32,33]$. In the perpendicular specimens, the propagation values were calculated from the plateau region. The fracture toughness corresponding to crack initiation and crack propagation is shown in Figure 5.11. It can be seen that the initial fracture toughness of the perpendicular sample is slightly higher that of the parallel sample. Whereas, it can be seen that the propagation fracture toughness of the perpendicular $\perp$ specimens exceeds that of the parallel // specimens.

\subsubsection{Mandrel peel experiments}

The left graph in Figure 5.12 shows a typical force-displacement curve of a mandrel peel test for a parallel specimen and a force-displacement curve of the subsequent friction measurement. The friction coefficients for the parallel sample and perpendicular sample were $1.2 \pm 0.1 \%$ and $1.8 \pm 0.2 \%$, respectively.
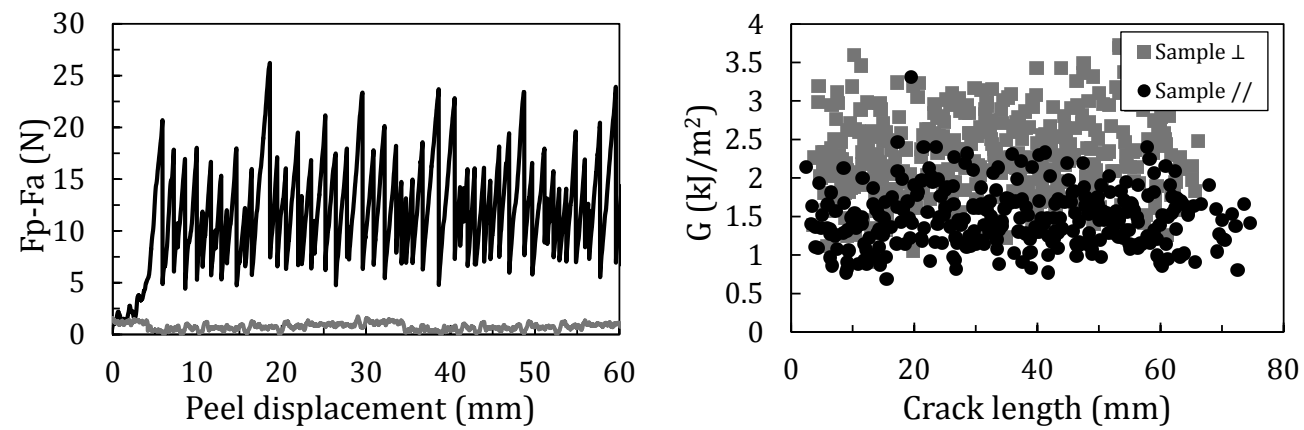

Figure 5.12: Left) Force vs. displacement during the mandrel peel test. The black line shows the actual test, while the grey line represents the subsequent run on the (now un-bonded) specimen to determine the friction in the setup. Right) Fracture toughness vs. crack length for all the mandrel peel specimens.

During the mandrel peel test, crack propagation showed a typical stick-slip behaviour. The repetitive behaviour of the test is schematically represented in Figure 5.13. At the beginning of the loading phase, the peel arm conforms to the mandrel (stage A). As the loading increase, no crack propagation is observed (stick), and the conformation of the peel arm to the mandrel cannot be maintained (stage B). As the force increases, and reaches a peak load, the stored energy in the system is enough to propagate the crack (stage C). A sudden unstable crack propagation is observed accompanied with an abrupt drop in the force (slip). By the end of this abrupt crack propagation, the peel arm completely conforms to the mandrel (stage A). This behaviour was repeatedly observed during testing. 


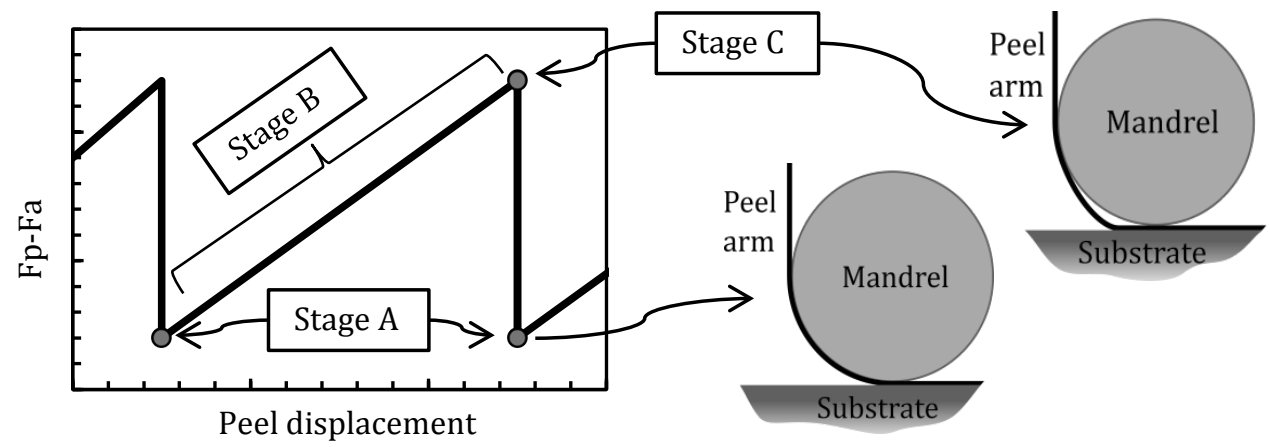

Figure 5.13: Schematic illustration of the peel arm behaviour during testing.

Similarly to the DCB analysis, the peak values in the force-displacement graphs were used to calculate the toughness values. The right graph in Figure 5.12 shows the interlaminar fracture toughness as a function of the peel distance (R-curve) measured for all the specimens. Similarly to the DCB test results, the R-curve remains flat along the crack length although the spread in values is quite large.

The average interlaminar fracture toughness per specimen is shown in the left graph in Figure 5.14. Subsequently, one interlaminar fracture toughness value per sample was calculated using the specimen averages (see Figure 5.14 right). The variation per specimens is seen to be large, though the results are consistent within the sample. Also here, and similar to the DCB and ELS results, the perpendicular sample is shown to have a higher fracture toughness than the parallel sample.
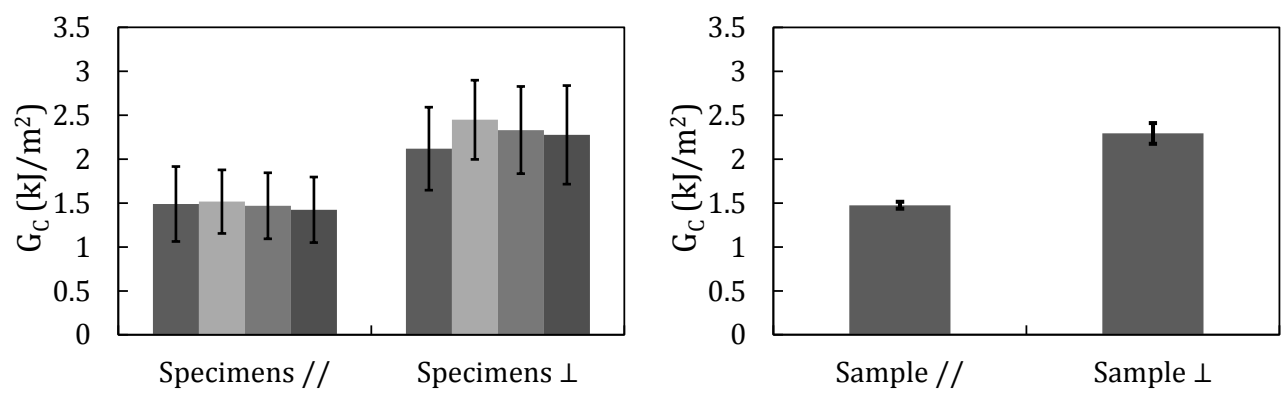

Figure 5.14: Left) Average toughness values for the different specimens with standard deviation. Right) Toughness values for the different samples with standard deviation.

\subsubsection{Fractographic Analysis}

The fracture surfaces were analysed using optical microscopy and Scanning Electron Microscopy (SEM). Firstly, a comparison at a low magnification of the failure surfaces of a parallel and a perpendicular specimen is presented in order to identify the mechanisms 
that cause the higher toughness of the perpendicular samples. Secondly, an analysis at higher magnifications is presented, with the main objective of identifying the predominant failure modes (i.e. opening, shearing or mixed) during the MP test.

\subsubsection{Influence of crack propagation direction}

Figure 5.15 shows the fracture surfaces of a perpendicular (left) and parallel (right) DCB specimen, with the crack propagating from right to left. Both surfaces look quite similar and show fibre bundles as well as matrix-rich regions between the bundles most of the time. Opposed to what is shown by other authors in similar testing [7,34], crack deflection and branching were rarely observed. The difference in toughness between the parallel and perpendicular samples can be explained by considering the interface morphology. Two factors will be elaborated here. The first is related to the constituents at the crack front, while the second is related to the crack path tortuosity.

Figure 5.16 provides a schematic representation of the fracture surfaces to ease the analysis regarding the first point. The left illustration shows that the crack front for the parallel specimens is composed of both fibre bundles and matrix pockets. Moreover, this composition does not change with crack propagation provided the crack is wide compared to the unit cell size. This is not the case for the perpendicular specimens, as is shown in the right illustration. Here, the constituent composition at the crack tip varies along the crack length with matrix-rich zones between the bundles exactly lining up with the crack front at regular intervals. At these instances the crack, across its full width, is forced to propagate through the tough matrix material, resulting in high load peaks and interlaminar toughness as was shown in the previous section.
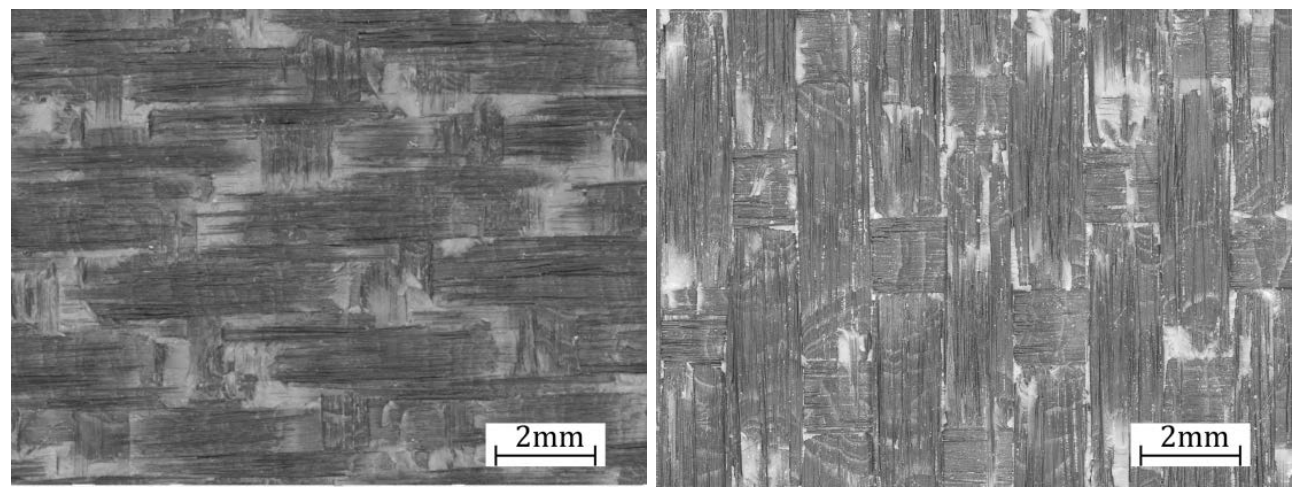

Figure 5.15: Fracture surface of two DCB specimens. Left) parallel specimens. Right) a perpendicular specimen. The crack propagation is from right to left. 


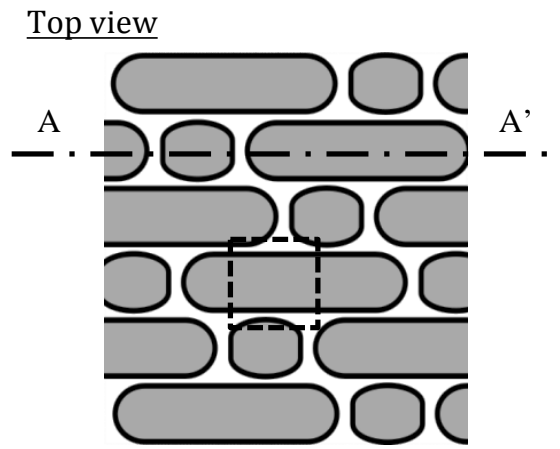

Cross section $\mathrm{AA}^{\prime}$

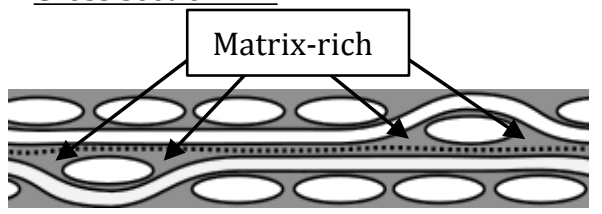

Figure 5.16: Left) Represent a parallel (//) specimen. Right) Represent a perpendicular ( $\perp$ ) specimen. The square boxes represent the areas where the high magnification SEM image was taken. The dotted lines in the bottom image (cross-section) represent the crack propagation path.

Apart from the constituent composition at the crack tip, the interlaminar toughness is also influenced by the tortuosity of the crack path with an increase in tortuosity leading to an increase of interlaminar toughness [7]. To investigate whether this played a role here, the height profile (roughness) of the delaminated surfaces were characterised using a confocal microscope. Figure 5.17 shows the obtained images for both specimen types. The crack path shows a higher tortuosity in case the crack propagation direction is perpendicular to the predominant fibre direction, i.e. the right graph in Figure 5.17. Similar observations were made by other authors as well $[3,7,34]$. As mentioned earlier, the higher tortuosity is reported to result in a higher interlaminar toughness.
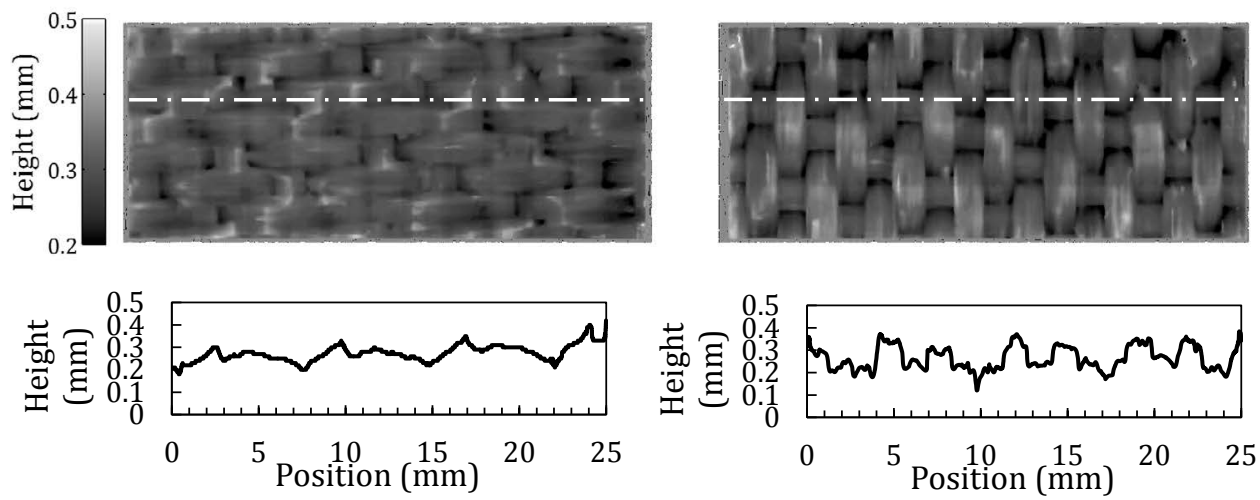

Figure 5.17: Fracture surface topology. Left) A DCB parallel specimen. Right) A DCB perpendicular specimen. The white dash-dotted line represents the position where the height was analysed in the lower charts. 
Both factors, i.e. the alignment of matrix-rich zones with the crack front and the high crack path tortuosity, are believed to contribute to the increased interlaminar toughness of the perpendicular samples.

\subsubsection{Mandrel peel failure mode}

The fracture surfaces of the DCB and ELS samples were also analysed to identify the characteristic features of pure mode I and pure mode II failure and compare these to that of the mandrel peel specimens. Figure 5.18, Figure 5.19 and Figure 5.20 show the fracture surfaces of the parallel specimens tested using DCB, ELS and mandrel peel, respectively. The area where the micrographs were taken is schematically represented in Figure 5.16. Figure 5.18 shows the fracture surface of a DCB specimen. Two regions can be distinguished. The main and predominant region corresponds to fast brittle failure characterised by rivers, scarps and cusps (Figure 5.18 left and centre) [35]. The second region is characterised by a larger amount of plastic deformation and drawing of the matrix, which is related to slow ductile plastic deformation [35]. The latter features were difficult to find. They appear as narrow strips close to the positions where unstable crack propagation starts.
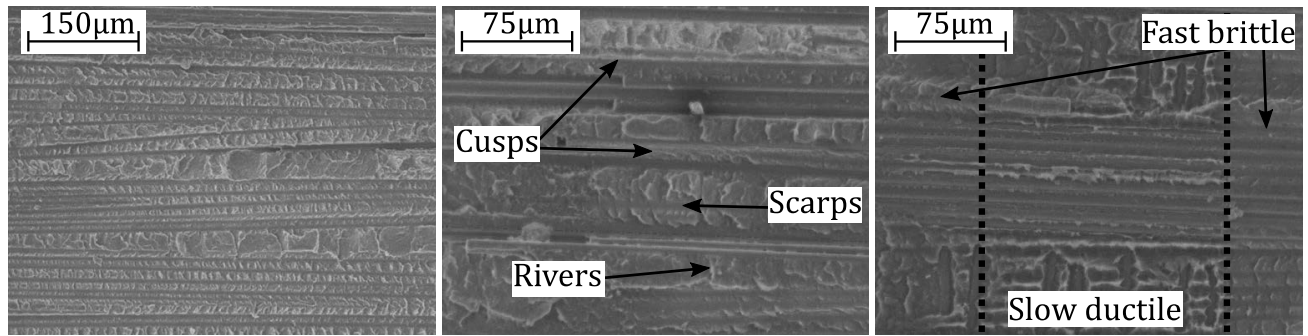

Figure 5.18: SEM fractography of a // DCB specimen. The image corresponds to a bundle with the fibres oriented in the same direction of the crack propagation. The crack propagates from right to left. Left) Region of unstable crack propagation. Centre) A zoomed-in look at a region of unstable crack propagation. Right) A zoomed-in look at a stable crack propagation region.

The fracture surface of the ELS specimen in Figure 5.19 shows traces of significant shear deformation of the matrix material. The drawing direction of the matrix material is in the same plane as the fracture surface. These failure features are typical for mode II failure [36].
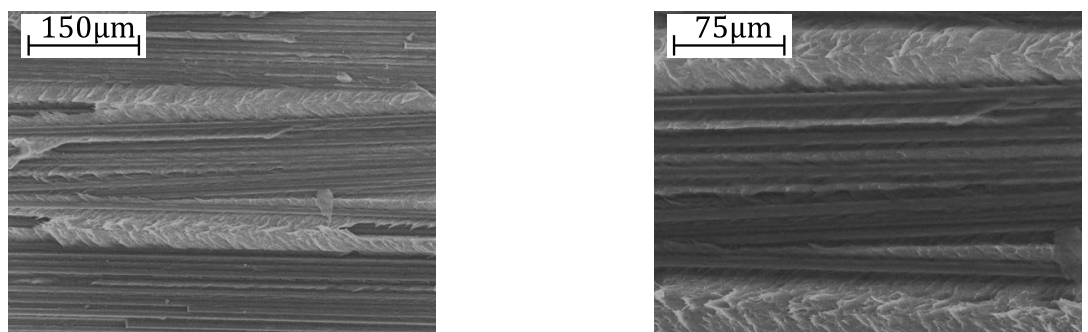

Figure 5.19: SEM fractography of a // ELS specimen where the crack propagates from right to left. The right image is a detail and close-up view of the left image. 
Finally, the fracture surfaces of an MP specimen are shown in Figure 5.20. The same two regions observed in the DCB sample, related to fast brittle propagation and to slow ductile failure, can also be found here. In this case, however, the regions corresponding to slow crack propagation are easier to find than in the DCB specimens, and apparent large plastic deformation of the matrix is observed. Nevertheless, the unstable crack propagation region is also still predominantly observed in the fracture surface. The features related to mode II failure were not observed in the mandrel peel specimens. This suggests that the failure mode of the mandrel peel test specimens was mainly an opening failure mode.
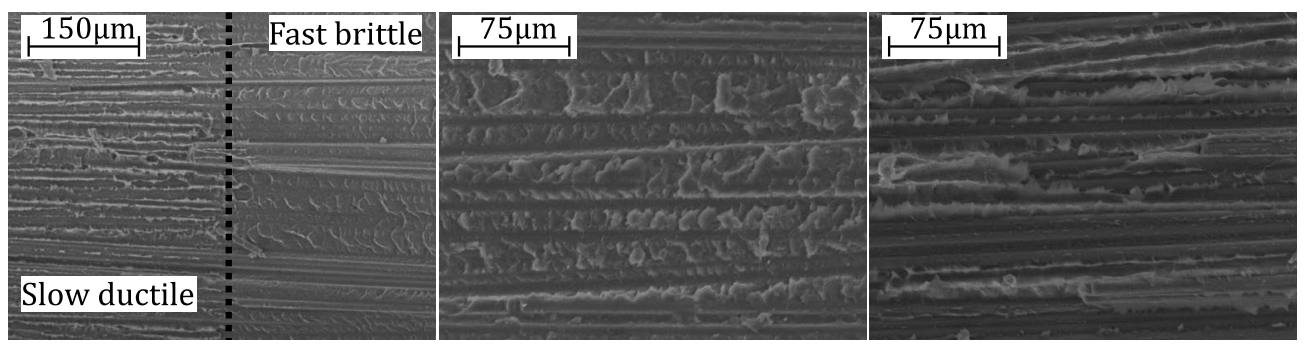

Figure 5.20: SEM fractography of a mandrel peel specimen. The crack propagates from right to left. Left) Combination of stable and unstable crack propagation. Centre) Closer look at the region of unstable crack propagation. Right) Closer look at a region of stable crack propagation.

\subsection{Discussion}

The applicability and validity of the mandrel peel test for the characterisation and measurement of interlaminar fracture toughness of woven composites based on the presented results is discussed here. The interlaminar fracture toughness values as measured using the DCB, ELS and mandrel peel test methods are summarised in Table 5.2. As it can be seen, the fracture toughness values measured by the mandrel peel test are close to the values obtained by DCB testing and far from the ELS test results. Moreover, the characteristic features of opening mode failure shown by the fracture surfaces of the mandrel peel specimens further reinforce the idea that the mode mixity of the mandrel peel test is low and it is close to mode I. For this reason, the MP test is only compared with DCB tests in the remainder of this section. Further, the discussion concentrates on the test methodology and does not address the difference between parallel and perpendicular direction which was already elaborated in the results section.

\begin{tabular}{ccccc}
\hline Sample & $\begin{array}{c}\text { DCB } \\
\left(\mathrm{kJ} / \mathrm{m}^{2}\right)\end{array}$ & $\begin{array}{c}\text { MP test } \\
\left(\mathrm{kJ} / \mathrm{m}^{2}\right)\end{array}$ & $\begin{array}{c}\text { ELS } \\
\text { Initiation } \\
\left(\mathrm{kJ} / \mathrm{m}^{2}\right)\end{array}$ & $\begin{array}{c}\text { ELS } \\
\text { Propagation } \\
\left(\mathrm{kJ} / \mathrm{m}^{2}\right)\end{array}$ \\
\hline Parallel $(/ /)$ & $1.65 \pm 0.12$ & $1.50 \pm 0.08$ & $4.7 \pm 0.4$ & $5.3 \pm 0.4$ \\
Perpendicular $(\perp)$ & $2.59 \pm 0.19$ & $2.29 \pm 0.12$ & $5.8 \pm 0.4$ & $8.5 \pm 0.2$ \\
\hline
\end{tabular}

Table 5.2: Mean sample interlaminar fracture toughness values measured by DCB, MP, and ELS test with one standard deviation. 
From a practical viewpoint, the mandrel peel test was found to be relatively simple to perform with straightforward simple sample preparation and data reduction procedure. The mandrel peel test requires less instrumentation compared to the DCB test, as there is no need to measure the crack length during testing. Moreover, at least for the material system tested in this work, the mandrel peel test generates more fracture toughness values for a single specimen than the DCB test. This is due to the mandrel which arrests any unstable crack propagation. The distance between subsequent instabilities, calculated as the average incremental crack growth length between two maximum force peaks, is shown in Table 5.3. It can be noticed that the incremental crack growth length for the mandrel peel test is more than 20 times shorter distance than the value observed in the DCB test. Consequently, for specimens of the same length the mandrel peel test generates more data points than the DCB test, resulting in a higher statistical relevance of the results of the mandrel peel test. Moreover, the table also illustrates that the average incremental crack growth length between subsequent instabilities is shorter for the perpendicular sample than for the parallel sample. This may suggest that crack arresting point is also governed by the woven structure, the toughness of the specimen and the mandrel peel setup, therefore, further research is required to understand the governing mechanism behind this observation.

\begin{tabular}{|c|c|c|}
\hline Sample & $\begin{array}{c}\text { Average incremental } \\
\text { crack growth length }(\mathrm{mm})\end{array}$ & $\begin{array}{c}\text { Standard deviation } \\
(\mathrm{mm})\end{array}$ \\
\hline DCB // & 20.3 & 2.2 \\
\hline $\mathrm{DCB} \perp$ & 16.9 & 2.0 \\
\hline MP // & 0.83 & 0.07 \\
\hline $\mathrm{MP} \perp$ & 0.48 & 0.05 \\
\hline
\end{tabular}

Table 5.3: Average distance between peaks for the different samples tested.

Figure 5.21 shows the average fracture toughness and standard deviation measured by DCB and mandrel peel test for each specimen (left) and the sample (right). For both samples, parallel and perpendicular, it can be observed that the DCB and MP tests yield a similar interlaminar fracture toughness value. Nevertheless, at specimen level (left graph in Figure 22), the DCB test shows slightly lower standard deviation compared to mandrel peel test, although the number of points per test is rather limited $(<10)$. Furthermore, at sample and specimen level, the DCB shows a slightly higher mean value compared to the mandrel peel test, which will be addressed hereafter. The possible reason for this observation is discussed hereafter. 

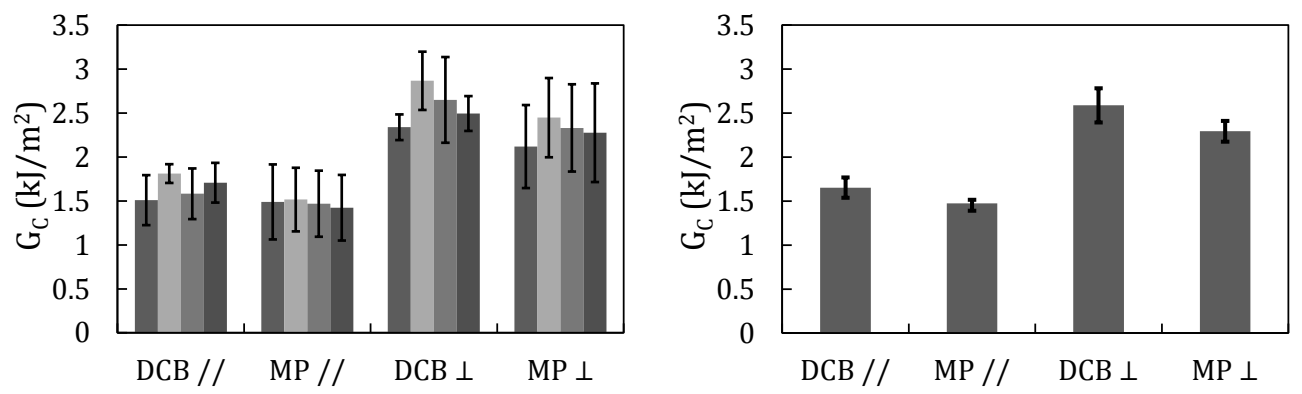

Figure 5.21: Left) Average toughness values for the different specimens with standard deviation. Right) Toughness values for the different samples with standard deviation.

Figure 5.22 shows a plot of normalised frequency of the interlaminar fracture toughness for the two test methods. All single interlaminar fracture toughness values measured for each specimen within each sample were considered as independent values to calculate the frequency of occurrence. A normal distribution fit was used to interpret the results. Firstly, it can be noted that the MP test follows a normal distribution fit, whereas the DCB results do not follow the normal distribution as well as the mandrel peel results. This could partly be due to the lower number of values within the population of the DCB test samples. Secondly, a slight difference in the mean values between the DCB and the mandrel peel can be noticed, where the DCB test shows higher interlaminar fracture toughness for both parallel and perpendicular samples. Finally, it can be noted that, for both tests, the tails of the normal distributions for high values overlap, while the lower tail of MP test extends to smaller values as well. From a physical viewpoint, the difference in mean value and the position of the normal distribution tails can be explained as follows. During DCB testing, each time unstable crack propagation occurs, the material itself has to stop the instability. Therefore, the probability of crack arrest is higher in the tougher (matrix-rich) regions. During the MP test, however, unstable crack propagation is mainly arrested by the mandrel, which means that the crack arrest position will not necessarily be in a region of high toughness. As discussed earlier, this is also shown by the average incremental crack growth length which does not correspond to typical average weave related distances. The subsequent re-initiation toughness values are measured close to the crack arrest points. Thus, the DCB test measures the fracture toughness in a tough region, while mandrel peel test measures the fracture toughness in more random position. This phenomenon might explain the observation that the DCB test measures higher apparent toughness values as compared to the mandrel peel test. In other words, the tougher regions are overrepresented in the DCB data, which results in an overestimation of the fracture toughness. 

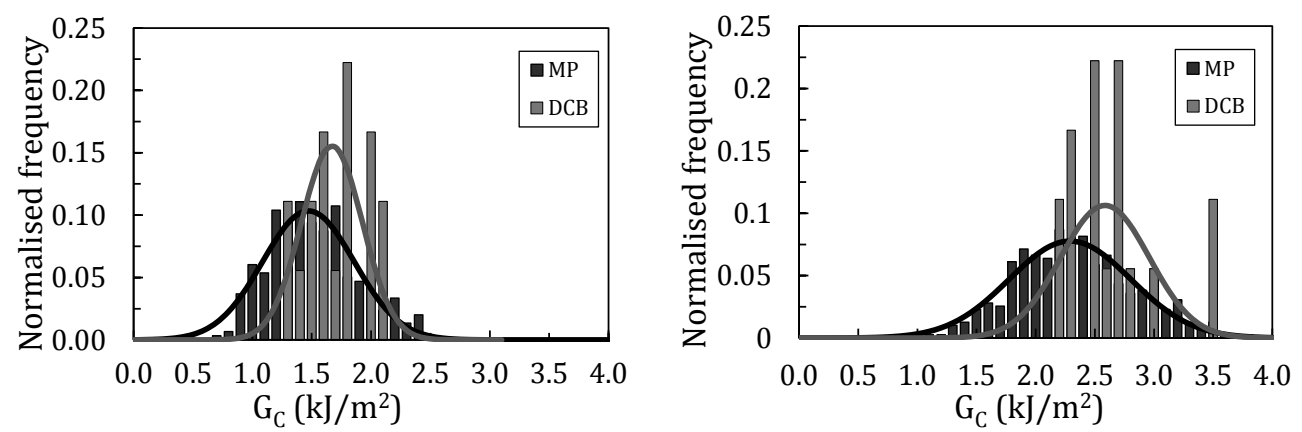

Figure 5.22: Normalised frequency as a function of interlaminar fracture toughness for double cantilever beam (DCB) and mandrel peel test (MP). Left parallel sample. Right) Perpendicular sample.

Another possible factor that could contribute to the difference in the values measured between mandrel peel test and DCB test is that the interface for both tests is not exactly the same, as indicated earlier. In the DCB specimens, the crack propagates along the warp bundles, whereas it travels along the weft bundles for the mandrel peel specimens. Still, the effect of crack travelling along warp or weft fibres on the interlaminar fracture toughness is not well described in the open literature, and therefore further attention is required in the future.

\subsection{Conclusions}

The interlaminar fracture toughness of a woven 5HS Carbon/PEEK laminate was investigated using the Double Cantilever Beam (DCB), End-Loaded Split (ELS), and Mandrel Peel (MP) test methods. Crack propagation in two directions was studied, i.e. crack propagation parallel and perpendicular to the predominant fibre direction at the interface. As expected, the perpendicular samples showed a higher fracture toughness than the parallel ones. Furthermore, in line with observations from other researchers, the ELS test showed higher toughness than the DCB test. Also, both DCB and MP showed unstable crack propagation, whereas crack propagation was stable in ELS tests. The interlaminar fracture toughness values measured by the mandrel peel test were similar to the values measured by the DCB test, which suggests that the mode-mixity of the mandrel peel test is low and hence it is close to mode I. Moreover, reinforcing this idea, the DCB and mandrel peel test specimens both show characteristic fractographic features of mode I failure, while ELS specimens show characteristic features of shear mode failure.

The mandrel peel test can be considered to be an easy and fast test compared to the DCB test. In this work, it was suggested that the presence of a strong stick-slip behaviour in the DCB test tends to overestimate the interlaminar fracture toughness values. Moreover, the mandrel peel test is able to measure the fracture toughness over a large number of distributed points in the test area, producing more than 20 times the amount of data points per unit crack length compared to the DCB test. The higher amount of crack (re-)initiation 
points measured by the mandrel peel test can be considered to make the mandrel peel test statistically more relevant than the DCB test. To conclude, the mandrel peel test seems to be an interesting alternative to the DCB test for woven fabric reinforced composites.

\subsection{References}

[1] I. Paris, P. J. Minguet and K. T. O'Brien, "Comparison of delamination characterization for IM7/8552 composite woven and tape laminates," ASTM STP 1436, pp. 372-390, 2003.

[2] P. Suppakul and S. Bandyopadhyay, "The effect of weave pattern on the mode-I interlaminar fracture energy of E-glass/vinyl ester composites," Compos. Sci. Technol., vol. 62, pp. 709-717, 2002.

[3] N. Alif, L. A. Carlsson and L. Boogh, "The effect of weave pattern and crack propagation direction on mode I delamination resistance of woven glass and Carbon composites," Composites Part B, vol. 29, pp. 603-611, 1998.

[4] M. Kotaki and H. Hamada, "Effect of interfacial properties and weave structure on mode I interlaminar fracture behaviour of glass satin woven fabric composites," Composites Part A, vol. 28A, pp. 257-266, 1997.

[5] B. J. Briscoe, R. S. Court and D. R. Williams, "The effect of fabric weave and surface texture on the interlaminar fracture toughness of aramid/epoxy laminates," Compos. Sci. Technol., vol. 47, pp. 261-270, 1993.

[6] A. F. Gill, P. Robinson and S. Pinho, "Effect of variation in fibre volume fraction on modes I and II delamination behavior of 5HS woven composites manufactured by RTM," Compos. Sci. Technol., vol. 69, pp. 2368-2375, 2009.

[7] T. Ogasawara, A. Yoshimura, T. Ishikawa, R. Takahashi, N. Sasakib and T. Ogawa, "Interlaminar fracture toughness of 5 harness satin woven fabric Carbon fiber/epoxy composites," Advanced Composite Materials, vol. 21.1, pp. 45-56, 2012.

[8] M. Olave, I. Vara, H. Husabiaga, L. Aretxabaleta, S. V. Lomov and D. Vandepitte, "Nesting effect on the mode I fracture toughness of woven laminates," Composites Part A: Applied Science and Manufacturing, vol. 74, pp. 166-173, 2015.

[9] T. K. O'Brien, "Interlaminar fracture toughness: the long and winding road to standardization," Composites- Part B: Engineering, vol. 29B(1), pp. 57-62, 1998.

[10] A. J. Brunner, B. R. K. Blackman and P. Davies, "A status report on delamination resistance testing of polymer-matrix composites," Engineering Fracture Mechanics, vol. 75(9), pp. 2779-2794, 2008.

[11] I. De Baere, S. Jacques, W. Van Paepegem and J. Degrieck,"Study of the Mode I and Mode II interlaminar behaviour of a Carbon fabric reinforced thermoplastic," Polymer Testing, vol. 31.2, pp. 322-332, 2012.

[12] R. Frassine and A. Pavan, "Viscoelastic effects on the interlaminar fracture behaviour of thermoplastic matrix composites: I. Rate and temperature dependence in unidirectional PEI/Carbon-fibre laminates," Composites Science and Technology, vol. $54,1995$.

[13] R. Fracasso, M. Rink, A. Pavan and R. Frassine, "Effects of strain-rate and temperature on the interlaminar fracture toughness of interleaved PEEK/CF composites," Composites Science and Technology, vol. 61(1), pp. 57-63, 2001. 
[14] P. Compston and P. Y. Jar, "Comparison of interlaminar fracture toughness in unidirectional and woven roving marine composites," Applied Composite Materials, vol. 5.3, pp. 189-206, 1998.

[15] T. W. Webb and E. C. Aifantis, "Crack growth resistance curves and stick-slip fracture instabilities," Mechanics Research Communications, vol. 24, pp. 123-130, 1997.

[16] T. W. Webb and E. C. Aifantis, "Stick- Slip Instabilities in Fracture," Computational Mechanics, pp. 1353-1358, 1995.

[17] D. Barquins and M. Maugis, "Stick-Slip and peeling of adhesive tapes," Adhesion, vol. 12, pp. 205-222, 1988.

[18] M. Ciccotia, B. Giorgini and M. Barquins, "Stick-slip in the peeling of an adhesive tape: evolution of theoretical model," International Journal of Adhesion and Adhesives, vol. 18, no. 1, pp. 35-40, 1998.

[19] A. J. Kinloch, C. C. Lau and J. G. Williams, "The peeling of flexible laminates," International Journal of Fracture, vol. 66, pp. 45-70, 1994.

[20] P. J. Hine, B. Brew, R. A. Duckett and I. M. Ward, "Failure mechanisms in continuous Carbon-fibre reinforced PEEK composites," Compos. Sci. Technol., vol. 35, pp. 31-51, 1989.

[21] "ISO 8510-1:1990 standard. Adhesives - Peel test for a flexible-bonded-to-rigid test specimen assembly - Part 1: 90 degree peel," 1990.

[22] L. F. Kawashita, D. R. Moore and J. G. Williams, "The Development of a Mandrel Peel Test for the Measurement of Adhesive Fracture Toughness of Epoxy-Metal Laminates," The Journal of Adhesion, vol. 80 (3), pp. 147-167, 2004.

[23] T. Kok, W. J. B. Grouve, L. L. Warnet and R. Akkerman, "Effect of ply orientation on bond strength in fiber-placed composites," ICCM20 proceedings., 2015.

[24] Y. Su, M. de Rooija, W. J. B. Grouve and L. L. Warnet, "Characterisation of metalthermoplastic composite hybrid joints by means of a mandrel peel test," Composites Part B: Engineering, vol. 95, pp. 293-300, 2016.

[25] W. J. B. Grouve, L. L. Warnet and R. Akkerman, "Critical assessment of the mandrel peel test for fiber reinforced thermoplastic laminates," Eng. Frac. Mech, vol. 101, pp. 96-108, 2013.

[26] "TenCate material, datasheets," 2017. [Online]. Available: http://www.tencate.com/advancedcomposites/default.aspx.

[27] "ISO 15024 Standard Test Method for Mode I interlaminar Fracture Toughness, Gic, of unidirectional Fibre-Reinforced Polymer Matrix Composites," 1997.

[28] "ISO 15114- Fibre-reinforced plastic composites - Determination of the mode II fracture resistance for unidirectionally reinforced materials using the calibrated endloaded split (C-ELS) test and an effective crack length approach," International Organisation for Standardisation, 2014.

[29] S. Hashemi, A. J. Kinloch and J. G. Williams, "The analysis of interlaminar fracture in uniaxial fibre-polymer composites.," Proceedings of the Royal Society of London A: Mathematical, Physical and Engineering Sciences., vol. 427, 1990.

[30] F. Sacchetti, W. J. B. Grouve, L. L. Warnet and I. Fernandez Villegas, "Woven fabric composites: Can we peel it?" Procedia Structural Integrity, 2016.

[31] J. A. Nairn, "Fracture mechanics of composites with residual thermal stresses," Journal 
of Applied Mechanics, vol. 64.4, pp. 804-810, 1997.

[32] H. Vu-Khanh and H. Wang, "Use of end-loaded-split (ELS) test to study stable fracture behaviour of composites under mode II loading," Composite Structures, Vols. 36(1-2), pp. 71-79, 1996.

[33] S. Hashemi, A. J. Kinloch and J. G. Williams, "The effect of geometry, rate and temperature on the mode I, mode II and mixed-mode I/II interlaminar fracture of Carbon-fiber/poly(ether-ether ketone) composites," Journal of Composite Materials, vol. 24, pp. 918-956, 1990.

[34] N. Alif, L. A. Carlsson and J. W. Gillespie, "Mode I, mode II, and mixed mode interlaminar fracture of woven fabric Carbon/epoxy," Composite Materials: Testing and Design, vol. 13, 1997.

[35] D. Purslow, "Matrix fractography of fibre-reinforced thermoplastics, Part 1. Peel failures," Composites, vol. 18.5, pp. 365-374, 1987.

[36] D. Purslow, "Matrix fractography of fibre-reinforced thermoplastics, Part 2. Shear failures," Composites, vol. 19.2, pp. 115-126, 1988. 


\subsection{Appendix - A}

The energy release per unit area associated with the thermal stresses was calculated from the curvature of the peel arm, as the change in elastic energy from the flat configuration to the curved configuration. Considering a beam subjected to a pure bending, the curvature $(k)$ of its neutral line can be expressed as:

$$
k=\frac{1}{\rho}=\frac{M}{E I},
$$

where $\rho$ is the radius of curvature, $M$ the moment applied to the beam, $E$ the bending modulus, and $I$ the moment of inertia. The strain energy of a beam subjected to a bending moment $M$ is equal to

$$
U=\frac{1}{2} \int_{0}^{l}\left(\frac{M^{2}}{E I}\right) d x .
$$

Combining (5.8) and (5.9) the strain energy per unit of area can be calculated as

$$
\frac{d U}{d A}=\frac{1}{2 w} \frac{E I}{\rho^{2}}=\frac{1}{24} \frac{E h^{3}}{\rho^{2}},
$$

where $w$ is the width of the beam. The radius of curvature of the peel arm was measured by taking pictures of the un-bonded peel arm using an HP scanner at a resolution of 2400 DPI. The images were then analysed using the software package ImageJ. An approximate radius of curvature of $75 \mathrm{~mm}$ was measured for both parallel and perpendicular specimens, but in opposite directions. For simplification, the bending modulus of the peel arm was considered as the bending modulus measured in the compliance calibration test (see Table 5.1). The thickness of the peel arm was measured as $0.3 \mathrm{~mm}$ using a micrometre screw gage. A total energy per unit of area of around $10 \mathrm{~J} / \mathrm{m}^{2}$ was calculated using the aforementioned values. For this case it can be seen that the residual thermal stresses contribute less than $1 \%$ to the total energy release rate compared with the interlaminar fracture toughness measured with the mandrel peel test. For this reason the residual stresses were neglected in this study. 



\section{Chapter 6: Discussion}

The objective of this work was to identify, analyse and when possible quantify the relation between physical state and structural features induced by the fusion bonding process and the resulting mechanical performance of the joints. The investigated factors were the degree of surface contamination of the substrates before bonding, the degree of crystallinity at the bond line, the thickness of the matrix-rich bond line, the fibre architecture and the direction of crack propagation. To evaluate the mechanical performance, interlaminar toughness was used as a measure for mechanical performance. The present chapter is aiming at broadening the discussion. Firstly, an overview of the qualitative relationships between the abovementioned factors and the interlaminar fracture toughness is presented. The governing mechanisms that affect the interlaminar fracture toughness are then presented and discussed. Secondly, the focus of the discussion about the relationship between structure and performance is shifted from interlaminar fracture toughness towards the global load bearing capability of the fusion bonded joint. Finally, the knowledge gained throughout this research is applied to draw guidelines for an advanced fusion bonded joint with optimised interlaminar fracture toughness.

\subsection{Structure - interlaminar fracture toughness relationship}

The work in this thesis is aimed at identifying, analysing, and wherever possible, at quantifying the relationship between structural features in the bond line and the performance of fusion bonded joints. For this purpose, experimental methods were developed which allowed the controlled variation of single features, which in this thesis are surface contamination, matrix bond line thickness, degree of crystallinity and fibre architecture. Subsequently, the interlaminar fracture toughness of the weld interface was used as a measure for the performance. The fracture toughness of the joint was found to be sensitive to variations in the aforementioned microstructural weld line features. A summary of the relationships observed between the structural features and the interlaminar fracture toughness is presented below. Figure 6.1 summarises the observed relationships. The aim of this section is to highlight the common governing mechanisms behind these relationships. 


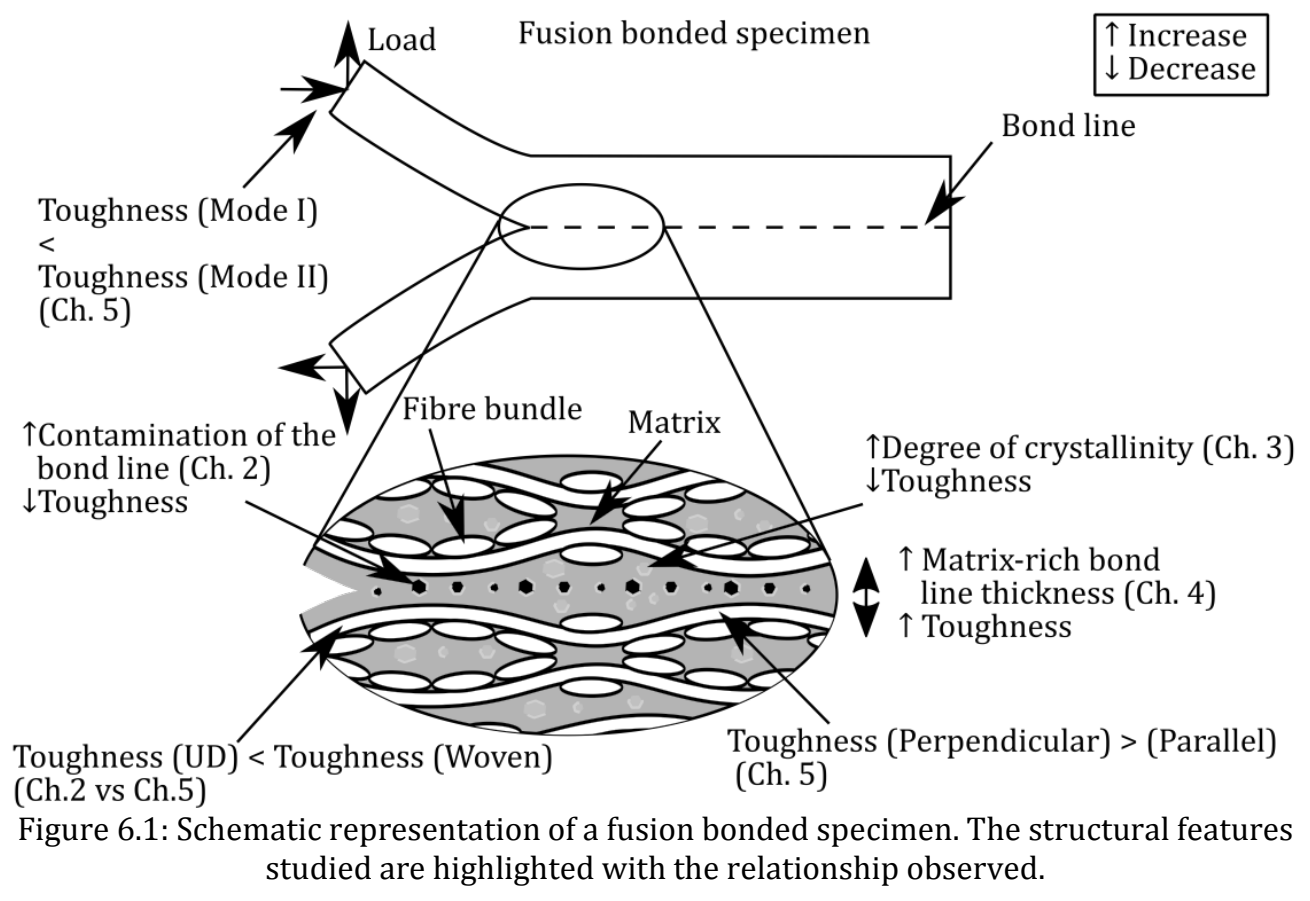

\subsubsection{Bond line contamination}

In chapter two, the presence of release media contaminants on the surface of unidirectional Carbon/PEEK substrates was investigated. The interlaminar fracture toughness of co-consolidated joints was found to be similar to the toughness of the parent material when low levels of contamination were measured on the surface of the substrates. However, in the presence of considerable contamination, only $1 / 3$ of the performance remained after co-consolidation. Moreover, the joints with low fracture toughness presented flat fracture surfaces, whereas the specimens with high fracture toughness showed rough fracture surfaces with local plastic deformation of the matrix.

\subsubsection{Matrix degree of crystallinity}

In chapter three, the effect of the degree of crystallinity of the PPS matrix in flat Carbon/PPS laminates on the interlaminar fracture toughness was investigated. A decrease in the degree of crystallinity from $33 \%$ (reference sample) to $12 \%$ (stampformed sample with the lowest mould temperature) was found to result in a doubling of the interlaminar fracture toughness. The samples with the lowest degree of crystallinity showed the highest local plastic deformation of the matrix on the fracture surfaces. Besides, the fracture surfaces of the laminates with the lowest crystallinity showed indications of some degradation of the fibre-matrix interface strength. 


\subsubsection{Matrix-rich bond line thickness}

In chapter four, the thickness of the matrix-rich bond line in unidirectional Carbon/PEEK fusion bonded joints was varied. Samples with thicker matrix-rich bond line yielded higher interlaminar fracture toughness. The interlaminar fracture toughness was almost doubled when a $200 \mu$ m-thick resin film was added to the bond interface, compared to a specimen without any additional film. The fracture surfaces of the samples with higher interlaminar fracture toughness showed higher local plastic deformation. For the same unidirectional Carbon/PEEK system, the presence or absence of fibre migration towards the matrix-rich bond line was found to have no effect on the interlaminar fracture toughness of the fusion bonded samples.

\subsubsection{Fibre architecture}

In chapter five, the interlaminar fracture toughness of 5HS Carbon/PEEK woven fabric composites was investigated. The mode I interlaminar fracture toughness of the woven composite laminates under study was found to be $25 \%$ higher than that of the UD Carbon/PEEK material when the crack propagation during the test was parallel to the predominant direction of the fibres. Even though quantitative measurements were not carried out, the fracture surfaces of the woven fabric were observed to be rougher than the ones of UD material (comparison between chapter two and chapter five). Moreover, the fracture surfaces of the woven fabric reinforced laminates showed high plastic deformation of the matrix, amply present in the pockets between the bundles. Besides, in this comparison, it is worth noticing that while the unidirectional composites showed stable crack propagation, the woven fabrics showed unstable crack propagation.

\subsubsection{Direction of crack propagation}

For the same 5HS Woven Carbon/PEEK material, a $50 \%$ increase in the interlaminar fracture toughness was observed, when the crack was forced to propagate perpendicular instead of parallel to the predominant bundle direction. The toughness was correlated with the interaction between crack front, the weave and the matrix pockets. Besides, the fracture surface of the perpendicular specimens was observed to be rougher than the parallel specimens.

\subsubsection{Mode I vs. mode II}

Finally, in chapter five, the same 5HS Carbon/PEEK woven material system was subjected to mode I and mode II fracture toughness tests. As reported in the literature, the material showed higher interlaminar fracture toughness for mode II testing [1]. The mode II specimens showed a higher local plastic deformation of the matrix on their fracture 
surfaces with respect to the specimens tested in mode I. Besides, in this comparison, it is worth noticing that while the Mode I test samples showed unstable crack propagation, the Mode II samples showed stable crack propagation.

\subsubsection{Mechanisms}

A proper development of healing of the interface is required to achieve a good interlaminar fracture toughness of fusion bonded joints. In chapter two, the presence of contaminants at the bond line probably prevented the process of complete healing and this caused a reduction in the interlaminar fracture toughness. When proper healing occurs during fusion bonding, pull-out of polymer chains and polymer chain scission are the first mechanisms that appear related to energy consumption during crack propagation, at least for unreinforced polymers [2,3]. When these two mechanisms are active, the stresses transferred across the interface can be large enough to start plastic deformation of the matrix which will further dissipate energy.

The influence of crystallinity (chapter three), matrix bond line thickness (chapter four) and fibre architecture (chapter five) on toughness can (partly) be explained by energy dissipation through local plastic deformation of the matrix at the interface. The energy dissipated through plastic deformation during crack propagation is one of the mechanisms that increases the interlaminar fracture toughness [4]. The second mechanism found to increase the interlaminar fracture toughness is the crack path tortuosity. A higher crack path tortuosity not only increases the area of fracture, but also increases the local driving force at the crack tip required for the deflection or twist angle of the crack tip. These two mechanisms result in a higher consumption of energy along crack propagation [5].

During this research, in some cases, the interlaminar fracture toughness of fusion bonded samples was found to outperform that of the parent material, as shown in chapters three and four. Such a higher performance was mainly related to the two energy dissipating mechanisms mentioned above, i.e. increased plastic zone and crack tortuosity. Figure 6.2 illustrates these two mechanisms of energy consumption. Later in this chapter, guidelines will be proposed on how to use these mechanisms in order to optimise joints for toughness.
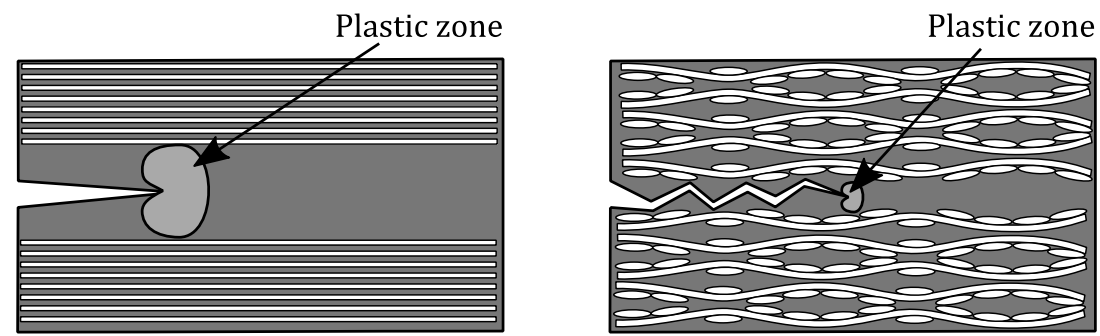

Figure 6.2: Schematic illustration of mechanisms of energy consumption. Left) Matrix plastic deformation. Right) Tortuosity of the crack propagation path. 


\subsection{The global load bearing capability of fusion bonded joint}

Although important, fracture toughness is not the only property that determines the load bearing capacity of joints. Other properties, such as strength, chemical resistance or high temperature performance, are important too. This section, therefore, aims to broaden the discussion by shifting the focus from interlaminar toughness to other important properties. The topics discussed here are partly based on the literature and partly on some preliminary experimental work.

\subsubsection{Effect of surface contamination}

As discussed previously, a high level of contamination on the surface of the substrates before fusion bonding partially blocks the full development of proper healing and hence inhibits the interdiffusion and entanglement of polymer chains across the bond line. This causes poor transfer of loads across the bonding interface. In chapter two, the effect of the contamination at the bond line was investigated by manufacturing autoclave consolidated fusion bonded joints. During the research, only two levels of contamination were achieved, high and low.

The presence of contamination at the bond line is expected to affect the global load bearing capacity of the joint. In chapter two it was shown that not only the interlaminar fracture toughness but also the interlaminar shear strength measured by short beam strength (SBS) test was significantly affected by the presence of the contaminants. A $80 \%$ reduction in the SBS was observed in the samples with high concentration of contaminants with respect to the parent material. This is in line with the findings of other researchers [6], who have shown that when the healing process is not fully completed, for instance, due to lack of temperature or time during processing, the mechanical performance of the joint is not fully developed.

\subsubsection{Effect of crystallinity}

The effect of the degree of crystallinity on the mechanical behaviour of non-reinforced semicrystalline polymers is well reported in the open literature [7]. The degree of crystallinity affects the static and dynamic properties, as well as the thermal and environmental stability of the polymers. In general, a higher degree of crystallinity is associated with higher stiffness and strength [8]. This change of behaviour, up to a certain extent, is expected to be transferred to the resulting composite materials where these polymers are used as a matrix. Even though the tensile properties in the fibre direction of long fibre composites are expected to be insensitive to the degree of crystallinity, other properties where the matrix plays a crucial role are expected to be affected. The impact resistance and the interlaminar fracture toughness $[9,10]$ are reported to decrease with higher degree of crystallinity, while the other properties such as interlaminar shear 
strength measured by short beam strength (SBS) and fibre-matrix interface adhesion measured by fibre pull-off strength are reported to increase with an increase in the degree of crystallinity [11].

In chapter three, the interlaminar fracture toughness was found to increase with a decrease of degree of crystallinity. Some scoping experiments were carried out to study the SBS of the laminates used in that study. The SBS tests were performed following the ISO standard 14130 [12]. Figure 6.3 left shows the examples of force vs. displacement curves of the SBS test and Figure 6.3 right shows the results of SBS as a function of degree of crystallinity. As mentioned previously, the SBS in the literature is reported to increase with higher degree of crystallinity. Nevertheless, a different trend was found for the scoping experiments. Firstly, when the degree of crystallinity decreases, the SBS increases until it reaches a maximum. Further decrease in crystallinity is accompanied by a drop in SBS. The force vs. displacement curves show an initial linear behaviour, but deviate at higher forces. This phenomenon is probably associated with the fact that a matrix with lower degree of crystallinity can comply more with the deformation before interlaminar failure occurs. A different behaviour was shown by the samples with the lowest degree of crystallinity, which start to yield at lower forces. This may be due to a reduction in fibrematrix interface strength due to the lower degree of crystallinity. The lower fibre-matrix strength possibly reduces the force required for the yielding of the specimen. These are preliminary results and further research is required to understand the observed behaviour. The trend shown by the SBS as a function of degree of crystallinity is different from the trend shown by the interlaminar fracture toughness. This is a clear example of how different properties pertaining to the mechanical performance of fusion bonded joints can be affected in different ways by variations in a certain structural feature.
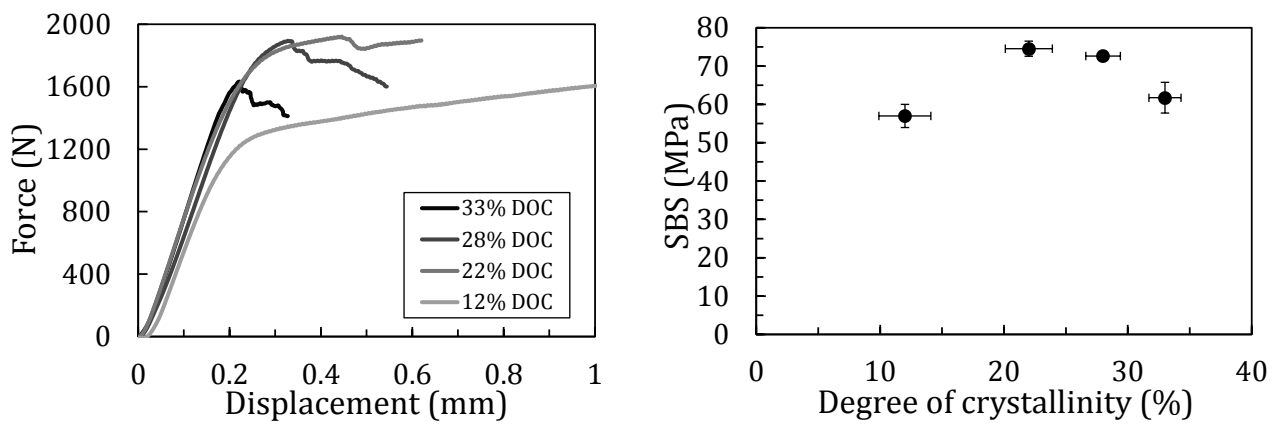

Figure 6.3: Left) Force vs. displacement curve for SBS test. For samples with different degree of crystallinity (DOC). Right) Short beam strength vs. degree of crystallinity.

The long-term properties, such as creep or chemical resistance of thermoplastics, are expected to improve with a higher degree of crystallinity. The presence of crystallites inhibits the slippage of polymer chains by acting as physical crosslinks. Consequently, the amorphous materials are reported to have a lower creep resistance than semicrystalline materials [13]. Regarding environmental resistance, in general, the crystalline regions 
behave as physical barriers that prevent the dissolution of the molecular network [14], which in turn results in semicrystalline polymer having a higher environmental resistance than amorphous polymers [15].

\subsubsection{Effect of bond line thickness}

The effect of a polymeric matrix-rich layer at the interface between the two substrates on the mechanical performance has been widely studied. Firstly, for adhesively bonded metallic or composites substrates [16, 17] and secondly, for composites with a thermoplastic or thermoset interleave $[18,19-21]$. As discussed previously in chapter five, the interlaminar fracture toughness tends to increase with an increase in matrix-rich bond line thickness. The effect of interleaving thickness on single lap shear strength [22, 23], mode II fracture toughness [18, 24-26] and mixed mode fracture toughness [21] was also studied in the past. In the aforementioned cases, the mechanical performance tends to improve with increasing interleaving thickness until reaching a plateau where the mechanical performance is insensitive to any further increase of the thickness of the matrix-rich layer. However, materials with a matrix-rich interlaminar interface results have a lower stiffness, and lower tensile strength [27-29].

Short beam strength experiments were performed on Carbon/PEEK specimens with an interleaved film. The specimens were cut from the autoclave samples manufactured as part of the work described in chapter five. The effect of additional polymer layers in the midplane of the laminate, i.e. bondline, on the SBS of the autoclave samples was tested. The tests were performed following the ASTM D2344 standard [30]. Figure 6.4 shows that the SBS was insensitive to the nominal interleaved thickness. It must however be noted that the failure mode observed during testing was not in compliance with the standard, as the specimens did not delaminate in their midplane. The failure mode observed was a combination of plastic deformation and loading pin indentation followed by interlaminar shear failure. As the failure mode does not comply with the standard, SBS can be only be considered as an apparent property.

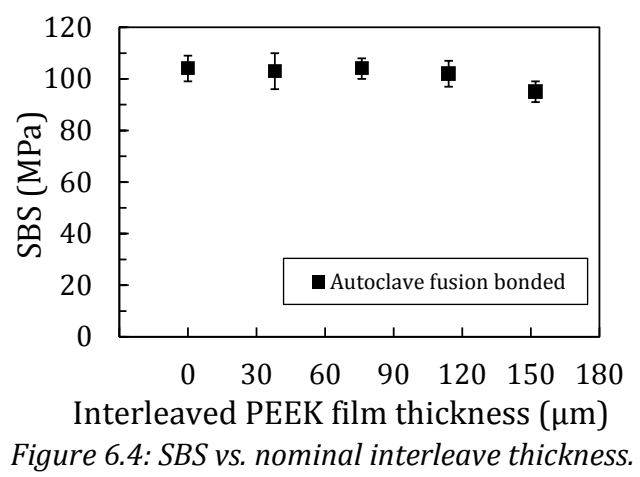




\subsubsection{Interface architecture - Unidirectional vs. Woven}

This section compares effects of the reinforcement architecture (unidirectional or woven) in the substrate on the mechanical performance of the fusion bonded joint. Unidirectional composites tend to have a higher fibre volume fraction than woven fabrics. Besides, the fibres in the woven composites are undulated due to the weave pattern. As a consequence, the strength and the stiffness of woven fabric are lower than their unidirectional counterparts. Contrary to the strength and stiffness, the interlaminar fracture toughness and impact resistance are usually found to be higher for woven fabric composites [31]. The higher damage tolerance is often explained by the irregular interlaminar structure of woven fabric composites, which forces a delamination (crack) to interact with the matrix regions and the weave structure during its propagation, leading to a more tortuous crack path $[32,33]$. To the author's knowledge, studies comparing the SBS and the S-LSS of fusion bonded joints of unidirectional and woven composites are not reported in the open literature. The SBS and the S-LSS of fusion bonded joints of the same matrix fibre combination have been reported, in some review papers, to have similar values for UD and woven composites $[34,35]$. Regarding the weave patterns of woven fabrics, the SBS was reported to decrease as the weave index increases [36]. Besides, for fusion bonded joints the LSS was reported to decrease when the predominant orientation of the fibres at the bond interface is perpendicular to the load direction [37].

\subsection{Towards an advanced fusion bonded joint}

Although this is not the primary objective of this thesis, the results reported in this work can be used to formulate guidelines for obtaining fusion bonded joints having a high interlaminar toughness. As discussed in the previous section, this may have negative consequences for some of the other joint properties, therefore it is up to the design engineer to decide which properties should prevail. For obtaining a joint with high toughness the following recommendations are given:

- A bond line with low crystallinity provides a high interlaminar fracture toughness.

- An additional layer of neat matrix material at the bond line interface improves the wetting between the substrates and will increase the interlaminar fracture toughness of the bond.

- Using woven fabrics at the bond line instead of UD material is advisable. Although the woven fabric studied in this work showed unstable crack propagation, it had a higher interlaminar fracture toughness than the comparable UD material.

- When using woven fabrics at the bond line interface, a proper design of the joint where the crack propagation direction is perpendicular to the principal fibre direction will increase the interlaminar fracture toughness of the fusion bond joint. 
- Similar to adhesive bonds, the interlaminar fracture toughness in mode II was found to be higher than mode I, at least for woven fabric composites. Therefore, the use of fusion bonded joints is preferable for applications where shear stresses are predominant over opening stresses.

\subsection{References}

[1] R. H. Martin and G. B. Murri, "Characterization of mode I and mode II delamination growth and thresholds in AS4/PEEK composites," Composite Materials: Testing and Design, vol. 9, 1990.

[2] D. B. Kline and R. P. Wool, "Polymer welding relations investigated by a lap shear joint method," Polymer Engineering \& Science, vol. 28.1, pp. 52-57, 1988.

[3] Y. H. Kim and R. P. Wool, "A theory of healing at a polymer-polymer interface.," Macromolecules, vol. 16(7), pp. 1115-1120, 1983.

[4] P. J. Hine, B. Brew, R. A. Duckett and I. M. Ward, "Failure mechanisms in continuous Carbon-fibre reinforced PEEK composites," Compos Sci Technol, vol. 35, pp. 31-51, 1989.

[5] J. P. Lucas, "Delamination fracture: effect of fiber orientation on fracture of a continuous fiber composite laminate," Engineering Fracture Mechanics, vol. 42.3, pp. 543-561, 1992.

[6] R. P. Wool, "Adhesion at polymer-polymer interfaces: a rigidity percolation approach," Comptes Rendus Chimie, vol. 9.1, pp. 25-44, 2006.

[7] H. F. Mark, "Encyclopedia of polymer science and technology, concise," John Wiley \& Sons, 2013.

[8] J. E. Spruiell, "A review of the measurement and development of crystallinity and its relation to properties in neat poly(phenylene sulfide) and its fiber reinforced composites," Technical report, Oak Ridge National Laboratory, 2005.

[9] P. Davies, W. J. Cantwell, P. Y. Jar, H. Richard, D. J. Neville and H. H. Kausch, "Cooling rate effects in Carbon fiber/PEEK composites," ASTM, Philadelphia, pp. 70-88, 1991.

[10] S. L. Gao and J. K. Kim, "Cooling rate influences in Carbon fibre/PEEK composites. Part III: impact damage performance," Composites Part A, vol. 32, pp. 775-785, 2001.

[11] S. L. Gao and J. K. Kim, "Cooling rate influences in Carbon fibre/PEEK composites. Part II: interlaminar fracture toughness," Composites Part A: Applied Science and Manufacturing, vol. 31.6, pp. 517-530, 2000.

[12] "ISO 14130 - Fibre-reinforced plastic composites - Determination of apparent interlaminar shear strength by short-beam method," 1997.

[13] D. M. Bigg, "Mechanical property enhancement of semicrystalline polymers-A review," Polymer Engineering \& Science, vol. 28.13, pp. 830-841, 1988.

[14] F. N. Cagswell, "Thermoplastic aromatic polymer composites: a study of the structure, processing and properties of Carbon fibre reinforced polyetheretherketone and related materials," Elsevier, 2013.

[15] S. Béland, "High Performance Thermoplastic Resins and their Composites," William Andrew Publishing, 1990.

[16] A. J. Kinloch and S. J. Shaw, "The fracture resistance of a toughened epoxy adhesives," 
The Journal of Adhesion, vol. 12(1), pp. 59-77, 1981.

[17] F. Ozdil and L. A. Carlsson, "Plastic zone estimates in mode I interlaminar fracture of interleaved composites," Engineering Fracture Mechanics, vol. 41(5), pp. 645-658, 1992.

[18] O. Ishai, H. Rosenthal, N. Sela and E. Drukker, "Effect of selective adhesive interleaving on interlaminar fracture toughness of graphite/epoxy composite laminates," Composites, vol. 19(1), pp. 49-54, 1988.

[19] M. Hojo, T. Ando, M. Tanaka, T. Adachi, S. Ochiai and Y. Endo, "Modes I and II interlaminar fracture toughness and fatigue delamination of CF/epoxy laminates with self-same epoxy interleaf," International Journal of Fatigue, 2006.

[20] K. Shivakumar and R. Panduranga, "Interleaved polymer matrix composites - A review," Paper presented at the 54th AIAA/ASME/ASCE/AHS/ASC Structures, Structural Dynamics, and Materials Conference, 2013.

[21] S. Singh and I. K. Partridge, "Mixed-mode fracture in an interleaved Carbonfibre/epoxy composite," Composites Science and Technology, vol. 55(4), pp. 319-327, 1995.

[22] W. J. Cantwell, P. Davies, P. E. Bourban, P. Y. Jar, H. Richard and H. H. Kausch, "Thermal joining of Carbon fibre reinforced PEEK laminates," Composite Structures, vol. 16.4, pp. 305-321, 1990.

[23] K. M. Bak, M. Dinesh, K. Kalaichelvan and G. K. Vijayaraghavan, "Effect of Adhesive Thickness Area of Single Lap Joints in Composite Laminate Using Acoustic Emission Technique and FEA," Insight-Non-Destructive Testing and Condition Monitoring, 2012.

[24] S. F. Chen and B. Z. Jang, "Fracture behaviour of interleaved fiber-resin composites," Composites Science and Technology, vol. 41.1, pp. 77-97, 1991.

[25] L. F. da Silva, De Magalhaes, F. A. C. R. G. Chaves and M. F. S. F. De Moura, "Mode II fracture toughness of a brittle and a ductile adhesive as a function of the adhesive thickness," The Journal of Adhesion, vol. 86.9, pp. 891-905, 2010.

[26] A. Aksoy and L. A. Carlsson, "Crack tip yield zone estimates in mode II interlaminar fracture of interleaved composites," Engineering Fracture Mechanics, vol. 39.3, pp. 525-534, 1991.

[27] N. Sela and O. Ishai, "Interlaminar fracture toughness and toughening of laminated composite materials: a review," Composites, pp. 423-35, 1989.

[28] Q. Yaun, K. Friedrich and J. Karger-Kocsis, "Low-energy charpy impact of interleaved CF/EP laminates," Applied Composite Materials, vol. 2(2), pp. 119-133, 1995.

[29] J. W. Kim and J. S. Lee, "Influence of Interleaved Films on the Mechanical Properties of Carbon Fiber Fabric/Polypropylene Thermoplastic Composites," Materials, vol. 9(5), pp. 344, 2016.

[30] "ASTM D2344 Standard Test Method for Short-Beam Strength of Polymer Matrix Composite Materials and Their Laminates".

[31] I. Paris, P. J. Minguet and K. T. O'brien, "Comparison of delamination characterization for IM7/8552 composite woven and tape laminates," ASTM STP 1436, pp. 372-390, 2003.

[32] P. Suppakul and S. Bandyopadhyay, "The effect of weave pattern on the mode-I 
interlaminar fracture energy of E-glass/vinyl ester composites," Compos. Sci. Technol., vol. 62, pp. 709-717, 2002.

[33] N. Alif, L. A. Carlsson and L. Boogh, "The effect of weave pattern and crack propagation direction on mode I delamination resistance of woven glass and Carbon composites," Composites Part B, vol. 29, pp. 603-611, 1998.

[34] A. Yousefpour, M. Hojjati and J. Immarigeon, "Fusion bonding/welding of thermoplastic composites," Journal of Thermoplastic Composite Materials, vol. 17(4), pp. 303-341, 2004.

[35] C. Ageorges, L. Yea and M. Hou, "Advances in fusion bonding techniques for joining thermoplastic matrix composites: a review," Composites Part A: Applied Science and Manufacturing, vol. 32(6), pp. 839-857, 2001.

[36] S. W. Yurgartis and J. P. Maurer, "Modelling weave and stacking configuration effects on interlaminar shear stresses in fabric laminates," Composites, vol. 24(8), pp. 651658, 1993.

[37] H. Shi, I. F. Villegas and H. E. N. Bersee, "Strength and failure modes in resistance welded thermoplastic composite joints: effect of fibre-matrix adhesion and fibre orientation," Composites Part A: Applied Science and Manufacturing, vol. 55, pp. 1-10, 2013. 



\section{Chapter 7: Conclusions and recommendations}

\subsection{Conclusions}

The objective of this work was to identify, analyse and, if possible, to quantify the relation between the physical state, the structural features induced by the fusion bonding process, and the resulting mechanical performance of fusion bonded joints. For this purpose, novel experimental procedures were developed and used to manufacture generic fusion bonded specimens with variations in specific features in a controlled manner. The investigated features were the degree of surface contamination of the substrates before bonding, the degree of crystallinity at the bond line, the thickness of the matrix-rich bond line, and the fibre architecture at the bond line. Subsequently, fracture mechanics methods were used to experimentally quantify the effect of these variations on the mechanical performance. The major conclusions of this work relate on the one hand to the developed experimental methods and procedures, and on the other hand to the interrelation between structural features and joint toughness.

\subsubsection{Experimental procedures}

- Interlaminar fracture toughness testing techniques were found to be sensitive to the variations in the structural features induced by the fusion bonded process studied. Besides, interlaminar fracture toughness testing techniques were found to be able to quantify the effects on the mechanical performance.

- The stamp forming process can effectively be used to emulate fast welding processes. Compared to actual welding processes, it provides more control and allows for varying a single feature, in this thesis the degree of crystallinity and the matrix bond line thickness, while ensuring proper consolidation. The process was shown to be a very effective tool to study the interrelation between structural features and the performance of fusion bonded joints.

- The mandrel peel test presents an efficient way to characterise the interlaminar fracture toughness of woven fabric reinforced thermoplastic laminates. Compared to the DCB test, it yields more data points per unit crack length and hence provides a more accurate representation of the toughness. Moreover, the test is easy to perform, as there is no need to measure crack length during testing. 


\subsubsection{Structure-property relation in fusion bonded thermoplastic composites}

- The presence of release media contaminants on the surface of UD Carbon/PEEK substrates can have a significant detrimental effect on the toughness of the resulting joint; the interlaminar toughness was found to be reduced by more than $60 \%$ in the worst case. Contrary to popular belief as often mentioned in literature, surface contamination can have an effect on the mechanical performance of welded joints.

- A linear relationship was found between the degree of crystallinity and the interlaminar toughness of Carbon/PPS laminates. The influence of crystallinity is quite pronounced, shown by a toughness decreasing by more than $50 \%$ when the degree of crystallinity increases from 12 to $33 \%$. The obtained experimental results also suggest that the degree of crystallinity has a bigger effect on the fracture toughness than crystalline morphology.

- The relationship between the matrix-rich bond line thickness and the interlaminar fracture toughness was studied for unidirectional Carbon/PEEK fusion bonded laminates with different matrix-rich bond line thicknesses. A higher interlaminar fracture toughness was observed when the matrix-rich bond line thickness increased. The interlaminar fracture toughness was almost doubled with respect to that of the parent material when an approximately $200 \mu \mathrm{m}$-thick resin film was added to the bond interface. For the same unidirectional Carbon/PEEK system, the presence or absence of fibre migration towards the matrix-rich bond line was found to have no significant effect on the interlaminar fracture toughness of the fusion bonded samples.

- The fibre architecture at the interface has a significant influence on the interlaminar toughness. The mode I interlaminar fracture toughness of 5HS woven fabric Carbon/PEEK was found to be at least $25 \%$ higher than the interlaminar fracture toughness of UD reinforced Carbon/PEEK. Furthermore, the crack propagation direction was found to have a large influence on the interlaminar fracture toughness. Crack propagation perpendicular to the predominant bundle direction in the 5HS Carbon/PEEK material results in a toughness increase of $50 \%$, compared to crack propagation parallel to the predominant fibre direction. 


\subsection{Recommendations}

The present thesis focused on the interrelation between the physical state and structural features of the bond line, and the resulting mechanical performance of fusion bonded thermoplastic composite joints. Although this work presents an important step towards predictable, reliable and robust fusion bonding processes, further progress is still required. Recommendations for future research can be made on the interrelation between microstructure and performance and on the predictability of joint performance.

\subsubsection{Microstructure - performance relationship}

The following recommendations are made for further research on the interrelation between bond line microstructure and structural performance of fusion bonded joints:

- The physical state and microstructure of the bond line are not fully defined by the features studied in this work. Additionally, residual stresses, degree of healing, void fraction, and degree of degradation are amongst other features that further define the bond line. The effects of these features on the mechanical performance need to be addressed as well in order to truly progress towards predictive joint performance.

- This work used the static interlaminar fracture toughness to quantify the mechanical performance of fusion bonded joints. Although important, interlaminar toughness is not the only relevant mechanical property. Mechanical properties such as the static strength, creep compliance and fatigue resistance of the joint will be critical for any application as well. It is therefore recommended to extend the experimental approach, developed in this thesis, to other relevant mechanical properties.

- The experimental approach followed in this work aimed at isolating the effect of a single feature on the toughness. In practice, however, multiple features may vary simultaneously. The variation of more than one feature at the same time may lead to a different response than the simple sum of the individual variations. Therefore, the effect on the mechanical performance of the interactions between different features requires further study.

\subsubsection{Towards predictable joint performance}

A proper understanding of the interrelation between materials, processing conditions and microstructure on the one hand, and microstructure and performance, on the other hand, allows the formulation of joint design and manufacturing guidelines. Predictive engineering tools could, moreover, play an important role here. To make progress, the following recommendations are made: 
- The physical state and structure of the bond line are determined by the processing conditions and the material properties. Further study is required to properly describe the relationship between materials, process and resulting physical state and mechanical performance of the bond, in order to use the knowledge gained in this work for practical applications.

- Once this relationship between process, structure and performance is well understood, models can be developed to predict the effect of process conditions on the resulting microstructure, and subsequently to predict the resulting mechanical performance. Combining these models enables the design of fusion bonded joints with predictable performance. Along with the development of such methods, extensive validation in actual fusion bonding processes will be required.

- Non-destructive inspection and inline monitoring techniques need to be developed for welded joints. The work in this thesis can turn out to be useful in this area as well. Techniques to measure specific structural features, such as the bond line thickness, could potentially be used to predict weld performance. 


\section{Acknowledgements}

I would like to express my deepest gratitude to a number of people who helped me along the journey of attaining a $\mathrm{PhD}$ degree.

First of all, I would like to thank my promotor Remko Akkerman for giving this opportunity and for encouraging me all along the past four years. I would like to express my gratitude to Harald Heerink and all the partners of TPRC to have given me the opportunity to work in such an excellent place. Thank to the technical advisory board of TPRC for bringing the industry close to the academia.

This thesis wouldn't have been possible without the support of my daily/weekly supervisors, who among them is my co-promoter, Irene F. Villegas. Unfortunately, we couldn't meet more often face to face; nevertheless, we managed to have many useful and lengthy discussions by phone. Thank you for all the time that you spent talking in front of a computer. Wouter Gouve, thanks for your support, your timeless availability, and needless to mention your constant good humour and encouraging words. Talking about good mood, we have Laurent Warnet. Thank you for your support inside and outside of the lab. Thank you all three for all your support and for taking care of me in particular along the tough path of writing.

My sincere appreciation is extended to Gert-Jan Nevenzel, Edwar Boer, Laura Vargas, Ivo Vrooijink and Bert Vos, who helped me in my daily work at the lab both at TPRC and at the University of Twente. I would like to extend my gratitude to our friends from the tribology group Walter Lette and Eric de Vries who, even if it was not their duty, helped me in the lab. Talking about the tribology group, I would like to thank Matthijn de Rooij, who gave me a helping hand in the interpretation of surface tension measurements and XPS spectroscopy. I would like to thank Gerard Kip for his assistance in performing the XPS measurements in the nano-lab at the University of Twente.

I would like to thank prof. dr. ir. G. Julius Vancso for the long discussion about polymer interfaces. I would like to thank Hubert Gojzewski for his help in nano indentation measurements with the atomic force microscope, that, unfortunately, didn't bring the results that we expected.

I would like to mention the team of secretaries at the university, Debbie Zimmerman, Belinda Bruinink, and Martina Tjapkes: thank you for all your help in these years and my sincere apologies for the excessive disturbance that I generated. I would like to thank the secretary team at TPRC, Iris de Klerk, Selma Kalee, and Renata Heerink. I would like to thank Nick van der Vall, who continuously controls the visual identity of TPRC. 
Thank you for all the well-educated people that supported me with excellent discussions throughout my research Ismet Baran, Roy Visser, Ton Bor, Martin van Drongelen, Bert Reitman and Sebastiaan Wijskamp. Among the well-educated people, I will like to extend my acknowledgement to Aniform team: Rene Ten Thije, Sebastiaan Haanappel, and Dennis Brands.

For those who worked close to me in my research, I would like to extend my acknowledgement: Lourdes Blanco Salgado, Judith Chevalier, Sylvain Delattre and Colin Paillet, who joined in some projects with me, thank you for your contributions and help during my research.

Ohhh, my dear colleagues, this acknowledgement has a particular space for you! You made the hours at work feel like it was not heavy work. Each of you knows the fun time that we shared together. Thank you: Devi Wolthuzen, Jeroen (Henk) Houwers, Thijs Donderwinkel, Tijtse Slange, Mark Bouwman, Guillaume Vincent, Erick krämer, Ramona Sitohang, Marten van der Werff and Jagadeesh Narayana. My colleagues at the UT, with whom I didn't share that much time, but still the time that we shared was fun! Lily Shaojie Liu, Sybren Jansma, Amin Zaami, Waqas Ali, Ozan Erartsin, Arka (orco) Bhakta, Hosseini Mohammad, and Yibo $\mathrm{Su}$.

Thank you to my three official and unofficial paranymphs Mohammed Iqbal Abdul Iqbal Abdul Rasheed Mohammed Rasheed Iqbalos, Uli and Thijs Kok: you have been much more than my moral support along these years. உன்னுடைய எல்லா உதவிக்காகவும் இன்னும் ஒருமுறை இக்பாலோஸ் நன்றி.

Last but not the least, I would like to acknowledge my family and my girlfriend for their priceless backing.

Francisco, July 2017 


\title{
Publications
}

\author{
Journal
}

1. L. Andena, L. Castellani, A. Castiglioni, A. Mendogni, M. Rink, and F. Sacchetti, "Determination of Environmental Stress Cracking Resistance of Polymers: Effects of Loading History and Testing Configuration", Engineering Fracture Mechanics, vol 101, pp 33-46, 2013.

2. F. Sacchetti, W. J. B. Grouve, L.L. Warnet, and I. F. Villegas, "Effects of release media on the fusion bonding of Carbon/PEEK laminates" Composites Part A: Applied Science and Manufacturing, vol 94, pp 70-76, 2017.

\section{Publication in preparation}

1. F. Sacchetti, W. J. B. Grouve, L.L. Warnet, and I. F. Villegas, "Effect of cooling rate on the interlaminar fracture toughness of unidirectional Carbon/PPS laminates", To be submitted to Engineering Fracture Mechanics.

2. F. Sacchetti, W. J. B. Grouve, L.L. Warnet, and I. F. Villegas, "Effect of resin-rich bond line thickness and fibre migration on the toughness of UD Carbon/PEEK joints", Submitted to Composites Part A: Applied Science and Manufacturing.

3. F. Sacchetti, W. J. B. Grouve, L.L. Warnet, and I. F. Villegas, "Interlaminar fracture toughness of 5HS Carbon/PEEK laminates. A comparison between DCB, ELS and mandrel peel tests", To be submitted to Polymer Testing.

\section{Conference proceedings}

1. L. Andena, L. Castellani, L. Franchini, J. Menegari, M. Rink, and F. Sacchetti, "Determination of ESC Resistance of Polymers: Effects of Loading History and Testing Configuration", 6th International Conference on Fracture of Polymers, Composites and Adhesives, Les Diablerets (CH) 2011.

2. L. Andena, L. Castellani, A. Castiglioni, A. Mendogni, M. Rink, F. Sacchetti, and A. Adib, "Environmental crack initiation and propagation in polyethene under different loading conditions", International conference on Deformation, Yielding and Fracture of Polymers (NL), 2012.

3. L. Blanco, F. Sacchetti, W. J. B. Grouve, and E. Rodríguez, "Optimización del proceso de soldadura por ultrasonidos de CF-PEEK", XI Congreso Nacional de Materiales Compuestos MATCOMP15, Madrid (E), 2015. 
4. F. Sacchetti., W. J. B. Grouve, L.L. Warnet, and I. F. Villegas, "Influence of surface preparation on fusion bonding of thermoplastic composites", 20th International Conference on Composite Materials, Copenhagen (DK), 2015.

5. F. Sacchetti., W. J. B. Grouve, L.L. Warnet, and I. F. Villegas, "Woven fabric composites: Can we peel it?", Procedia structural integrity, vol 2, pp 245-252, 2016.

\section{Collaborations}

1. L. Andena, M. Rink, C. Marano, F. Briatico-Vangosa, and L. Castellani, "Effect of processing on the environmental stress cracking resistance of high-impact polystyrene", Polymer Testing, vol 54, pp 40-47,2016. 


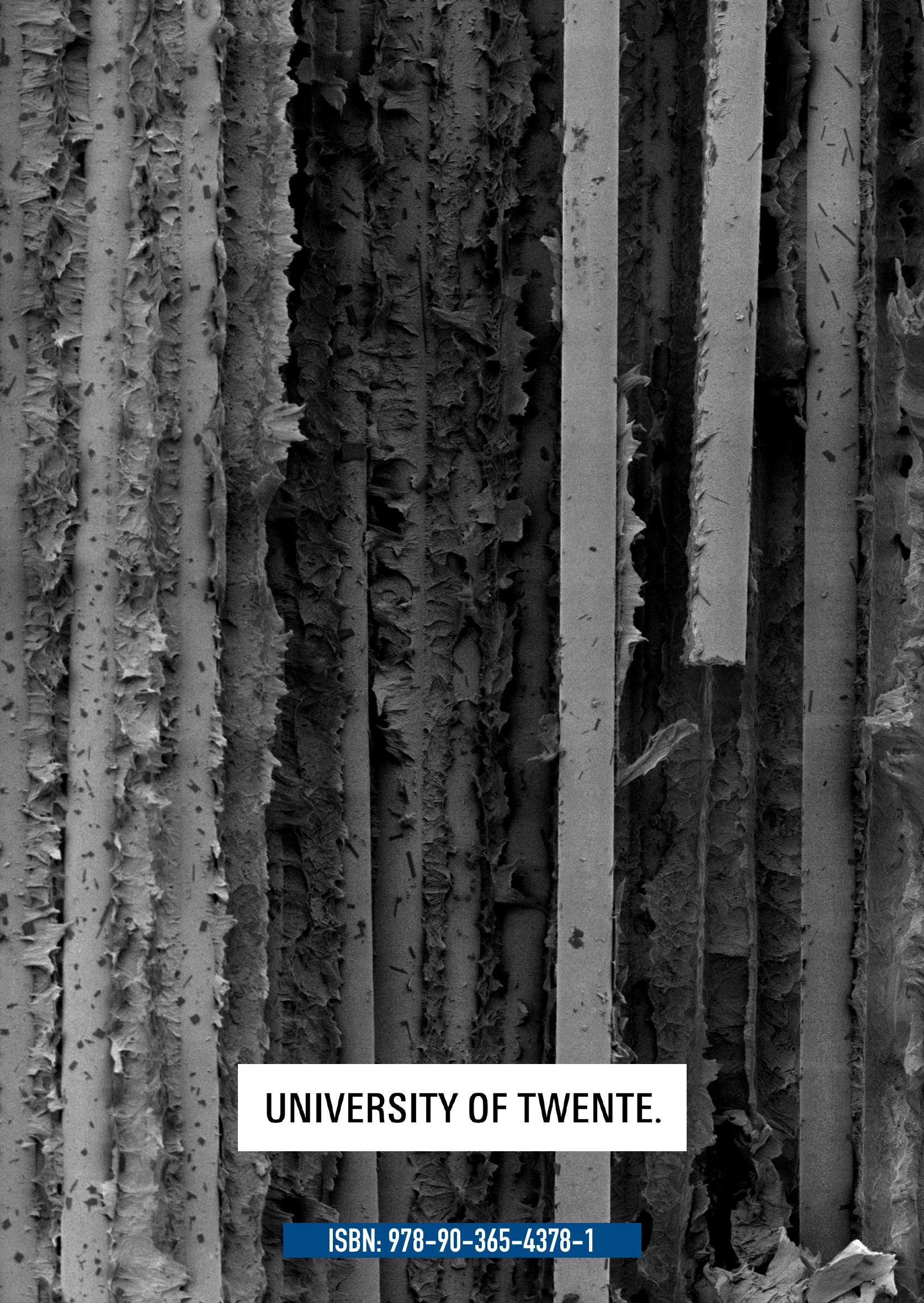

